\title{
International Society of Sports Nutrition Position Stand: Probiotics
}

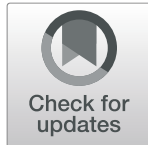

\author{
Ralf Jäger ${ }^{1^{*}}$ (D), Alex E. Mohr², Katie C. Carpenter ${ }^{3}$, Chad M. Kerksick ${ }^{4}$, Martin Purpura', Adel Moussa ${ }^{5}$, \\ Jeremy R. Townsend ${ }^{6}$, Manfred Lamprecht ${ }^{7}$, Nicholas P. West ${ }^{8}$, Katherine Black ${ }^{9}$, Michael Gleeson ${ }^{10}$, \\ David B. Pyne ${ }^{11}$, Shawn D. Wells ${ }^{12}$, Shawn M. Arent ${ }^{13}$, Abbie E. Smith-Ryan ${ }^{14}$, Richard B. Kreider ${ }^{15}$, Bill I. Campbell ${ }^{16}$, \\ Laurent Bannock ${ }^{17}$, Jonathan Scheiman ${ }^{18}$, Craig J. Wissent ${ }^{19}$, Marco Pane ${ }^{20}$, Douglas S. Kalman ${ }^{21}$, Jamie N. Pugh ${ }^{22}$, \\ Jessica A. ter $\mathrm{Haar}^{23}$ and Jose Antonio ${ }^{24}$
}

\begin{abstract}
Position statement: The International Society of Sports Nutrition (ISSN) provides an objective and critical review of the mechanisms and use of probiotic supplementation to optimize the health, performance, and recovery of athletes. Based on the current available literature, the conclusions of the ISSN are as follows:

1) Probiotics are live microorganisms that, when administered in adequate amounts, confer a health benefit on the host (FAO/WHO).

2) Probiotic administration has been linked to a multitude of health benefits, with gut and immune health being the most researched applications.

3) Despite the existence of shared, core mechanisms for probiotic function, health benefits of probiotics are strain- and dose-dependent.

4) Athletes have varying gut microbiota compositions that appear to reflect the activity level of the host in comparison to sedentary people, with the differences linked primarily to the volume of exercise and amount of protein consumption. Whether differences in gut microbiota composition affect probiotic efficacy is unknown.

5) The main function of the gut is to digest food and absorb nutrients. In athletic populations, certain probiotics strains can increase absorption of key nutrients such as amino acids from protein, and affect the pharmacology and physiological properties of multiple food components.

6) Immune depression in athletes worsens with excessive training load, psychological stress, disturbed sleep, and environmental extremes, all of which can contribute to an increased risk of respiratory tract infections. In certain situations, including exposure to crowds, foreign travel and poor hygiene at home, and training or competition venues, athletes' exposure to pathogens may be elevated leading to increased rates of infections. Approximately $70 \%$ of the immune system is located in the gut and probiotic supplementation has been shown to promote a healthy immune response. In an athletic population, specific probiotic strains can reduce the number of episodes, severity and duration of upper respiratory tract infections.

(Continued on next page)
\end{abstract}

\footnotetext{
* Correspondence: ralf.jaeger@increnovo.com

This position stand is dedicated to the late Dr. Mike Greenwood who made

significant contributions to the development of the ISSN and JISSN.This

position stand has been adopted by the Austrian Society of Sports Nutrition

(Österreichische Gesellschaft für Sporternährung (ÖGSE)).Submitted to the

ISSN Research Committee for consideration as a Position Stand of the

SocietyOctober 31, 2019

${ }^{1}$ Increnovo LLC, Milwaukee, WI, USA

Full list of author information is available at the end of the article
}

(c) The Author(s). 2019 Open Access This article is distributed under the terms of the Creative Commons Attribution 4.0 International License (http://creativecommons.org/licenses/by/4.0/), which permits unrestricted use, distribution, and

reproduction in any medium, provided you give appropriate credit to the original author(s) and the source, provide a link to the Creative Commons license, and indicate if changes were made. The Creative Commons Public Domain Dedication waiver (http://creativecommons.org/publicdomain/zero/1.0/) applies to the data made available in this article, unless otherwise stated. 


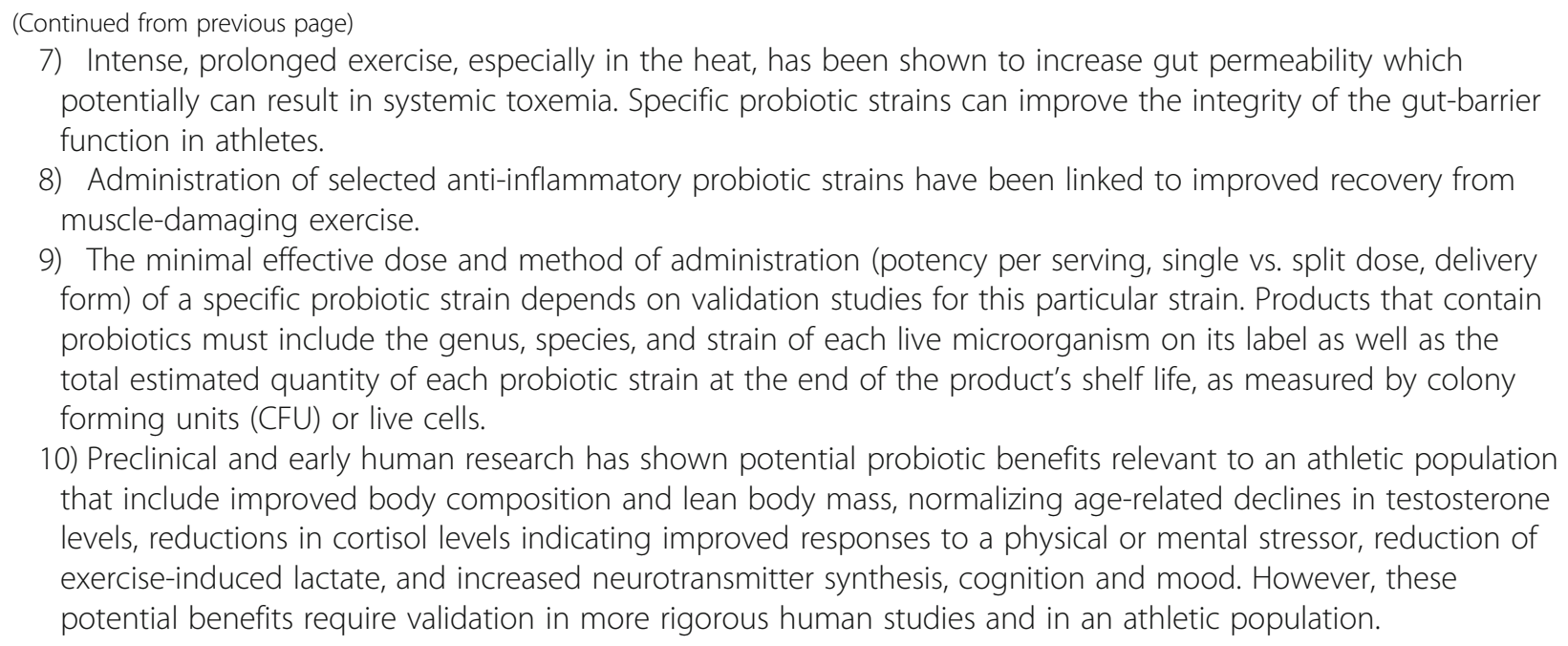

10) Preclinical and early human research has shown potential probiotic benefits relevant to an athletic population that include improved body composition and lean body mass, normalizing age-related declines in testosterone levels, reductions in cortisol levels indicating improved responses to a physical or mental stressor, reduction of exercise-induced lactate, and increased neurotransmitter synthesis, cognition and mood. However, these potential benefits require validation in more rigorous human studies and in an athletic population.

Keywords: Gut-muscle-Axis, Microbiome, Microbiota, Sport performance, Muscle

\section{Introduction}

The term probiotic is derived from the Latin preposition "pro," which means "for" and the Greek word "biotic" meaning "life". Probiotics are widely considered to be healthpromoting microorganisms. As outlined in Table 1 and as defined by the World Gastroenterology Organization (WGO), various ingredients can function in probiotic, prebiotic, and symbiotic roles. The Food and Agriculture Organization of the United Nations (FAO) and the World Health Organization (WHO) defines probiotics as "live microorganisms that, when administered in adequate amounts, confer a health benefit on the host" [1]. Additionally, the International Olympic Committee (IOC) has stated that, "Probiotics are live micro-organisms that when administered orally for several weeks can increase the numbers of beneficial bacteria in the gut. These have been associated with a range of potential benefits to gut health, as well as modulation of immune function" [5]. Unique in comparison to other dietary supplements, probiotic preparations contain live, viable, defined microorganisms in sufficient numbers to provide beneficial health effects [6]. Table 1 provides an overview of common definitions and classifications related to probiotic research.

The probiotic principle dates back to over 100 years ago. In 1908, Elie Metchnikoff [7] suggested that it would be possible to modify the microbiota in our bodies and replace harmful microbes with useful microbes. Reported health benefits of probiotics include modulation of the immune response, maintenance of the intestinal barrier, antagonism of pathogen adhesion to host tissue, and production of different metabolites such as vitamins, short-chain fatty acids (SCFAs), and molecules that act as neurotransmitters involved in gut-brain axis communication [8]. In the last several decades, research in the area of probiotics has progressed considerably and significant advances have been made in the selection and characterization of specific probiotic cultures. A growing number of dietary supplements containing probiotics are commercially available worldwide, and the number of products being marketed to improve the health and performance of athletes continues to increase substantially. To appropriately describe a probiotic, the genus, species, and strain of each live microorganism (see Table 2) must be detailed on a product label. Additionally, the product label should include the total estimated quantity of each probiotic strain at the end of the product's shelf life, as measured by colony forming units (CFU) or live cells. Moreover, only a 70\% DNA-DNA reassociation is needed for strains to be regarded as the same species [9]. The difference between a Homo sapiens and its most closely related species, the chimpanzee (Pan troglodytes) is 98.4\%. Reassociation rates of humans with other primates like Gorilla (97.7\%), Orangutan (96.5\%), Siamang gibbon (95.5\%), and the Hamadras baboon (92.7\%) are also relatively high. Further, Lemur (78\%) are still within the range for probiotics to be considered the same species (see Fig. 1). Analyzing potential health benefits of probiotics must occur on a strain level, and consumption of probiotic products only disclosing genus and species, but not the strain, on the label should be discouraged.

Probiotics are available commercially in capsule or tablet forms, as powder sachets, in the form of liquids and in specific foods such as yogurt and nutrition bars. While fermented foods, such as sauerkraut or kimchi, contain live microbes, they are currently not classified as probiotics, as those products have not been sufficiently studied for their health benefit as stipulated by the 
Table 1 Definitions of common terminology and classifications in probiotic research

\begin{tabular}{|c|c|}
\hline Concept & Definition \\
\hline Probiotics & Live microorganisms which, when administered in adequate amounts, confer a health benefit on the host [1]. \\
\hline Prebiotic & A substrate that is selectively utilized by host microorganisms conferring a health benefit on the host [2]. \\
\hline Synbiotics & $\begin{array}{l}\text { A synbiotic product beneficially affects the host in improving the survival and implantation of live microbial dietary } \\
\text { supplements in the gastrointestinal tract by selectively stimulating the growth and/or activating the metabolism of } \\
\text { one or a limited number of health-promoting bacteria [3]. }\end{array}$ \\
\hline Postbiotics & $\begin{array}{l}\text { Postbiotics are bioactive components produced by beneficial bacteria (through a natural fermentation process) which } \\
\text { have biological activity in the gut (e.g. short-chain fatty acids) [4]. }\end{array}$ \\
\hline Immunobiotics & Inactivated probiotics (e.g. heat-killed), in which the dead cells maintain their immune benefit. \\
\hline Gut & $\begin{array}{l}\text { The gastrointestinal tract is a long tube that starts in the mouth and ends at the anus. Its main function is to process } \\
\text { food. Approximately } 70 \% \text { of antibody producing cells are is located in the digestive system. }\end{array}$ \\
\hline Microbiota vs. Microbiome & $\begin{array}{l}\text { The gut microbiota is a diverse ecosystem consisting of bacteria, archaea, viruses, protists and fungal communities } \\
\text { (mycobiome) living in the human gut. Microbiome refers to the collection of genomes from all microorganisms in } \\
\text { a particular environment }\end{array}$ \\
\hline Transient vs. Resident Strain & $\begin{array}{l}\text { Supplementary probiotics are transient strains. There is currently no evidence that supplementary probiotics can } \\
\text { permanently colonize in the gut as resident strains resist colonization by transient strains. Transient probiotics } \\
\text { strains may have numerous beneficial health effects by positively interacting with the immune system or } \\
\text { stimulating growth of beneficial resident strains. }\end{array}$ \\
\hline Alpha-Diversity & $\begin{array}{l}\text { Represents the number of species and the proportion in which each species is represented in the microbiota. A } \\
\text { high alpha diversity is present when there is a high number of species and their quantities are alike. }\end{array}$ \\
\hline Beta-Diversity & $\begin{array}{l}\text { Beta-diversity broadly reflects the species composition diversity between regional and local sites. The beta diversity } \\
\text { measures the turnover of species between two regions in terms of gain or loss of species }\end{array}$ \\
\hline Classes of probiotics & Definition \\
\hline Lactic acid bacteria (LAB) & $\begin{array}{l}\text { Nonpathogenic, nontoxigenic, Gram-positive, fermentative bacteria that are associated with the production of lactic } \\
\text { acid from carbohydrates. LAB grow anaerobically, but unlike other anaerobes, most can grow in the presence of } \\
\text { oxygen. Examples include Lactobacillus (ssp. acidophilus, fermentum, plantarum, rhamnosus, casei, reuteri, gasseri), } \\
\text { Streptococcus (e.g. salivarius, thermophilus) and Lactococcus. }\end{array}$ \\
\hline Bifidobacteria & $\begin{array}{l}\text { Bifidobacteria are among the first microbes to colonize the human gastrointestinal tract. Examples include } \\
\text { Bifidobacterium bifidum, longum, animalis, and breve. Bifidobacteria are not LAB. They are, however lactic acid } \\
\text { producing bacteria (but through a very different metabolic pathway). }\end{array}$ \\
\hline Spore-forming bacteria & $\begin{array}{l}\text { Soil-based probiotics, also referred to endospores, are the dormant form of bacteria that are highly resistant to } \\
\text { physical and chemical influences. Upon ingestion, these spores have a high survival rate through the stomach } \\
\text { and germinate in the small intestine. Examples include Bacillus (e.g. coagulans, subtilis). Spore forming bacteria } \\
\text { are not necessarily of soil origin. They can also be found in fermented foods. }\end{array}$ \\
\hline Yeast & Examples include Saccharomyces boulardii. \\
\hline
\end{tabular}

definition of probiotics. Stability concerns during manufacture and shelf-life limit food and supplement delivery forms. Probiotics exhibit strain-specific differences in their ability to colonize the gastrointestinal (GI) tract, clinical efficacy, and the type and magnitude of benefits to health in a range of different population cohorts [10]. The effects of probiotics in athletes have been less described in comparison to animal studies and human clinical conditions in the general population. However, the body of probiotic research in recreational and competitive athletes is expanding, including investigations in GI health, exercise performance, recovery, physical fatigue, immunity, and body composition.

Role of diet and exercise on an athlete's gut microbiome Numerous factors such as age, genetics, drug use, stress, smoking, and especially diet can all affect the gut microbiome, influencing a complex ecosystem that is highly dynamic and individual [11-14]. In relation, physical activity has been an area of growing interest in gut microbiome research and appears to promote a healthassociated microbiota. In the context of athletes, the present body of literature suggests their microbiota has several key differences in comparison to other populations, likely driven, in part, by exercise and diet. Indeed, several observational studies have investigated the difference in the composition of the gut microbiota between those who are highly physically active (including athletes) and a range of other populations. Reported results include that a higher abundance of health-promoting bacterial species [15-17], increased microbiome diversity [16, 18], and greater relative increases in metabolic pathways (e.g. amino acid and antibiotic biosynthesis and carbohydrate metabolism) and fecal metabolites (e.g. microbial produced SCFAs; acetate, propionate, and butyrate) are associated with enhanced fitness $[17,19]$.

The current evidence supports the role of exercise as an important behavioral factor that can affect qualitative and 
Table 2 Example illustrating the names of a bacterium ( $L$. rhamnosus GG) at different taxonomic levels

\begin{tabular}{ll}
\hline Taxonomic level & Name \\
\hline Domain & Bacteria \\
Phylum & Firmicutes \\
Class & Bacilli \\
Order & Lactobacillales \\
Family & Lactobacillaceae \\
Genus & Lactobacillus \\
Species & Lactobacillus rhamnosus \\
Strain & Lactobacillus rhamnosus GG \\
\hline
\end{tabular}

quantitative changes in the gut microbial composition with benefit to the host. Exercise appears to be able to enrich microbiota diversity [20-25], increase the Bacteroidetes-Firmicutes ratio [23], stimulate the proliferation of bacteria which can modulate mucosal immunity [26], improve barrier functions [27], and stimulate bacteria capable of producing substances that protect against GI disorders [28, 29]. Recent research provides further evidence for a role of exercise in shaping the microbiome, with elite runners having a greater abundance of Veillonella that appears to confer a metabolic advantage for endurance exercise by converting exercise-induced lactate to propionate. Pre-clinical studies with Veillonella show a $13 \%$ increase in endurance performance [30]. It is likely that the diverse, metabolically favorable intestinal microbiome evident in the elite athlete is the cumulative manifestation of many years of high nutrient intake and high degrees of physical activity and training throughout youth, adolescence and during adult participation in professional sports [31].

In researching the human gut microbiota, it is difficult to examine exercise and diet separately as this relationship is compounded by changes in dietary intakes that often are associated with physical activity (e.g., increased protein intake in resistance trained athletes or carbohydrate intake in endurance athletes

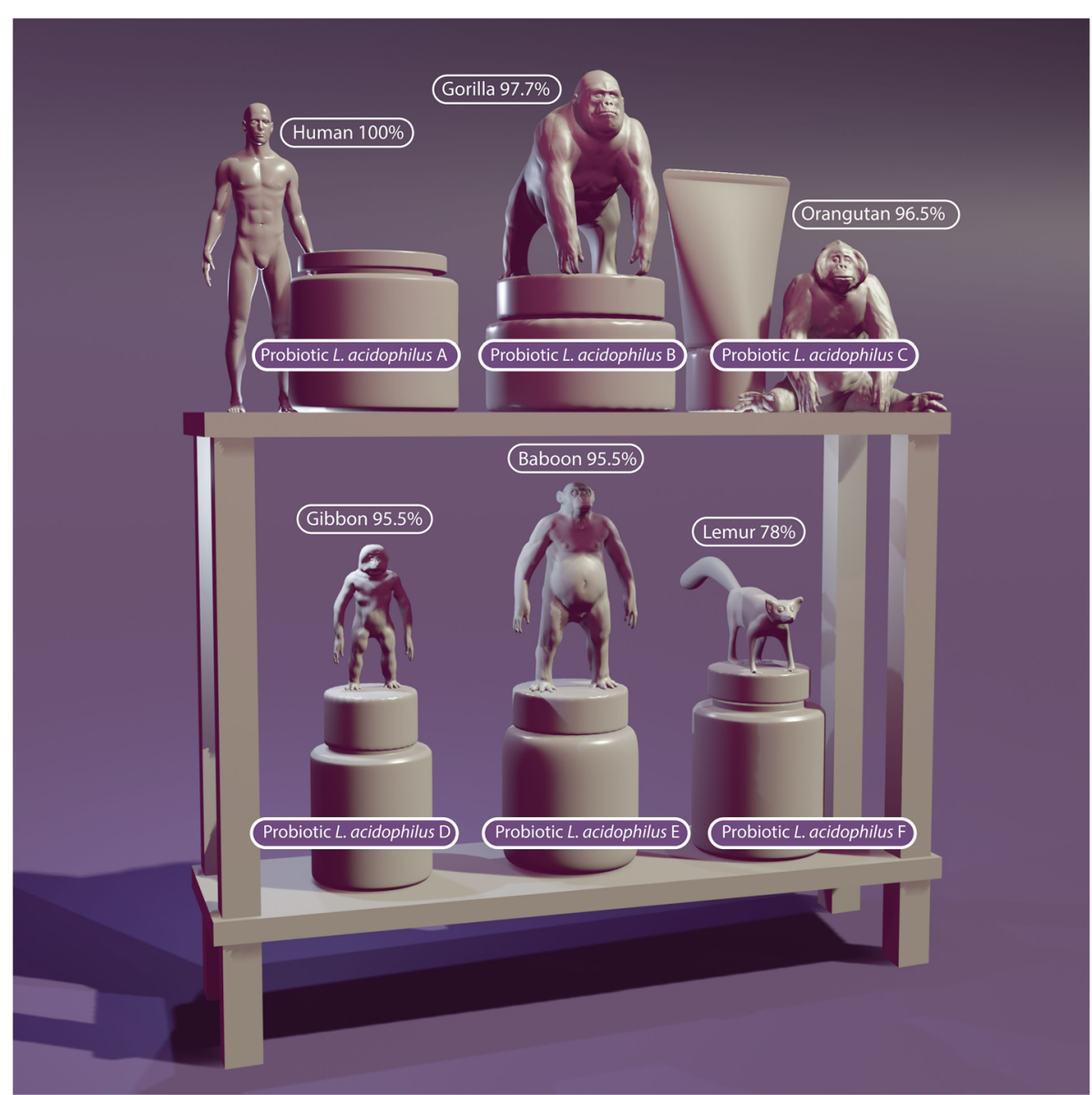

Fig. 1 Probiotic benefits are strain specific and probiotics must be described as genus, species and strain, as genetic variation between the same genus and species can be as significant as the difference between a human and a lemur (illustration by Stephen Somers, Milwaukee, WI, USA) 
and increased total energy and nutrient intake in general). Furthermore, comparing the microbiota of nonathletes to athletes and ascribing any observed differences to exercise alone is not advisable. Athletes generally consume a diet that differs from the general population that has implications for the composition of the gut microbiome.

Diet is an established modulator of gut microbiota composition, with significant change reported within $24 \mathrm{~h}$ of a dietary modification [32]. Various food components, dietary patterns, and nutrients all have the potential to alter considerably the growth of different gut microbial populations. Partitioning of individuals into enterotypes appears to be driven by whether their primary dietary patterns include high complex carbohydrate (Prevotella) or high fat/protein (Bacteroides) consumption [33]. Protein intake appears to be a strong modulator of the microbiota $[20,32,34]$, with whey protein showing some potential benefits that need further study in humans [31,35]. Carbohydrates are well known for their profound effect on the gut microbiota, with increased intake of dietary fiber associated with microbial richness and/or diversity [36, 37]. In athletes, higher intakes of carbohydrates and dietary fiber appear to be associated with increased abundance of Prevotella [17, 38]. The specific effects of fat on the gut microbiota is difficult to isolate, however, the types of fats consumed appear to be important [39]. Increased fat intake may promote higher concentrations of bile-tolerant bacteria (presumably because an extremely high fat intake is known to increase bile acid secretion) [32]. Further research is needed to determine the synthesis kinetics and clinical consequence of bile acids and their byproducts during increased nutritional intake and metabolic demands during exercise.

Based on the current body of evidence, the athlete gut microbiome may possess a functional capacity that is primed for tissue repair and a greater ability to harness energy from the diet with increased capacity for carbohydrate, cell structure, and nucleotide biosynthesis [19]. This assertion reflects the significant energy demands and tissue adaptation that occurs during intense exercise and elite sport. It appears that being physically active is another important factor in the relationship between the microbiota and host metabolism. Intervention-based studies to delineate this relationship will be important and may provide further insights into optimal therapies to influence the gut microbiota, and its relationship with health and disease as well as athletic performance. Fig. 2 illustrates that an athlete's gut microbiota is different from a sedentary individual with increased diversity and greater abundance of health promoting bacterial species linked to exercise and increased protein intake.

\section{Key Points 1 - Role of diet and exercise on an athlete's gut microbiome. \\ - Active individuals appear to display a higher abundance of health- promoting bacterial species and increased microbiota diversity. \\ - Body composition and physical activity are positively correlated with several bacterial populations. \\ - Overall exercise can enrich the microbiota diversity, increase the Bacteroidetes-Firmicutes ratio, stimulate the proliferation of bacteria which can modulate mucosal immunity, and improve barrier functions. \\ - Diet is an established modulator of gut microbiota composition and activity, with marked changes in microbiota composition evident within $24 \mathrm{~h}$ of a dietary modification. \\ - Protein intake appears to be a strong modulator of microbiota diversity, with whey protein showing some potential benefits that need further study in humans. \\ - Higher intakes of carbohydrate and dietary fiber in athletes appear to be associated with increased abundance of Prevotella. \\ - The specific effects of fat on the gut microbiota is difficult to isolate, however, the types of fats consumed appear to be important.}

\section{Benefits of probiotic supplementation in athletes}

Strenuous and prolonged exercise places stress on the GI tract that increases the likelihood of multiple symptoms associated with a disturbed gut microbiota and decreased performance [40], including abdominal cramping, acid reflux (heartburn), nausea, vomiting, diarrhea, and permeability of the gut that may precipitate systemic endotoxemia [41]. As a major gateway for pathogen entry, the GI tract is heavily protected by the immune system. Modulation of the immune system to increase defenses against upper respiratory tract infection (URTI) is the potential benefit of probiotics for athletes that has been most extensively researched [40]. The microbiome may also have indirect functional influence on various indices of exercise performance and recovery [42-46]. Therefore, probiotics as functional modulators of the microbiome can potentially promote health, exercise adaptation, and performance in athletes.

Probiotics may regulate the mucosal immune response [47], improve the activity of macrophages [48] and modulate the expression of the genes associated with macrophage activity. Probiotics may also interact with Toll-like receptors (TLRs) and downregulate the expression of nuclear factor (NF)- $\mathrm{kB}$ and proinflammatory cytokines $[49,50]$. Additionally, levels of anti-inflammatory cytokines and immunoglobulins, immune cell proliferation, and production of proinflammatory cytokines by $\mathrm{T}$ cells may be modulated following probiotic supplementation [51, 52]. However, it 
is often difficult to study athletes during training and competition, and a wide range of interactions between diet, physical activity and other lifestyle stresses needs to be considered. Understanding whether probiotics play a role in athletic performance is of particular interest to athletes who work to improve their results in competition as well as reduce recovery time during training. Moreover, this knowledge may be relevant and of direct benefit to general human health.

The study of probiotic supplementation in athletes and physically active individuals is quite new with the first study in humans published by Clancy et al. [53]. Over the last 13 years, the popularity and number of publications has increased substantially (see Table 3). The number of products containing probiotics directed towards those that exercise is increasing.

\section{The effect of probiotic supplementation on performance}

Research specifically designed to investigate the effect of probiotic supplementation on performance has been less common and overall the results are mixed. Earlier studies that reported performance outcomes generally had primary aims related to immunity and GI health. Of the 24 studies that assessed some metric of athletic performance, 17 reported a null effect, while 7 reported significant improvement. However, more recent research indicates that probiotic supplementation can promote improvements in exercise performance through various pathways in athletes and physically active individuals using discrete strains of probiotics.

Some studies have used single probiotic strain interventions. For example, in a 16-week study investigating the effect of Lactobacillus fermentum VRI-003 on the immunity in 20 elite male distance runners, measures of performance (which included training duration, intensity, and $\left.\mathrm{VO}_{2} \max \right)$ did not change significantly [57]. Similarly, in 80 competitive cyclists, 11 weeks of supplementation with $L$. fermentum $\left(P C C^{\circ}\right.$ ) had no effect on peak power or $\mathrm{VO}_{2}$ max [61]. Four weeks of supplementation with Lactobacillus gasseri OLL2809 and

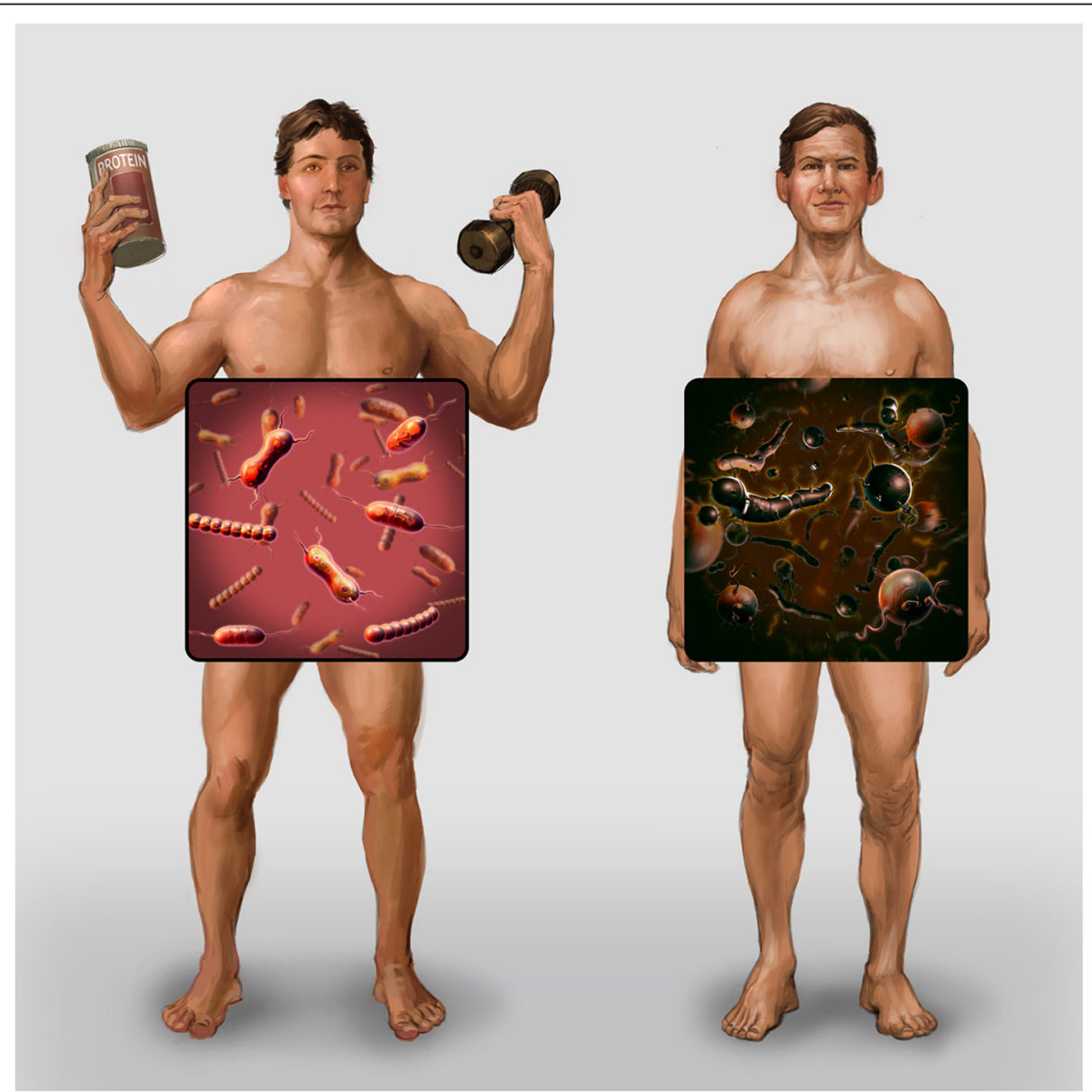

Fig. 2 Early research indicates that gut bacteria reflect the activity level of its host. An athlete's gut microbiota is different from a sedentary individual: increased diversity and greater abundance of health promoting bacterial species linked to exercise and increased protein intake (illustration by Stephen Somers, Milwaukee, WI, USA) 


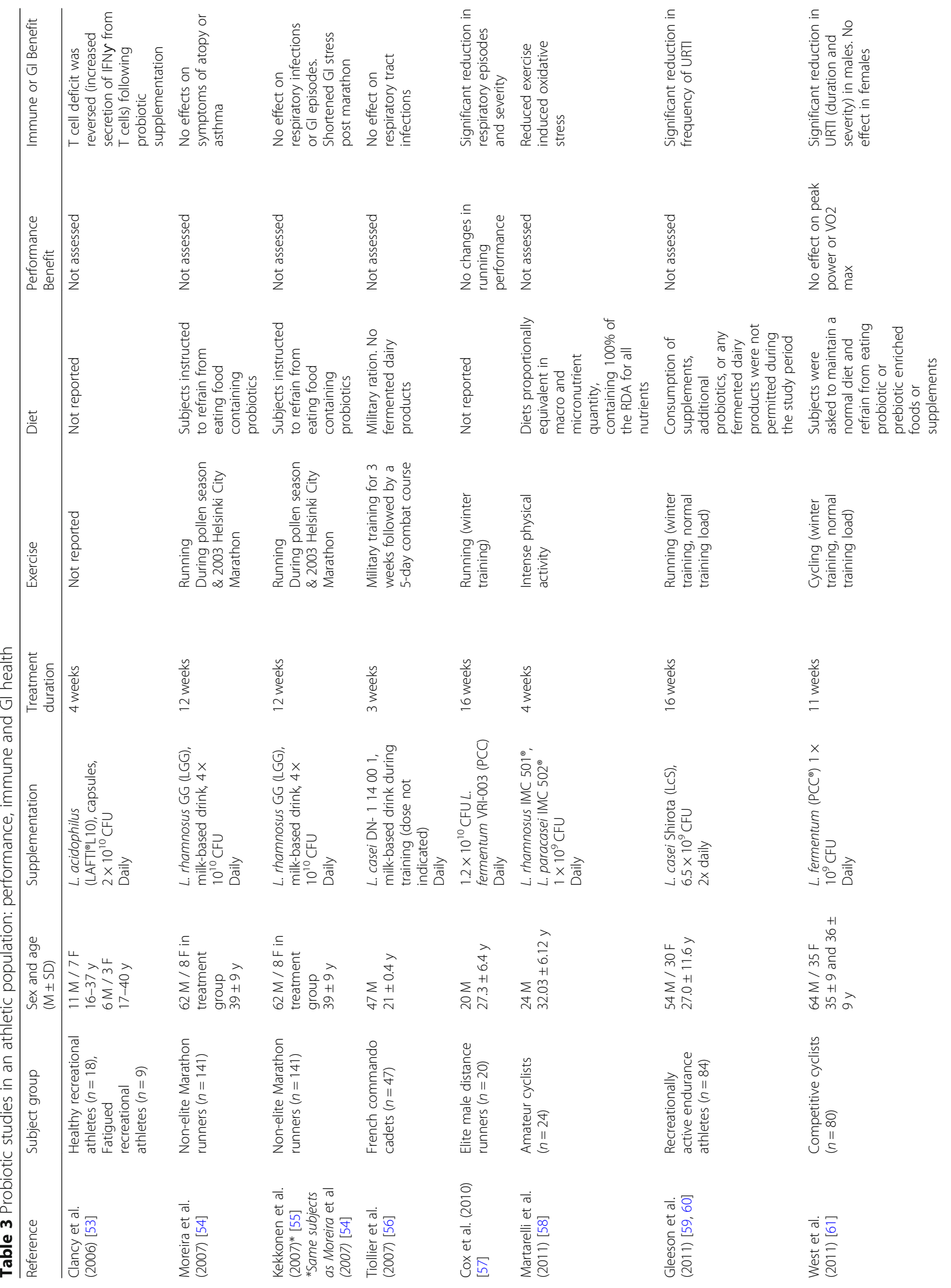




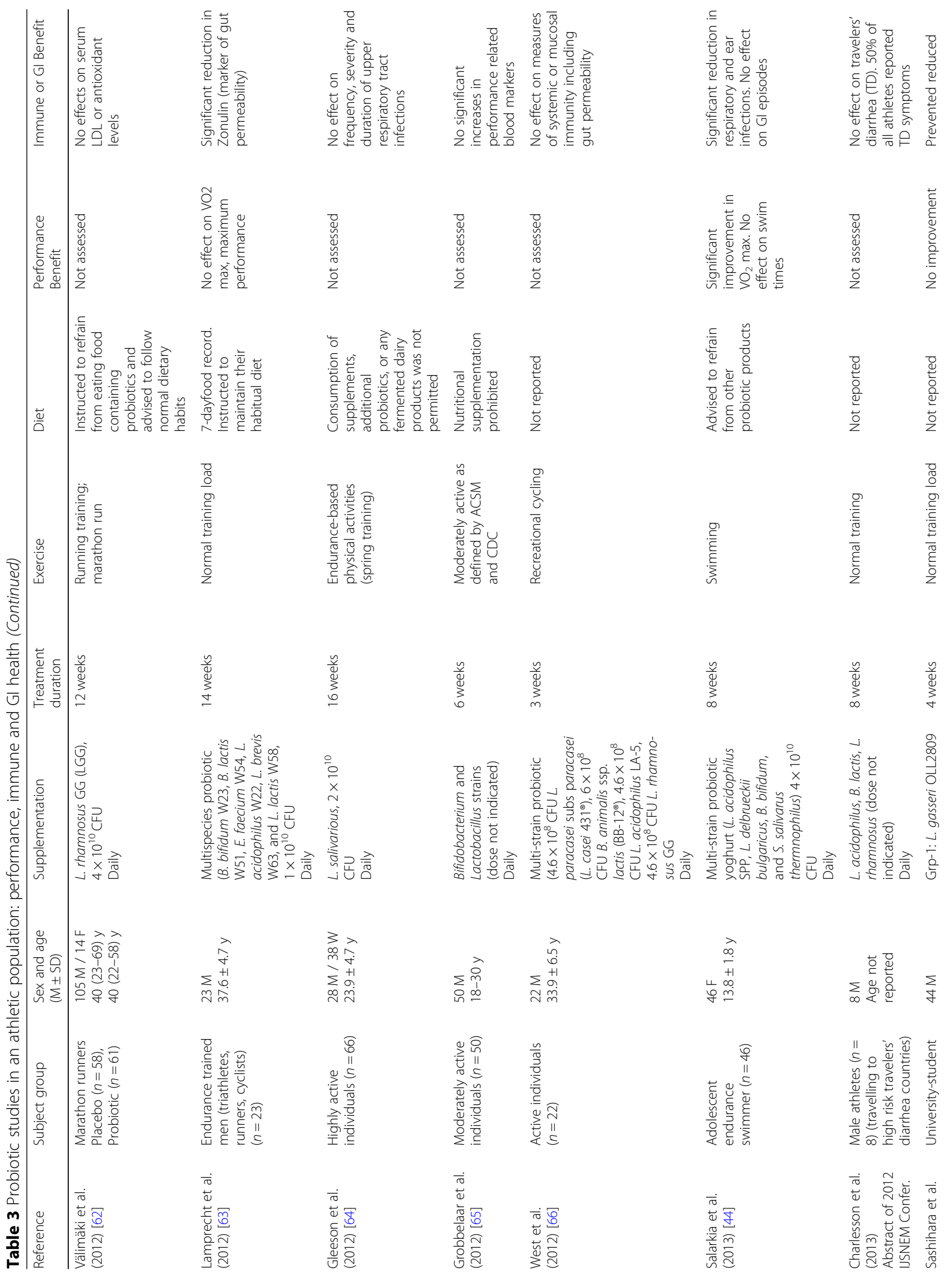




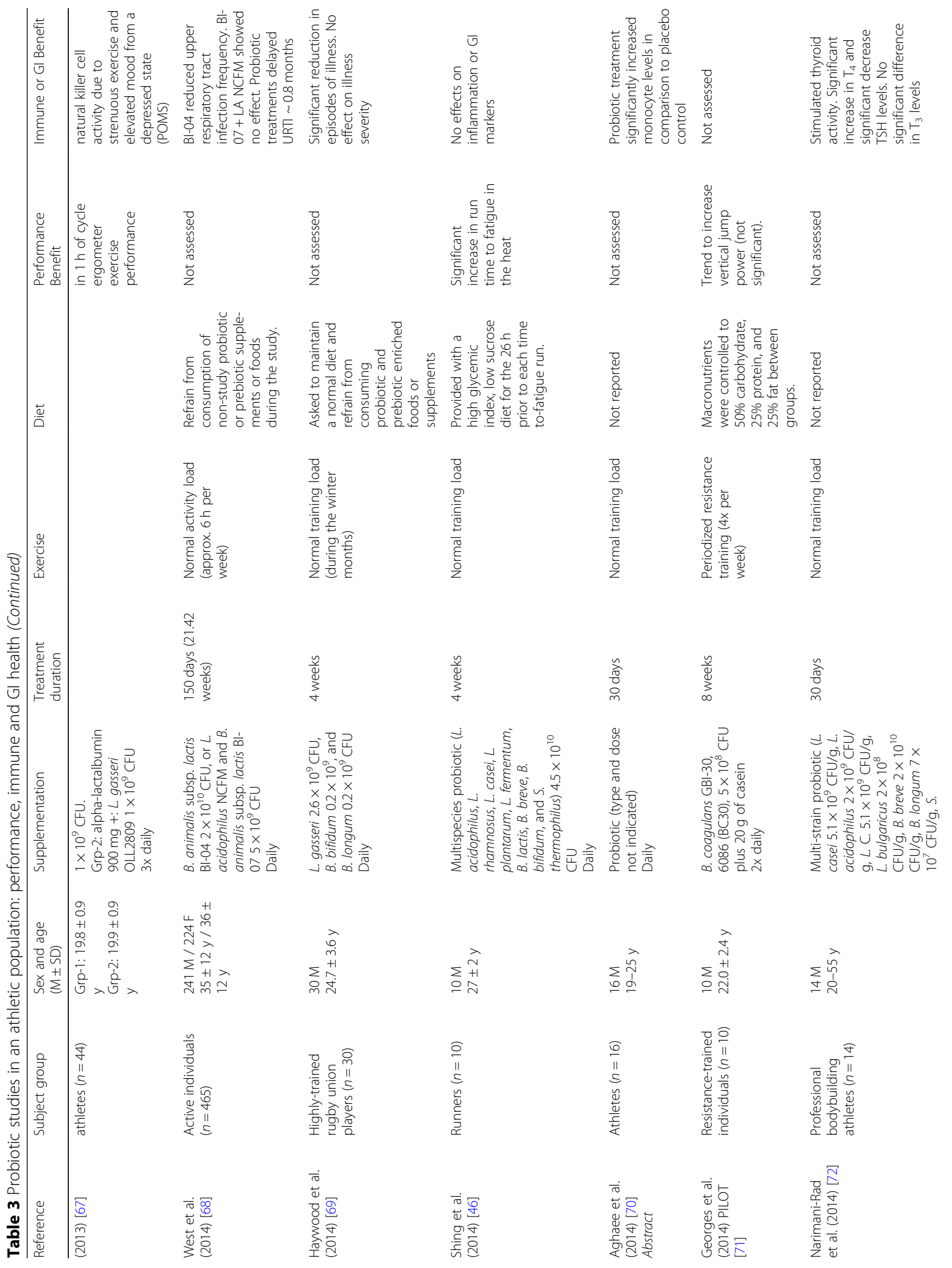




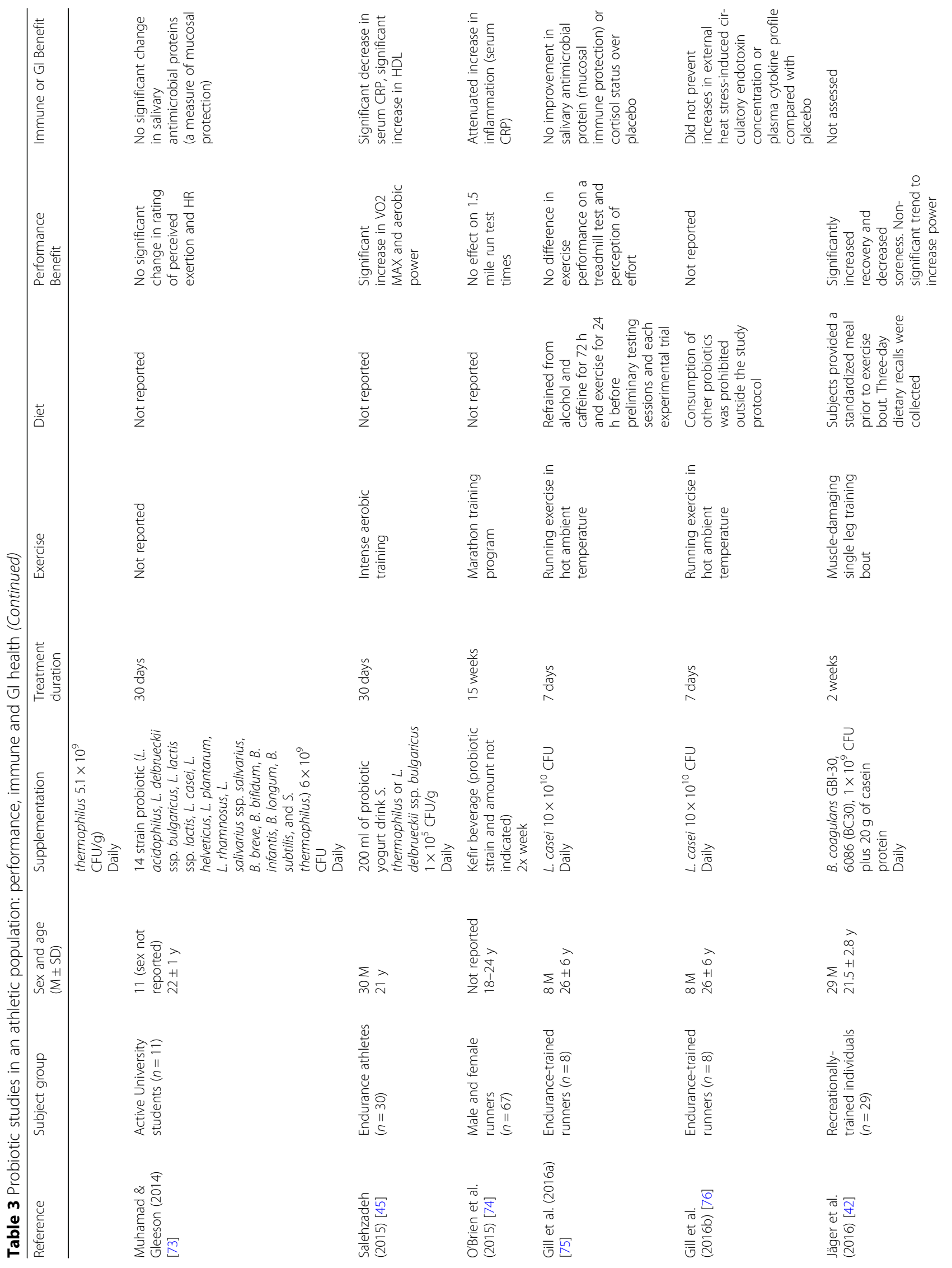




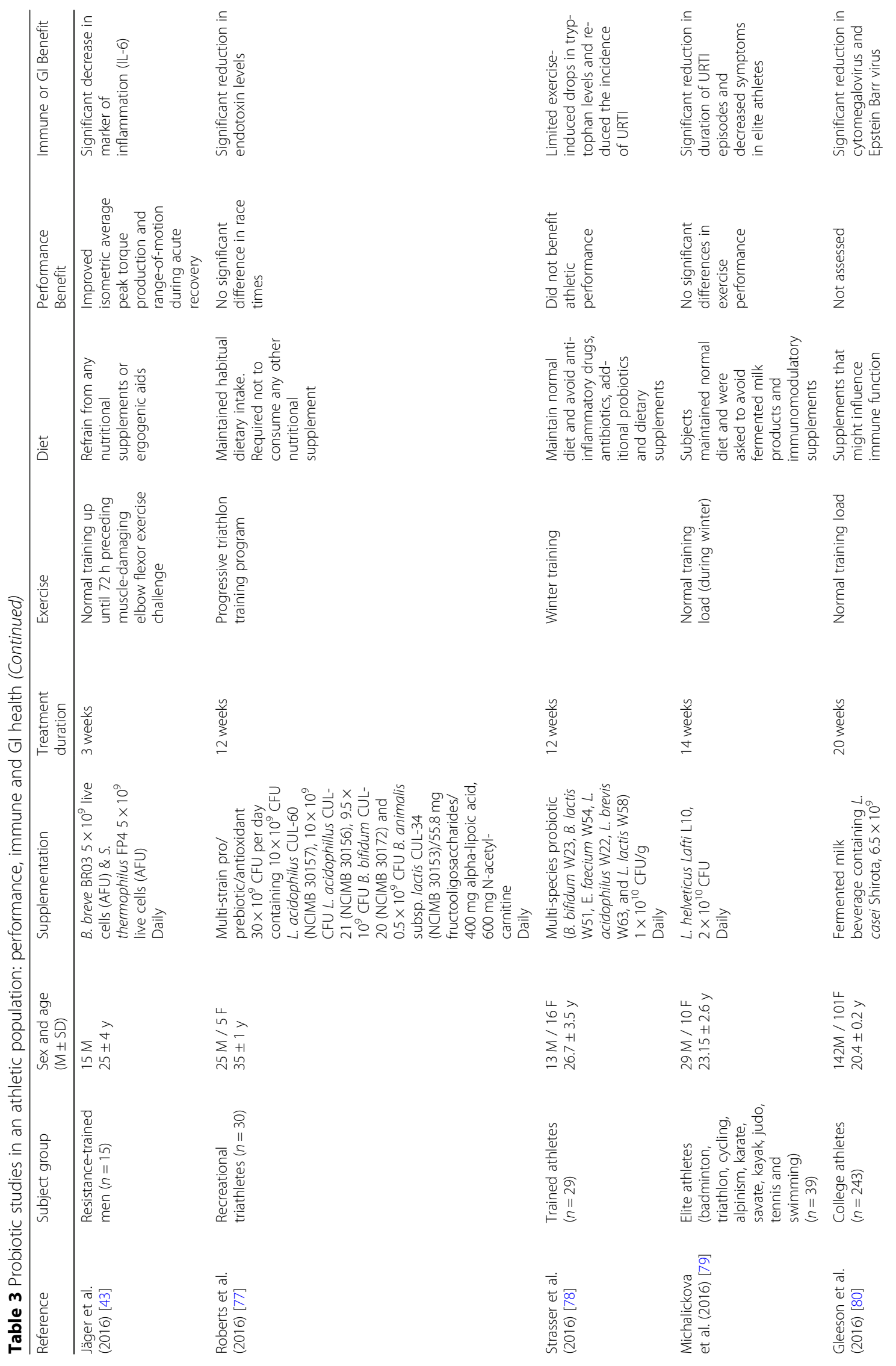




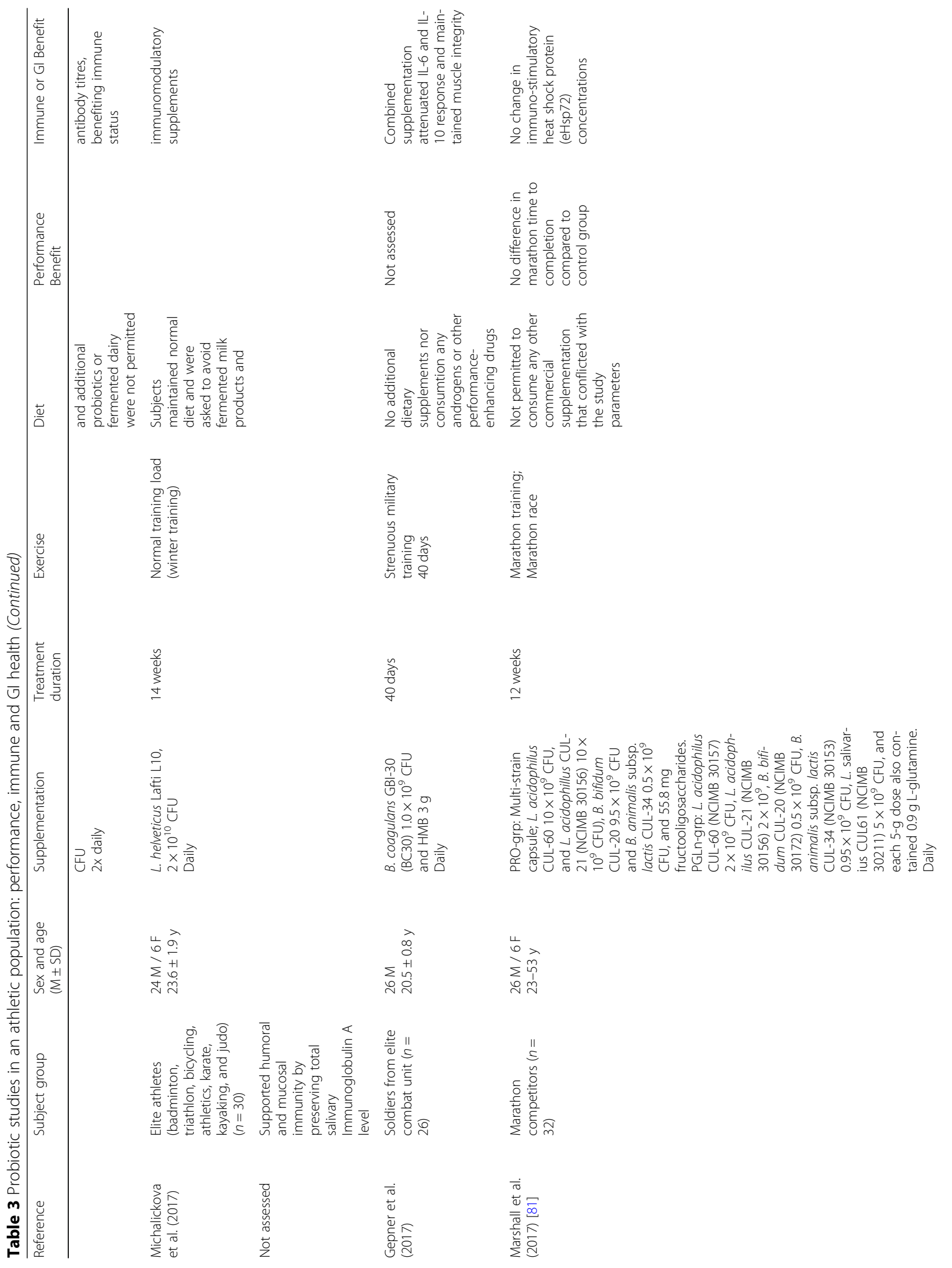




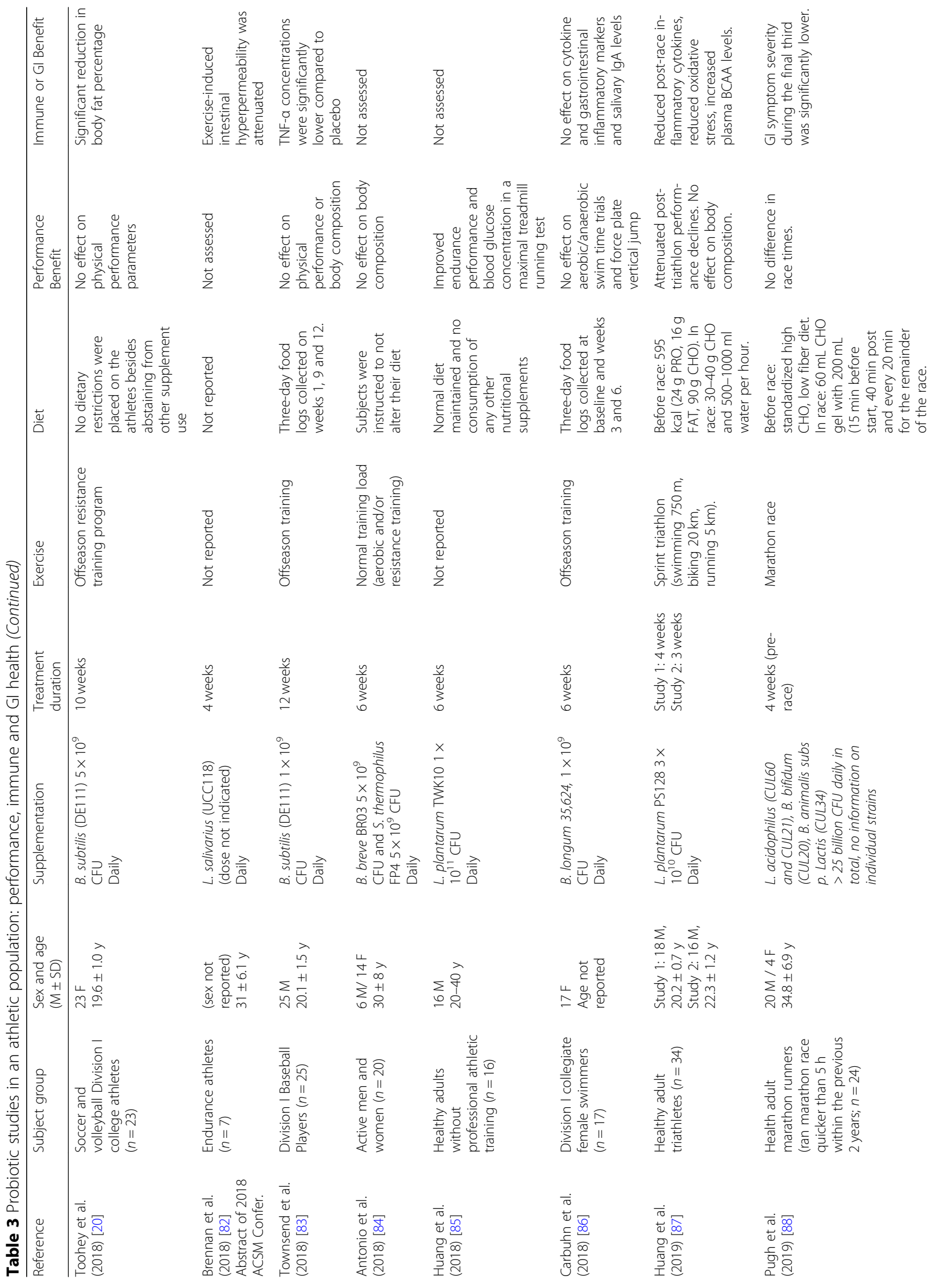




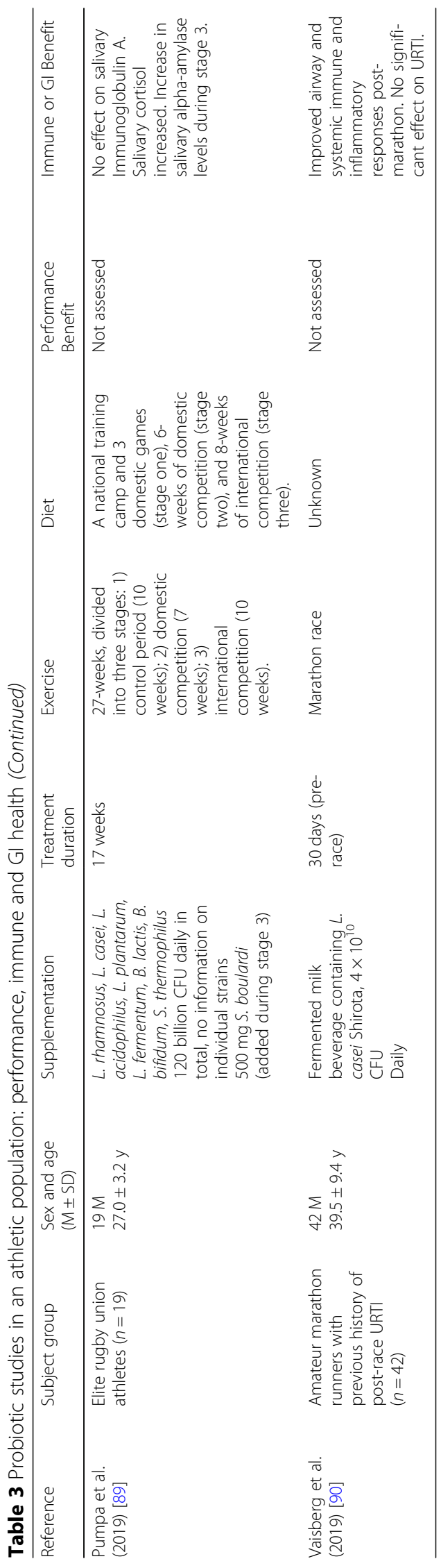


alpha-lactalbumin in 44 university-student athletes did not improve cycle ergometer performance [67]. Gill et al. [75] did not find a difference in perception of effort during a treadmill test in eight male endurance-trained runners who supplemented with a high-dose of Lactobacillus casei $\left(10 \times 10^{10} \mathrm{CFU}\right)$. Finally, in 39 elite athletes from various sports, 14 weeks of Lactobacillus helveticus Lafti L10 supplementation during the winter did not elicit significant differences in exercise performance as measured by $\mathrm{VO}_{2}$ max, treadmill performance time, maximal heart rate and heart rate recovery [79]. The single strain interventions used in these five studies did not produce an aerobic performance benefit.

Null findings were similarly reported in several studies investigating the effects of multi-strain probiotics on aerobic performance. For instance, in endurance-trained men, 14 weeks of a multi-species probiotic had no effect on $\mathrm{VO}_{2}$ max and maximum performance [63]. In a study designed to determine the effects of a 30-day period of supplementation with a 14-strain probiotic at rest, and in response to an acute bout of prolonged cycling exercise for $2 \mathrm{~h}$ at $60 \% \mathrm{VO}_{2} \max$ in 11 active, healthy adults there was no significant change in rating of perceived exertion and heart rate [73]. In another study assessing the effects of a multi-strain probiotic (along with $55.8 \mathrm{mg}$ fructooligosaccharides, $400 \mathrm{mg}$ alpha-lipoic acid, $600 \mathrm{mg} \mathrm{N}$-acetylcarnitine) in 30 recreational athletes over 12 weeks of progressive triathlon training no significant differences were found in race times [77]. Marshall et al. [81] investigated the effects of a multi-strain probiotic for 12 weeks of marathon training in a group of 32 marathon competitors and found no difference in marathon time to completion compared to the control group.

However positive results were reported in thirty endurance athletes supplementing with a yogurt drink, either containing Streptococcus thermophilus or Lactoba cillus delbrueckii ssp. bulgaricus or no probiotics over 30 days during intense aerobic training. There was a significant increase in $\mathrm{VO}_{2} \max$ and aerobic power in the Cooper aerobic test [45]. In thirty-three trained athletes, 12 weeks of winter training supplementation with a multispecies probiotic did not benefit athletic performance; however, the training load (hours per week) was higher in those who supplemented with the probiotic blend vs. the placebo group [78]. One explanation for these findings could be that probiotics may enable better performance capabilities and training adherence when the risk of URTI development is reduced, as individuals with fewer episodes of infections such as common colds are able to train more often and harder. Further, Strasser et al. [78], noted that the multi-species probiotic limited exercise-induced reductions in circulating tryptophan concentration. Higher serum tryptophan levels may enhance the tryptophan transport into the brain and support serotonin metabolism, which can influence an individual's sensation of fatigue and thus potentially affect training adherence and performance [91]. Interestingly, $\mathrm{VO}_{2} \max$ was positively correlated with preexercise serum tryptophan levels at a moderate magnitude, supporting a role of tryptophan metabolism in training performance.

Huang et al. [85], found increased endurance performance and elevated blood glucose concentration following exercise-to-exhaustion after 6 weeks of high dose $\left(1 \times 10^{11} \mathrm{CFU}\right)$ Lactobacillus plantarum TWK10 (a plant Lactobacillus strain isolated from Taiwanese pickled vegetables) supplementation in healthy male adults. However, as these were untrained males and no aerobic exercise intervention was reported in this study, these data should be interpreted conservatively in relation to endurance athletes. These results might be explained by an anti-inflammatory effect from $L$. plantarum TWK10 [92] on skeletal muscle and improvement in energy harvest, possibly related to glycogenesis regulation for exercise demand. Interestingly, L. plantarum KX041 can maintain intestinal permeability and exert antioxidant capacity [93]. Moreover, certain strains of $L$. plantarum activate cell growth signaling pathways in gut enterocytes which in turn increases protein metabolism in the gut [94]. Further, $L$. plantarum can rescue the shunted growth phenotype in malnourished mice by activating muscle, bone, and organ growth [95].

In a study investigating the effect of a multi-strain probiotic yogurt on performance in adolescent female endurance swimmers over 8 weeks, there was a significant improvement in $\mathrm{VO}_{2} \max$ [44]. The improvement in $\mathrm{VO}_{2}$ max was attributed to the reduction in number and duration of URTI for athletes following intake of the multistrain probiotic yogurt. In another study researching the effect of multi-strain probiotics Shing et al. [46] found 4 weeks of supplementation improved time to fatigue while running in the heat for ten male runners. While the mechanism for improvement was unclear, it was speculated that probiotics may exert small to large effects on GI structural integrity, endotoxin translocation and immune modulation that combine to enhance exercise performance. In contrast, a Kefir beverage (a naturally fermented milk beverage containing a defined mixed microbial culture of lactic acid bacteria and yeasts) consumed over 15 weeks of marathon training by sixty-seven male and female runners had no effect on 1.5 mile run test performance [74]. Currently, there are more studies showing a benefit for multi-strain probiotics in relation to performance measures compared to single-strain probiotics. While there are some encouraging results, a large majority of studies have found no effect on aerobic performance. It appears that some of the positive benefits of probiotic supplementation may be indirect by 
allowing for improved gut integrity or immune modulation. However, additional research is warranted including investigating potential performance outcomes beyond aerobicbased endurance exercise.

Other studies have explored the effect of probiotic supplementation in relation to resistance training on muscle recovery and body composition. A pilot study in ten subjects using resistance trained males supplemented $20 \mathrm{~g}$ of casein protein with or without Bacillus coagulans GBI30, 6086 (BC30) for 8 weeks following a periodized resistance training program showed a trend to increase vertical jump power [71]. Jäger et al. [43] speculated that the potential improvement in vertical jump performance may have been related to improved muscle recovery through gut microbial modulation. In a follow up study, $20 \mathrm{~g}$ of casein protein co-administered with B. coagulans GBI-30, 6086 (BC30) or a placebo in recreationally-trained individuals for 2 weeks increased recovery and decreased soreness after a muscle-damaging single-leg training bout [43]. Furthermore, exercise-induced muscle damage was decreased as measured by serum creatine kinase, which may also indicate improved cellular integrity rather than damage per se. While not fully understood, candidate mechanisms of action included the production of digestive enzymes that are active under gut conditions (e.g. alkaline proteases) and these proteases can digest proteins more efficiently than the endogenous human proteases alone [43, 96, 97]. Further, $B$. coagulans GBI-30, 6086 enhances the health of the cells of the gut lining through improved nutrient absorption including minerals, peptides, and amino acids by decreasing inflammation and encouraging optimum development of the absorptive area of the villi [98]. In vitro, B. coagulans GBI30, 6086 can increase protein absorption [99]. The combination of B. coagulans GBI-30, 6086 with casein protein may have acted synergistically to augment digestion and modulate absorption.

In fifteen resistance-trained men, 3 weeks of Bifidobacterium breve BR03 and S. thermophilus FP4 supplementation improved isometric mean peak torque production and range-of-motion during acute recovery after a muscledamaging elbow flexor exercise challenge in comparison to a control group [42]. While mechanisms behind these observations were not described, these strains can have antiinflammatory effects [100-102] and colonize in different areas of the GI tract. However, using the same strains and dose, Antonio et al. [84], failed to see a significant effect on body composition in highly-trained men and women over a longer, six-week period. In both of the above studies participants were not provided supplemental protein. Toohey et al. [103] investigated the effects of Bacillus subtilis DE111 probiotic supplementation on muscle thickness and strength, body composition, and athletic performance in Division I female volleyball and soccer athletes for 10 weeks of an offseason resistance training program. Both groups consumed a protein and carbohydrate recovery drink (consisting of $45 \mathrm{~g}$ carbohydrates, $20 \mathrm{~g}$ protein, and $2 \mathrm{~g}$ fat) immediately after each training session. Probiotic supplementation with the post-workout recovery drink yielded greater reductions in body fat and increases in fat free mass after 10 weeks of resistance training than a placebo. Although no performance advantages were observed, Toohey et al. [103], speculated that supplementation may have promoted improved dietary protein absorption and utilization, contributing to improvements in body composition by increasing dietary protein-induced thermogenesis and altering satiety signaling. It seems that several strains of lactic acid bacteria, including L. gasseri SBT 2055, Lactobacillus rhamnosus ATCC 53103, and the combination of $L$. rhamnosus ATCC 53102 and Bifidobacterium lactis $\mathrm{Bb} 12$, are effective at reducing fat mass in obese humans [104]. Additionally, other strains of $B$. breve have shown anti-obesity effects in both humans [105] and mice [106].

Townsend et al. [83], evaluated the effect daily $B$. subtilis (DE111) supplementation on physical and performance adaptations in Division I collegiate baseball players following 12 weeks of offseason resistance training. On training days, placebo or probiotic capsules were consumed immediately postworkout with a protein and carbohydrate recovery drink (consisting of $36 \mathrm{~g}$ carbohydrates, $27 \mathrm{~g}$ protein, and $2 \mathrm{~g}$ fat). There were no group differences observed between those who took the probiotic and placebo for any measure of strength, performance, or body composition. However, those athletes who did supplement with probiotics had significantly lower serum TNF- $\alpha$ concentrations than the placebo group. Elevations in TNF- $\alpha$ have been linked to suppressed protein synthesis, disordered sleep, and impaired muscular performance [107-109]. The null performance findings reported by Townsend et al. [83] and Antonio et al. [84] may have been the result of an inability for the probiotic supplement to modify healthy participants' microbiomes. Indeed, the subjects in these two studies were young, healthy and highly active. In this regard, systematic reviews $[110,111]$ and an original investigation involving supplementation [112] of probiotic supplementation in adults indicate that probiotic supplementation is more likely to alter the microbiome composition of dysregulated microbiomes compared to healthy ones. While probiotic consumption may not alter microbiome composition, it can alter functionality by up regulation of gene expression and metabolic pathways. As noted for aerobic performance, it is also plausible that probiotic supplementation confers an indirect effect on performance and that the training, diet, and recovery of the 
individuals in some of these studies were optimal enough to mask any small additional benefits.

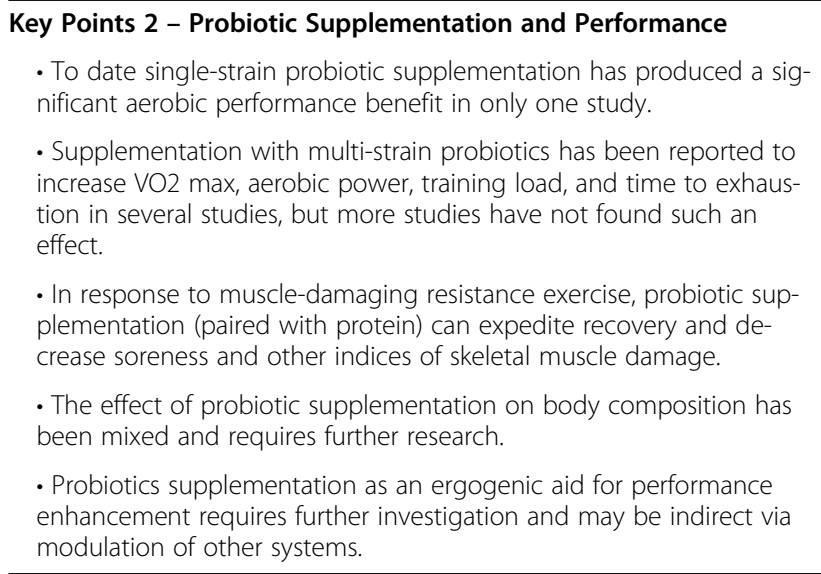

\section{The effect of probiotic supplementation on the immune system}

The mucosal lining of the GI tract represents the firstline-of-defense against invading pathogens and is an important interface with the host immune system. Exhaustive physical exercise negatively impacts immunity, reducing of the count and function of immune cells, such as natural killer (NK) cells and T lymphocytes. Proinflammatory cytokines such as IL- 1, TNF- $\alpha$ and IFN- $\gamma$ generally remain unchanged after prolonged exercise whereas the inflammation-responsive cytokine IL- 6 and anti-inflammatory cytokines such as IL-10, IL-1ra, sTNFR increase markedly. The increase in IL-6 is not solely in response to inflammation in this situation as it also originates from contracting muscle and is associated with glycogen regulation. Gene expression in white blood cells is upregulated for most anti-inflammatory markers and downregulated for pro-inflammatory markers and TLR signaling. The anti-inflammatory hormone cortisol is also elevated [53, 57, 59, 113, 114]. Changes in immune health are associated with increased incidence of URTIs and disorders of the GI tract $[46,53]$ which have the potential to impair physical performance and/or cause an athlete to miss training or competition [115]. These conditions usually occur during competitive periods that are commonly represented by higher intensities and greater volumes of exercise [116], affecting the athlete's health and impairing physical performance when needed most [115]. In this context, interventions that prevent or mitigate these conditions can indirectly improve physical and competition performance. Among the nutritional supplements used in modulation of the immune response of athletes, probiotics are noteworthy [92].

Probiotics appear to augment intestinal communication between the host immune system and commensal bacteria to establish mutualistic benefits. The roles of microbialderived SCFAs, particularly butyric acid in the colon, are important in mucosal homeostasis through regulation of epithelial turnover and induction of regulatory $\mathrm{T}$ (Treg) cells [117]. Beyond the GI tract, probiotics have an immunomodulatory effect through the common mucosal immune system, in which cells from inductive sites (e.g., Peyer's Patches in the intestines) translocate to mucosal surfaces following interaction with antigen-presenting cells [118].

Research investigating the effects of probiotics on immune outcomes have been the most prevalent type of research in athletic populations. Of the 22 studies reviewed in this Position Stand that assessed the effect of probiotics on outcomes related to the immune system, 14 reported significant improvement, whereas 8 reported no effects.

Of particular relevance to athletes is the reduction in incidence and/or severity of symptoms from illnesses like URTI. In a large study of 465 active individuals who had a normal activity load of approximately $6 \mathrm{~h}$ per week, West et al. [68] compared a single strain treatment consisting of Bifidobacterium animalis ssp. lactis $\mathrm{Bl}-04$ and doublestrain probiotic consisting of Lactobacillus acidophilus NCFM and B. animalis subsp. lactis Bi-07 to placebo over a 150-day intervention. Daily B. animalis ssp. lactis Bl-04 supplementation for 150 days was associated with a $27 \%$ reduction in the risk of any URTI episode compared to placebo supplementation. Supplementation with the double-strain probiotic resulted in a 19\% decrease of URTI risk, although this was not statistically significant. Moreover, both probiotic supplement groups exhibited a $\sim 0.8$-month delay in time to illness. Importantly, healthy active individuals with a lighter training load, and presumably at a lower risk for URTIs, also appeared to benefit from a probiotic supplement.

The majority of studies that have investigated the potential benefits of probiotics on URTIs have been conducted in endurance athletes with generally high training loads. For example, Cox et al. [57] studied the effect of $L$. fermentum VRI-003 (PCC) over 16 weeks of winter training in 20 elite male distance runners on incidence of illness and infection. Probiotic supplementation significantly reduced URTI incidence and severity compared to placebo. Specifically, those in the treatment group reported less than half the number of days of respiratory illness symptoms compared to the control group during the intervention. While not significant, there was a trend for enhanced T-lymphocyte function, which may be in part responsible for the immunological benefits. Similarly, Gleeson et al. [60] examined the effects of Lactobacillus casei Shirota during 4 months of winter training in endurance-based recreational athletes and observed a significant reduction in URTIs compared to placebo. In addition, salivary IgA 
concentration was significantly higher in those consuming the probiotic. However, severity and duration of symptoms were similar between the treatment and placebo groups. Supplementation with the same strain 30 days prior to a marathon race resulted in improved systemic and airways immune responses, and showed a trend toward improved incidents and duration of URTI post-marathon [90]. In competitive cyclists, West et al. [61] reported reduced severity of self-reported symptoms of lower respiratory illness and use of cold and flu medication over an 11-week winter training period with $L$. fermentum $\left(\mathrm{PCC}^{\circ}\right.$ ) compared to placebo. Interestingly, this effect was only noted in males and not females. Strasser et al. [78] examined the effect of 12 weeks of treatment with a multi-strain probiotic on the incidence of URTIs and metabolism of aromatic amino acids after exhaustive aerobic exercise in highly trained athletes during the winter. Daily supplementation with probiotics reduced the incidence of URTI compared to placebo. In addition, supplementation limited exercise-induced reductions in tryptophan levels, which may reduce the risk of developing an infection.

Beyond studies investigating traditional endurance athletes with high aerobic training loads, probiotic supplementation has also been examined in other athletes with varying demands. For instance, Salarkia et al. [44] reported that 8 weeks of supplementation with a multistrain probiotic yogurt reduced the number of episodes of URTIs in adolescent female swimmers compared to the same yogurt without probiotics. Haywood et al. [69] investigated the effect of a multi-strain probiotic over 4 weeks in 30 elite union rugby players to determine effectiveness on the number, duration and severity of infections. The probiotic group had lower incidence of infection-related symptoms compared to placebo, although there was no difference in the severity of the symptoms between the two treatment groups. In a study of an eclectic group of elite athletes training in badminton, triathlon, cycling, alpinism, athletics, karate, savate, kayak, judo, tennis, and swimming, Michalickova et al. [79] studied the effects of L. helveticus Lafti L10 over 14 weeks during the winter. Athletes all had high training loads of $>11 \mathrm{~h}$ per week and were winners of the national or European and world championships in their categories and sport. Supplementation with the probiotic significantly reduced the length of URTI episodes and lowered the number of symptoms per episode compared to placebo. Moreover, there was a significant increase of CD4+/CD8+ (T helper/T suppressor) cells ratio in the probiotic group. Previously, this ratio has been noted as an index sensitive to high training loads and was decreased after strenuous physical activity [36, 119]. In addition, low CD4+/CD8+ cell ratio is usually related to acute viral diseases [120].

Several studies that assessed similar outcomes did not report significant effects from probiotic supplementation compared to placebo. For example, a 12-week study on 141 non-elite marathon runners during pollen season supplementing daily with $L$. rhammnosus GG (LGG) did not find a significant effect on allergic markers [54] or on the incidence of UTRI episodes [55]. Similarly, there was no significant effect on URTI incidence in a study investigating the effect of $L$. casei supplementation in French soldiers participating in intense military training for 3 weeks in a 5-day combat course [56]. In addition, there was no difference in salivary IgA or total and differential leukocyte and lymphocyte subsets.

Gleeson et al. [64] examined the effects of daily supplementation of L. salivarius on 66 endurance-based recreational athletes during a four-month period in the spring. There was little effect on frequency, severity or duration of URTIs. In addition, circulating and salivary immune markers did not change over the course of the study and were not different between probiotic and placebo groups. Gleeson et al. [80] also assessed the effect of L. casei Shirota on the incidence of URTIs over a 20-week period during the winter in 243 college endurance athletes. Similarly, there was no significant difference between those that consumed the probiotic and the placebo treatment. However, there was a reduction in plasma cytomegalovirus and Epstein Barr virus antibody titers in seropositive athletes compared to placebo, an effect interpreted as a benefit to overall immune status.

While these null findings are important to consider, the current overall body of evidence is weighted notably in favor of probiotics on reduction of URTIs and related symptoms. However, a central issue in relation to the effects of probiotics on immunity, and probiotic research in general, is the large assortment of strains used. Shared, core mechanisms for probiotic function are evident, although some mechanisms may be more narrowly distributed, including those related to immunomodulation [121]. In addition, it is important to note that immune response is complex, as are many of the methodologies used to measure it. For example, an immunomodulatory effect of probiotics is attributed to the release of a large number of cytokines and chemokines from immune cells, which can further impact the innate and adaptive immune systems [122]. Therefore, it is not surprising that the beneficial effect of probiotic administration on the incidence of respiratory illness is possibly linked enhancement of systemic and mucosal immunity. It is possible changes occurred at this level and were not detected in studies that only measured URTI associated metrics. Future work in this area should pair the investigation of URTI incidence and symptomology with other markers of immune response to provide a more thorough understanding of how different probiotics might influence the immune system.

Although less common than symptom outcomes, several studies have provided encouraging evidence in regard to 
changes in circulating and salivary immune markers. For instance, Clancy et al. [53] sought to determine if immune variables differed between healthy and fatigued recreational athletes after Lactobacillus intervention. One month of daily $L$. acidophilus supplementation significantly increased secretion of interferon (IFN)- $\gamma$ from $\mathrm{T}$ cells in fatigued athletes to levels found in healthy athletes and increased the concentration of IFN- $\gamma$ in saliva of healthy control athletes. IFN- $\gamma$ is a cytokine intricately linked to mechanisms of control of both virus shedding and disease re-activation. Sashihara et al. [67] evaluated the immunopotentiation and fatigue-alleviation effects of $L$. gasseri OLL2809 supplementation for 4-weeks in 44 university-student athletes. Before and after the treatment period, the subjects performed strenuous cycle ergometer exercise for $1 \mathrm{~h}$. The probiotic supplementation prevented reduced NK cell activity after strenuous exercise which may enhance resistance against infections. In another short-term study, Aghaee et al. [70] reported that a probiotic supplement for 30 days in 16 male athletes increased blood monocyte levels following exhaustive exercise in comparison to placebo control. In a longer duration study, Michalickova et al. [79] investigated the effects of L. helveticus Lafti L10 supplementation on systemic humoral and mucosal immune response in 30 elite athletes with a high training load ( $>11 \mathrm{~h}$ per week) over 14 weeks in the winter. Those that consumed the probiotic exhibited attenuated decreases in total salivary IgA level compared to athletes in the placebo group. Given the fact that mucosal surface is the first-line-of-defense against different pathogens, this finding might have a practical application in terms of prevention of URTIs during strenuous exercise in elite athletes. In comparison to some of the previous studies that didn't report changes in immune parameters, yet noted a difference in URTI incidence, it is possible that in these circumstances these strains could have displayed antagonistic activities against pathogens and not direct stimulation of the immune system. These effects could include the production of antimicrobials, such as bacteriocins, and low molecular weight compounds such as hydrogen peroxide, lactic acid, and acetic acid [123-125]. These substances could function to outcompete pathogenic bacteria and help in easing or preventing URTI symptoms [126].

In contrast, West et al. [66] did not find significant effects of a synbiotic product including multi-strain probiotics (Lactobacillus paracasei ssp. paracasei (L. casei $\left.431^{\circ}\right)$, B. animalis ssp. lactis (BB- $\left.12^{\circ}\right)$, L. acidophilus LA5, L. rhamnosus GG) on markers of circulating and mucosal immunity in 22 recreational cyclists over a threeweek training period. In another small study of the effects of a multi-strain probiotic ( $L$. acidophilus, $L$. delbrueckii ssp. bulgaricus, Lactococcus lactis ssp. lactis, L. casei, L. helveticus, L. plantarum, L. rhamnosus, L. salivarius ssp. salivarius, B. breve, Bifidobacterium bifidum, B. infantis, Bifidobacterium longum, B. subtilis, and S. thermophilus) on mucosal immunity, Muhamad \& Gleeson [73] did not report a significant alteration in salivary antimicrobial proteins at rest or in response to an acute bout of prolonged exercise in 11 active, healthy adults after 30 days of supplementation. Using a high-dose probiotic treatment, Gill et al. [75] studied 8 male endurance runners who consumed $10 \times 10^{10} \mathrm{CFU}$ of L. casei for 7 days prior to a two-hour running exercise at $60 \%$ $\mathrm{VO}_{2} \mathrm{max}$ in hot ambient conditions $\left(34.0^{\circ} \mathrm{C}\right.$ and $32 \%$ relative humidity). Supplementation did not enhance salivary antimicrobial proteins responses and subsequent oral-respiratory mucosal immune status above placebo. Finally, Carbuhn et al. [86] explored the effects of $B$. longum 35,624 supplementation in 20 female Division I collegiate swimmers during a 6-week intense training phase on IgA. There were no difference in salivary IgA between groups throughout the study in agreement with a study investigating $B$. subtilis DE111 in collegiate baseball players [83].

Overall, the effect of probiotic supplementation on the immune system in athletes is likely positive and beneficial. Episodes of illness often occur during heavy exercise training periods, a time when athletes obtain the greatest improvements in fitness. Illness that interrupts individual training sessions may prevent athletes from maximizing the effects of their training program. Therefore, probiotic supplementation may be viewed as a viable dietary supplement to support immune function during these periods.

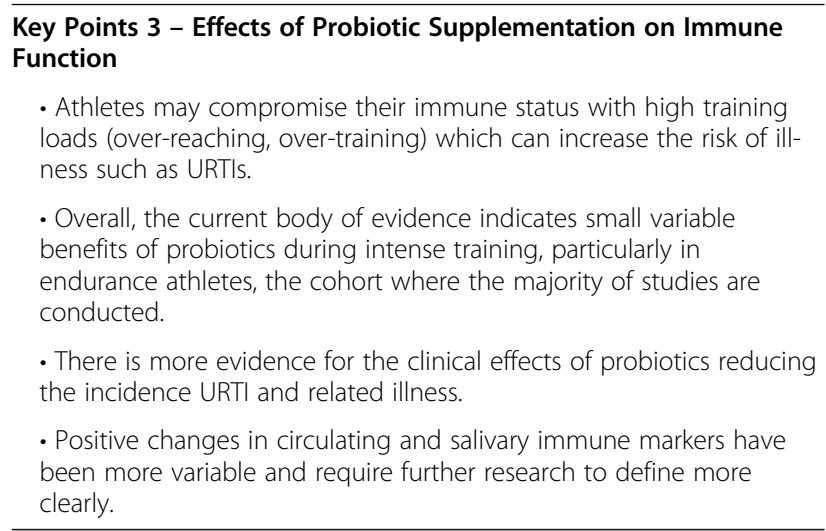

The effect of probiotic supplementation on GI tract health GI problems often occur in endurance athletes and particularly during prolonged events such as cycling, triathlons and marathons $[41,127]$. Symptoms such as nausea, cramping, bloating, and diarrhea most likely reflect redistribution of blood flow from the gut to the skin for cooling purposes. Exercise-induced redistribution of blood can result in splanchnic hypoperfusion as a possible mechanism for gut dysfunction [128, 129]. The physical up-and down movement of the gut during running 
could also explain an increase in the frequency of gut symptoms [41]. Interactions between prolonged exercise, challenging environmental conditions (temperature, altitude, humidity, etc.), and nutrient and fluid intake may also increase risk of gut problems [130]. Disruption in the GI system can impair the delivery of nutrients, and cause GI symptoms and decreased performance. The GI tract and particularly the gut are quite adaptable and can be targeted to improve the delivery of nutrients during exercise while at the same time alleviating some (or all) of the symptoms [131]. A major limitation of studies in this field is that the prevalence of GI illnesses overall is quite low, which makes it difficult to study without a large number of subjects. Probiotic supplementation in combination with other dietary strategies (e.g. consuming well-tolerated foods and drinks, avoiding spicy foods) could assist athletes with a history of GI problems. Moreover, probiotic supplementation potentially could improve GI health which has several indirect athletic benefits. Of the ten studies that assessed GI benefit in athletes and physically active individuals, the majority reported no effect. However, the methodology varied considerably, including probiotic type (species/strain), dosing, duration and study participants, making comparison difficult. Further, the overall result is not conclusive as four studies reported positive results. This latter group included significantly decreased concentrations of zonulin [63] and endotoxin [77], as well as intestinal hyperpermeability [132] and duration of GI-symptom episode. Research in this area has only been conducted intermittently over the past 10 years, with the need for future studies apparent.

In the first reported study investigating the effects of probiotics on GI health, Kekkonen et al. [55], reported no effect of L. rhamnosus GG on GI-symptom episodes in marathon runners after a three-month training period. However, the duration of a GI symptom episode was 57\% shorter in the probiotic group than in the placebo group. Eight weeks of supplementation with a multi-strain probiotic yogurt in adolescent female endurance swimmers did not affect GI symptoms [44]. In a study of elite union rugby players, subjects given a multi-strain probiotic over 4 weeks did not experience a significant reduction in GI episodes (including nausea, vomiting, diarrhea) compared to the placebo [69].

Investigating markers of gut permeability, West et al. [66] found no significant effect of multi-strain probiotic supplementation on the lactulose/mannitol ratio in active individuals after 3 weeks. Lamprecht et al. [63] explored the effects of 14 weeks of multi-species probiotic supplementation on zonulin from feces in trained men. Zonulin concentrations decreased significantly from slightly above normal into the physiological range in subjects that supplemented with the probiotics. Zonulin is a protein of the haptoglobin family released from liver and intestinal epithelial cells and has been described as the main physiological modulator of intercellular tight junctions [133]. Increased zonulin concentrations are related to changes in tight junction competency and increased GI permeability [133]. The "leak" in the paracellular absorption route enables antigens to pass from the intestinal environment, challenging the immune system to produce an immune response and subsequent inflammation and oxidative stress [134-136]. Lamprecht et al. [63] suggested that the supplemented probiotics may activate the TLR2 signaling pathway resulting in improved intestinal barrier function, thus reducing an athlete's susceptibility to endotoxemia and associated cytokine production [137].

Shing et al. [46] tested the effects of 4 weeks of multistrain probiotics supplementation on GI permeability when exercising in the heat in a small group of male runners. To assess GI permeability, subjects ingested lactulose and rhamnose before exercise and post-exercise urine was collected to measure the ratio. Further, urinary claudin-3, a surrogate marker of gut barrier disruption, and serum lipopolysaccharide (LPS) were measured. There was no significant effect on lactulose:rhamnose ratio, urinary claudin-3 or serum LPS and it is possible that 4 weeks may not have been sufficient to detect changes. In short-term, high dose single-strain probiotic supplementation (L. casei), male runners under heat stress did not exhibit any marked changes in resting circulatory endotoxin concentration or plasma cytokine profile compared with placebo [76]. Conversely, Roberts et al. [77] reported 12 weeks of supplementation with a multi-strain probiotic/prebiotic significantly reduced endotoxin levels in novice distance triathletes. However, no difference was identified in the assessment of intestinal permeability from urinary lactulose:mannitol ratio. This effect was reported both pre-race and 6 days post-race. Additionally, seven highly-trained endurance athletes who received 4 weeks of L. salivarius (UCC118) attenuated exerciseinduced intestinal hyperpermeability [132]. Most recently, 12 weeks of probiotic supplementation (B. subtilis DE111) had no effect on gut permeability as measured by zonulin in Division I baseball players [83].

\footnotetext{
Key Points 4 - Probiotic Supplementation and Gastrointestinal Health.

- Gl problems often occur in endurance athletes and can impair the delivery of nutrients, cause Gl symptoms and decrease performance.

- A small number of studies assessing Gl benefit in athletes and physically active individuals have yielded mixed results with considerable variation in methodology, making comparison difficult.

- Positive results reported included decreases in concentrations of zonulin and endotoxin, intestinal hyperpermeability and duration of Gl-symptom episodes.
}

\section{Mechanism of action}

Given that different strains and product formulations exist, explaining the mechanism of action becomes a rather 
complex task. An additional challenge in probiotic research is that a mechanism of action involving the gut microbiota is not confirmed, or even examined, in the majority of cases and there certainly are mechanisms outside of the GI tract systemically and in other microbiota niches. Clinical studies track probiotic "inputs" (whether a single strain or multiple strains) and health "outputs", often without knowing what happens in between. This shortcoming further emphasizes the need to not use the general term probiotics, when describing mechanisms of action, but try to specify the strains [138]. This does not mean the mechanisms are the same for each strain, nor that precise mechanisms have been proven. For example, bacterial strains such as $L$. reuteri SD2112 (ATCC 55730) and $L$. reuteri RC-14 are different genetically and functionally, with the former producing reuterin believed to be important for inhibition of pathogens in the gut [139] and the latter producing biosurfactants that inhibit attachment of uropathogens [140]. Finally, several food products and dietary supplements may contain multiple species and strains in the same product. To fully explain the in-depth mechanisms of action is both out of the scope of this Position Statement and poorly understood in general. However, interested readers are directed to other resources [138, 141]. The question whether multi-strain or multi-species probiotics are better than single strain or single species probiotics depends on the outcome measure, dosage, and study population. Potential additive or even synergistic benefits would need to be validated in a control clinical study, and currently those data do not exist. Mechanisms of action in relation to the effects of probiotic supplementation in athletes has been less described [40]. Here we discuss support of the gut epithelial barrier, increased adhesion to intestinal mucosa, the effects of postbiotics, modulation of the immune system, and improved nutrient absorption.

\section{Support of the gut epithelial barrier}

The intestinal barrier is a major defense mechanism used to maintain epithelial integrity and protect the host from the environment. Defenses of the intestinal barrier consist of the mucous layer, antimicrobial peptides, secretory IgA and the epithelial junction adhesion complex [142]. Once this barrier function is disrupted, bacterial and food antigens can reach the submucosa and induce inflammatory responses [143, 144]. Consumption of non-pathogenic bacteria can contribute to intestinal barrier function, and probiotic bacteria have been extensively studied for their involvement in the maintenance of this barrier. However, the mechanisms by which probiotics enhance intestinal barrier function are not fully understood. Anderson et al. [145] indicated that enhancing the expression of genes involved in tight junction signaling is a possible mechanism to reinforce intestinal barrier integrity. Probiotics may promote mucous secretion as one mechanism to improve barrier function and the exclusion of pathogens. Several Lactobacillus species have been noted to increase mucin expression in human intestinal cell lines and, in the case of a damaged mucosa, may thus help restoration of the mucus layer. However, this protective effect is dependent on Lactobacillus adhesion to the cell monolayer, which likely does not occur in vivo [146, 147]. Therefore, mucous production may be increased by probiotics in vivo, but further studies are needed to make a conclusive statement.

Strenuous and prolonged exercise place stresses on the GI tract that increase the likelihood of discomfort, abdominal cramping, acid reflux (heartburn), nausea, vomiting, diarrhea, and permeability of the gut that may allow endotoxemia to occur [41]. Splanchnic hypoperfusion leading to ischemia in the gut is accepted as a principal cause, with additional contributions from nutritional, mechanical (e.g., jarring), and genetic influences that make some individuals more susceptible than others [41]. Probiotic support to increase resilience of the GI tract against ischemia is of interest to athletes, particularly for those involved in prolonged endurance events that have the greatest occurrence of GI problems that can impair or stop performance. Mechanistically, prolonged or strenuous exercise may increase key phosphorylation enzymes [148], disrupting tight junction proteins claudin (influenced by protein kinase A) and occludin (influenced by both protein kinase $\mathrm{C}$ and tyrosine kinase). Acute changes in tight junction permeability and paracellular transport may lead to a greater prevalence of systemic LPS. LPS from Gramnegative intestinal bacteria may provoke immune responses and endotoxin-associated symptoms characteristic of GI complaints often experienced in runners [148]. Despite this, research is relatively sparse on whether prolonged training or ultra-endurance events actually result in elevated LPS, particularly in more "recreationally active" athletes; or whether targeted nutrition strategies offer beneficial support. LPS translocation across the GI tract can provoke systemic immune reactions with varied consequences [149]. Specifically, LPS attachment to LPS-binding protein and its transference to an MD 2/TLR4/CD14 complex activates NF- $\mathrm{kB}$ and various inflammatory modulators (TNF- $\alpha$, IL$1 \beta$, IL-6 and CRP). This sequence is considered a protective mechanism to minimize bacterial entry across the GI tract. Under normal physiological conditions, endotoxins from gram negative bacteria are usually contained locally, with only relatively small quantities entering the systemic circulation. However, when GI defenses are either disrupted (i.e., luminal damage from exercise) or LPS "sensing" is "overloaded", a heightened inflammatory response may result which could, in part, relate to GI symptoms associated with exercise [150]. This effect could have implications for daily recovery strategies throughout prolonged training periods, and in the days following ultra-endurance events. 
Roberts et al. [77] suggested a multi-strain pro/prebiotic intervention maintains tight junction stability. Further, studies have demonstrated that regular use of probiotics can improve epithelial resistance by establishing competitive "biofilm" formation. Indeed, as LPS types vary across Gramnegative bacteria species, some LPS are poorly sensed by TLR4 and may have more direct impact on NF- $\mathrm{kB}$ activation [151]. Therefore, prevention of LPS translocation through maintained epithelial integrity and/or increased preponderance of Gram-positive genera may offer potential therapeutic benefit [152]. Specifically, the provision of bacteria belonging to the Lactobacillus genus may work by activating TLR2 and hence produce more favorable innate immune responses $[153,154]$. Supplementation with a multi-strain probiotic for 14 weeks decreased fecal zonulin levels, supporting improved tight junction stability through improved intestinal barrier integrity [63]. A mechanistic explanation for an improved intestinal barrier function after probiotic treatment is provided by Karczewski et al. [155], who postulate that certain lactic bacteria might activate the TLR2 signaling pathway. TLR2 is localized in the membranes of intestinal wall cells and from there communicates with microbial products from Grampositive bacteria [115]. Furthermore, activation of the TLR2 signaling pathway can enhance epithelial resistance in vitro [156]. Therefore, supplemented probiotics may suppress bacteria that activate the zonulin system (e.g. Gram-negative bacteria), settle in the deep intestine, and activate the TLR2 signaling pathway.

\section{Adhesion to intestinal mucosa}

"Competitive exclusion" is a term used to describe the vigorous competition of one species of bacteria for receptor sites in the intestinal tract over another species. The mechanisms used by one species of bacteria to exclude or reduce the growth of another species include: creation of a hostile microecology, elimination of available bacterial receptor sites, production and secretion of antimicrobial substances and selective metabolites, and competitive depletion of essential nutrients [141]. Adhesion of probiotics to the intestinal mucosa has been shown to favorably modulate the immune system [157, 158] and pathogen antagonism [159]. In addition, probiotics are able to initiate qualitative alterations in intestinal mucins that prevent pathogen binding [160] while some probiotic strains can also induce the release of small peptides or proteins (i.e., defensins) from epithelial cells [161]. These small peptides/ proteins are active against bacteria, fungi and viruses [162] and may stabilize the gut barrier function [163]. Specific adhesiveness properties related to the interaction between surface proteins and mucins may inhibit the colonization of pathogenic bacteria and are a result of antagonistic activity by some strains of probiotics against adhesion of GI pathogens [164]. For example, lactobacilli and bifidobacteria can inhibit a broad range of pathogens, including E. coli,
Salmonella, Helicobacter pylori, Listeria monocytogenes, and Rotavirus [165-171]. To gain a competitive advantage, bacteria can also modify their environment to make it less suitable for their competitors, such as producing antimicrobial substances (i.e., lactic and acetic acid) [172]. Some lactobacilli and bifidobacteria share carbohydratebinding specificities with certain enteropathogens [173, 174], which makes it possible for the strains to compete with specific pathogens for the receptor sites on host cells [175]. In general, probiotic strains are able to inhibit the attachment of pathogenic bacteria by means of steric hindrance at enterocyte pathogen receptors [176].

\section{Postbiotics}

Postbiotics comprise metabolites and/or cell-wall components released by probiotics and offer physiological benefits to the host by providing additional bioactivity [4]. The potential benefits of these metabolites and/or cell wall components should not only be considered to be associated with probiotics but more generally to metabolites produced by bacteria during fermentation, including bile acid fermentation. Several compounds have been collected from several bacteria strains including SCFAs, enzymes, peptides, teichoic acids, peptidoglycan-derived muropeptides, endo- and exopolysaccharides, cell surface proteins, vitamins, plasmalogens, and organic acids [177-179]. Despite the fact that the mechanisms implicated in the beneficial health effects of postbiotics are not fully elucidated, they possess different functional properties including, but not limited to, antimicrobial, antioxidant, and immune modulation [4]. These properties can positively affect the microbiota homeostasis and/or the host metabolic and signaling pathways, physiological, immunological, neuro-hormone biological, regulatory and metabolic reactions [180, 181].

In the majority of cases, postbiotics are derived from Lactobacillus and Bifidobacterium species; however, Streptococcus and Faecalibacterium species have also been reported as a source of postbiotics [177, 179]. SCFAs produced by the gut microbiota act as signaling molecules improving regulation of lipid metabolism, glucose homeostasis, and insulin sensitivity through the activation of receptors such as G protein-coupled receptors (GPRs) to regulate of energy balance while maintaining metabolic homoeostasis $[182,183]$. Specific SCFAs (e.g. butyrate, acetate and propionate) also contribute to plasma cholesterol homeostasis in rodents and humans [184]. Some studies [185-187] determined that cell-free extracts from lactic acid bacteria exhibit higher antioxidant capacity than whole cell cultures, suggesting that the antioxidant capacity could be attributed to both enzymatic and non-enzymatic intracellular antioxidants.

Through postbiotic action, it seems plausible that probiotics can increase exercise performance as seen through a delay in fatigue in athletes by virtue of their production of SCFAs. In addition, species within the 
Lactobacillus genus synthesize lactic acid, which is converted to butyrate and later to acetyl-CoA, which is used in the Krebs Cycle to generate adenosine triphosphate (ATP). However, these processes occur mostly in the gut so whether or not this would impact skeletal muscle performance remains to be determined [188]. Another mechanism is by antioxidant action, which can attenuate muscle injury induced by reactive oxygen species, among others [92]. Antioxidant effects found in probiotics are linked to the synthesis of antioxidant substances such as vitamins B1, B5 and B6 [141]. Moreover, probiotic supplementation reduces the risk of developing hyperglycemia, a condition known to be linked to oxidative stress $[189,190]$. Finally, the improvement in intestinal homeostasis, including the absorption process, may favor the absorption of antioxidants, increasing the availability of these substances [58].

One of the proposed mechanisms involved in the health benefits afforded by probiotics includes the formation of low molecular weight compounds $(<1000 \mathrm{Da})$, such as organic acids, and the production of antibacterial substances termed bacteriocins $(>1000 \mathrm{Da})$. Organic acids, in particular acetic acid and lactic acid, have a strong inhibitory effect against Gram-negative bacteria, and are considered the main antimicrobial compounds responsible for the inhibitory activity of probiotics against pathogens [191-193]. The undissociated form of the organic acid enters the bacterial cell and dissociates inside its cytoplasm. The eventual lowering of the intracellular $\mathrm{pH}$ or the intracellular accumulation of the ionized form of the organic acid can lead to the death of the pathogen [194].

Intestinal bacteria also produce a diverse array of health-promoting fatty acids. Certain strains of intestinal bifidobacteria and lactobacilli can produce conjugated linoleic acid (CLA), a potent anti-carcinogenic agent [195, 196]. An anti-obesity effect of CLA-producing L. plantarum has been observed in diet-induced obesity in mice [197]. Recently, the ability to modulate the fatty acid composition of the liver and adipose tissue of the host upon oral administration of CLA-producing bifidobacteria and lactobacilli has been demonstrated in a murine model [196]. Finally, certain probiotic bacteria are able to produce so-called de-conjugated bile acids, which are derivatives of bile salts. De-conjugated bile acids show a stronger antimicrobial activity compared to that of the bile salts synthesized by the host organism [141].

\section{Modulation of the immune system}

Numerous studies have shown that prolonged intense physical exercise is associated with a transient depression of immune function in athletes. While moderate exercise beneficially influences the immune system [198], a heavy schedule of training and competition can impair immunity and increase the risk of URTIs due to altered immune function $[116,199,200]$. Both innate immunity and acquired immunity are decreased following prolonged exercise [199201]. It is well known that probiotic bacteria can exert an immunomodulatory effect; however, research from nonathletic populations may not be translatable to athletes. Further, the manipulation and control of the immune system by probiotics is difficult to evaluate and make general conclusions. However, several studies investigating the effects of probiotics in athletes have reported improvement in lowgrade inflammation [42, 63], as well as increased resistance to URTIs $[57,60,69,78]$ and reduced duration of URTI [79].

Modulation of the immune system to increase defenses against URTIs currently is the most extensively researched area. The GI tract is a major gateway for pathogen entry, and as such, is heavily protected by the immune system. The immune system can be divided between the innate and adaptive systems. The adaptive (acquired) immune response depends on $\mathrm{B}$ and $\mathrm{T}$ lymphocytes, which are specific for particular antigens. In contrast, the innate immune system responds to common structures called pathogen-associated molecular patterns (PAMPs) shared by the vast majority of pathogens [202]. The primary response to pathogens is triggered by pattern recognition receptors (PRRs), which bind PAMPs. The best-studied PPRs are TLRs. In addition, extracellular C-type lectin receptors (CLRs) and intracellular nucleotide-binding oligomerization domain-containing protein NOD-like receptors are known to transmit signals upon interaction with bacteria [203]. It is well established that probiotics can suppress intestinal inflammation via the downregulation of TLR expression, secretion of metabolites that may inhibit TNF- $\alpha$ from entering blood mononuclear cells, and inhibition of NF-kB signaling in enterocytes [202].

Probiotics can enhance innate immunity (first-line-ofdefense) by upregulating immunoglobulins, antimicrobial proteins, phagocytic activity, and natural killer cell activity, and enhance acquired immunity by improving antigen presentation and function of $\mathrm{T}$ and $\mathrm{B}$ lymphocytes to neutralize pathogens and virally-infected cells $[10,204]$. These effects are of particular importance to athletes because exercise may increase susceptibility to URTIs by decreasing salivary IgA, decreasing cell-mediated immunity by decreasing type $1 \mathrm{~T}$ lymphocytes to make recurrent infections more likely, and increasing glucocorticoid suppression of monocyte/ macrophage antigen presentation and $\mathrm{T}$ lymphocyte functions $[205,206]$. The majority of placebo-controlled clinical trials assessing the efficacy of probiotics for reducing incidence, duration, and severity of URTI in athletes report beneficial outcomes. However, many different probiotics have been used and the differences in trial protocols and outcome measures complicate the drawing of more specific conclusions.

\section{Improved nutrient absorption}

Supplementation with some probiotic strains has been suggested to improve dietary protein absorption and utilization [207]. While not fully elucidated, several studies 
indicate a plausible role [208], yet a clear mechanism of action is lacking. As noted, probiotics can potentially improve intestinal barrier function by modulating tight junction permeability which may improve nutrient absorption.

Improving the digestibility of protein can speed recovery of strength after muscle-damaging exercise [209], and promote glycogen replenishment after exercise. B. coagulans produce digestive enzymes [97] active under gut conditions (alkaline proteases). These proteases can digest proteins more efficiently than the endogenous human proteases alone [96]. B. coagulans GBI-30, 6086 enhances the health of the cells of the gut lining improving nutrient absorption including minerals, peptides, and amino acids by decreasing inflammation and encouraging optimum development of the absorptive area of the villi [98].

In a computer-controlled in vitro model of the small intestine, B. coagulans GBI-30, 6086 enhanced amino acid absorption while improving colon health [208]. In recreationally-trained males, Jäger et al. [43] found the coadministration of B. coagulans GBI-30, 6086 and $20 \mathrm{~g}$ of protein improved recovery 24 and $72 \mathrm{~h}$, and muscle soreness $72 \mathrm{~h}$ post-exercise. Furthermore, Toohey et al. [103], noted B. subtilis DE111 supplementation with a postworkout recovery drink containing $20 \mathrm{~g}$ of protein reduced body fat percentage after 10 weeks of resistance training compared with the same post-workout recovery drink and a placebo in female athletes. Toohey et al. [103] speculated improved amino acid uptake in the probiotic group may have resulted from more efficient protein digestion, simulating the effects of a higher daily protein intake.

\footnotetext{
Key Points 5 - Mechanisms of Action

- There are dozens of bacterial strains that can be considered as probiotics, particularly those that produce lactic acid. However, each strain is unique with respect to how it responds to and affects the host.

- The mechanisms underlying the beneficial effects of probiotics in athletes are largely unknown but are likely to be multifactorial.

- Consumption of some probiotic strains may improve intestinal barrier function by modulating tight junction permeability. However, the mechanisms by which probiotics enhance intestinal barrier function are not sufficiently studied.

- Adhesion of probiotics to the intestinal mucosa may be a mechanism for modulation of the immune system. Probiotics also cause alterations in intestinal mucins that prevent pathogen binding.

- Probiotics may support microbiota and postbiotic production which possess different functional properties including, but not limited to, antimicrobial, antioxidant, and immunomodulatory.

- Probiotics may enhance innate immunity by upregulating immunoglobulins, antimicrobial proteins, phagocytic activity, and natural killer cell activity, and also enhance acquired immunity by improving antigen presentation and function of $\mathrm{T}$ and $\mathrm{B}$ lymphocytes to neutralize pathogens and virally-infected cells.

- Probiotics can potentially modulate intestinal permeability and health of the cells of the gut lining improving nutrient absorption including minerals, peptides, and amino acids by decreasing inflammation and encouraging optimum development of the absorptive area of the villi.
}

\section{Safety and health}

The concept of probiotics is not new. Around 1900 Nobel laureate, Elie Metchnikoff, discovered that the consumption of live bacteria (L. bulgaricus) in yogurt or fermented milk improved some biological features of the GI tract [210]. Bacteria with claimed probiotic properties are now widely available in the form of foods such as dairy products and juices, and also as capsules, drops, and powders. Probiotics have been used safely in foods and dairy products for over a hundred years. Some of the most common commercially available strains belong to the Lactobacillus and Bifidobacterium genera. In this respect, well-studied probiotic species include Bifidobacterium (ssp. adolescentis, animalis, bifidum, breve, and longum) and Lactobacillus (ssp. acidophilus, casei, fermentum, gasseri, johnsonii, reuteri, paracasei, plantarum, rhamnosus, and salivarius) [211]. An international consensus statement in 2014 indicated that these are likely to provide general health benefits such as normalization of disturbed gut microbiota, regulation of intestinal transit, competitive exclusion of pathogens, and production of SCFAs [1].

Beyond athletes and physically active individuals, there is a large body of preclinical and clinical research on the GI benefits of probiotics in healthy individuals and in a wide range of health conditions. These applications include treatment and prevention of acute diarrhea, prevention of antibiotic-associated diarrhea, treatment of hepatic encephalopathy, symptomatic relief in irritable bowel syndrome, and prevention of necrotizing enterocolitis in preterm infants [212]. Overall, probiotics have an excellent safety profile with a large majority of clinical trials involving probiotics not giving rise to major safety concerns [213]. Of the adverse events (AEs) commonly reported, Marteau [214] outlined four classes of possible side effects of probiotic use: systemic infections, detrimental metabolic effects, cytokine-mediated immunologic adverse events in susceptible individuals, and transfer of antibiotic resistance genes. Of these, particular concern relates to probiotics potential to create (not improve or treat) systemic infections [49, 64, 215]. Further, probiotics have been studied in vulnerable groups, including infants, patients with severe acute pancreatitis, inflammatory bowel diseases, liver diseases, HIV, and other conditions [213, 216-218] with even greater cause for concern with the small number of products that contain high concentrations of up to $450-900$ billion live bacteria per dose [211]. Many of the studies reporting AEs (rarely serious AEs) either do not utilize the appropriate biological sampling and identification techniques or AEs are poorly reported.

Commercially available probiotic products can be divided into single-strain (defined as containing one strain of a well-defined microbial species) and multi-strain (containing 
more than one strain of the same species or genus). The term multispecies is also used for products that contain strains from more than one genus [211], for example a product with a $L$. acidophilus strain, a $L$. reuteri strain, and a B. longum strain. Treatment with probiotics may involve the consumption of large quantities of bacteria, so safety is a primary concern. There are two aspects to safety: establishing the adverse effect profile of specific single-strain and multi-strain supplements (i.e., the safety of the strain(s) per se), and ensuring that marketed supplements meet stringent quality standards to ensure the correct strains are present and the product is free of contamination [217].

Safety assessments should take into account the nature of the specific probiotic microbe, method of administration, level of exposure, health status of the recipients, and the physiological functions the microbes are intended to perform [213]. However, most probiotics in commercial use are derived from fermented foods with a long history of safe consumption, or from microbes that may colonize healthy humans [212]. All common probiotic species are considered safe for the general population by the European Food Safety Authority (EFSA), although this definition does not provide guidance on the increasing use of probiotics in people with medical conditions. Moreover the benefits of probiotics are not validated by EFSA, jeopardizing the use of the term probiotic without an approved claim with some exceptions such as in Italy, Czech Republic, and Bulgaria [211]. Going beyond history of safe use, since 2007 the EFSA lists species presumed safe for human consumption under the "Qualified Presumption of Safety" (QPS) concept. The approach is based on experience that for selected organisms there are no reasonable safety concerns for human health. The list regularly monitors the body of knowledge through extensive scientific literature review, applied to a wide array of micro-organisms added in the food-chain. The QPS list concerns consumption by the general healthy population and does not take into consideration potential risks for vulnerable populations and this is clearly mentioned. The U.S. Food and Drug Administration (FDA) classifies probiotics individually but has classified many as Generally Recognized As Safe (GRAS), safe for the use in foods and infant products [219].

A systematic literature review of probiotic safety published in 2014 reported that "the overwhelming existing evidence suggests that probiotics are safe" for the general population, and that critically ill patients, postoperative and hospitalized patients and immunocompromised patients were the most at-risk groups wherein AEs occurred [220]. The general consensus is that probiotic ingestion is safe [221, 222], with large doses well tolerated and failing to exhibit any toxicity [223]. Indeed, low CFU dosage and intervention periods between 2 weeks to 6 months are generally used within clinical research models [224, 225]. In this position stand, which reviews studies focused on probiotic supplementation in athletes and physically active individuals, 11 studies measured AEs and general supplementation tolerance, while 30 studies did not. Of the 11 studies, a general consensus was made to conclude that probiotic supplementation was generally well tolerated with a very low level of adverse health effects. There was one instance in which mild GI symptoms (5 episodes) were reported, including flatulence and stomach rumbles during supplementation with a multi-strain probiotic in 22 active individuals [66]. AEs are often not well recorded in nutritional studies in general and probiotics are no exception to this. Overall, from the current body of research probiotic supplementation for healthy athletes and physically active individuals appears safe. Caution is warranted for those with serious health conditions, such as severe acute pancreatitis, inflammatory bowel diseases, liver diseases, and HIV. In these instances, it is advised that the patient consult with their health care practitioner before supplementing. Another consideration is supplementing evidence-based dosages and keeping the probiotic properly stored. Unlike, other familiar sports supplements, probiotics are live organisms and may require specific storage requirements including refrigeration.

\footnotetext{
Key Points 6 - Safety and Health.

- Probiotics have been used safely in foods and dairy products for over a hundred years.

- Well-studied probiotic species include Bifidobacterium (ssp. adolescentis, animalis, bifidum, breve, and longum) and Lactobacillus (ssp. acidophilus, casei, fermentum, gasseri, johnsonii, reuteri, paracasei, plantarum, rhamnosus, and salivarius).

- Safety assessments should take into account the nature of the probiotic microbe, method of administration, level of exposure, health status of the recipients, and the underlying physiological functions the microbes are intended to perform.

- Four classes of possible side effects are commonly reported from probiotic use in vulnerable patient groups: systemic infections, detrimental metabolic effects, cytokine-mediated immunologic adverse events in susceptible individuals, and transfer of antibiotic resistance genes.

- The current body of research of probiotic supplementation for healthy athletes and physically active individuals suggests that they are safe for use.

- Caution is warranted for those with serious health conditions. In these instances, patients should consult with their health care practitioner before supplementing.

- Consumers are advised to supplement with probiotics strains and products within evidence-based dosages.
}

\section{Regulation}

Currently there is no clear set of recommendation or guidelines on probiotic use for athletes. The current body 
of research has investigated a wide variety of species/ strains, duration of use, and dosages with several different intended purposes (Table 4). The effects of probiotics are strain specific, and therefore, strain identity is important to link to a specific health effect as well as to enable accurate surveillance and epidemiological studies. Unfortunately, government regulatory organizations are highly varied across national borders and jurisdictions in regulation of probiotics, making uniform recommendations difficult.

In 2001, the FAO/WHO held the Expert Consultation on Evaluation of Health and Nutritional Properties of Probiotics, to develop standardized guidelines for evaluating probiotics in food that could lead to the substantiation of health claims [226]. The proposed guidelines recommend: 1) identifying of the genus and species of the probiotic strain by using a combination of phenotypic and genotypic tests as clinical evidence suggesting that the health benefits of probiotics may be strain specific, 2) in vitro testing to delineate the mechanism of the probiotic effect, and 3) substantiating the clinical health benefit of probiotic agents with human trials. Additionally, safety assessment of the probiotic strain should at a minimum determine: 1) patterns of antimicrobial drug resistance, 2) metabolic activities, 3) side effects noted in humans during clinical trials and after marketing, 4) toxin production and hemolytic potential if the probiotic strain is known to possess those properties, and 5) lack of infectivity in animal studies [226].

The regulation of probiotics differs between countries as there is no universally agreed framework. For the most part, probiotics are categorized as food and dietary supplements because most are delivered by mouth as a food or supplement. For example, Health Canada has provided a Natural Health Product monograph that includes dosage form(s), use(s) or purpose(s) recommended as well as minimum quantities for L. johnsonii (La1/Lj1/ NCC 533, an adjunct to physician-supervised antibiotic therapy in patients with $H$. pylori infections, $1.25 \times 10^{8}$ CFU) (all strains, $1 \times 10^{7} \mathrm{CFU}$ ), L. rhamnosus (GG, Management of acute infectious diarrhea, $6 \times 10^{9} \mathrm{CFU}$, management/risk reduction of antibiotic-associated diarrhea, $1 \times$ $10^{10} \mathrm{CFU}$ ) (all strains, $1 \times 10^{7} \mathrm{CFU}$ ), and S. boulardii / S.

Table 4 Dosage range in studies investigating the effect of specific probiotic genera in athletes and physically active individuals

\begin{tabular}{ll}
\hline Type & Dosage range \\
\hline Lactobacillus $(n=35)$ & $1 \times 10^{9}-10 \times 10^{10} \mathrm{CFU}$ \\
Bifidobacterium $(n=18)$ & $7 \times 10^{7}-9.5 \times 10^{9} \mathrm{CFU}$ \\
Streptococcus $(n=8)$ & $5 \times 10^{9}-4.5 \times 10^{10} \mathrm{CFU}$ \\
Bacillus $(n=5)$ & $5 \times 10^{8}-5 \times 10^{9} \mathrm{CFU}$ \\
Multi- species/strain $(n=17)$ & $2 \times 10^{9}-4.5 \times 10^{10} \mathrm{CFU}$ \\
\hline
\end{tabular}

cerevisiae (all strains, Risk reduction of antibiotic-associated diarrhea, $1 \times 10^{10} \mathrm{CFU}$ ) (all strains, $1 \times 10^{7} \mathrm{CFU}$ ). The probiotic product monograph contains both bacteria and fungi which have been pre-approved for the use or purpose which allows claims; "source of probiotics", "helps support intestinal/gastrointestinal health", "could promote a favorable gut flora" with $1 \times 10^{7} \mathrm{CFU}$ daily. The minimum daily dose is the sum of CFU per day provided by all live microorganisms that are present in the product, and not the minimum amount of CFU per day for each of the microorganisms. Further, a duration of use statement is not required, nor is there any guidance provided. Cautions include; "If you have fever, vomiting, bloody diarrhea, or severe abdominal pain, consult a health care practitioner prior to use" and "If symptoms of digestive disorders (e.g., diarrhea) occur, worsen and / or persist beyond 3 days, discontinue use and consult a health care practitioner." [227]. In Canada, probiotics have two modes of sale on the market, Natural and Non-Prescription Health Products Directorate (NNHPD) and Food Directorate [3, 228]. Health Canada uses a pre-market approval process for non-food like applications such as capsules, tablets, softgels and powders which requires companies to acquire a Natural Product Number (NPN) prior to bringing to market [3]. Table 5 below details the current licensed products and claims specific to sport performance using probiotic strain(s) in or outside the pre-approved monograph. This list is open access through the Health Canada LCNHPD (Licensed Natural Health Products Database) which allows consumers and retailers the ability to review claims on packaging to approved claims by the NNHPD [229].

Japan is viewed by many to be a global market leader given that probiotics are available as both foods and drugs [230], and was the first global jurisdiction to implement a regulatory system for functional foods and nutraceuticals in 1991. Under Japanese regulations, probiotic products are in a distinct category of foods known as Foods for Specific Health Uses (FOSHU). For probiotic food products, efficacy claims are prohibited on the labeling. If claims are to be made about efficacy, one must obtain special permission from the Ministry of Health and Welfare (MHLW) for the product to be considered FOSHU, for which substantiation of efficacy and safety is a mandatory requirement [231]. In Brazil, probiotics are considered as functional foods, and considered to be different from food. But legislation asks for safety and efficacy demonstration of food products and hence all these products must be registered and approved by a health authority called National Health Surveillance Agency Brazil (ANVISA) [230].

In the European Union, probiotics and food supplements are regulated under the Food Products Directive and Regulation (regulation 178/2002/EC; directive 2000/13/ EU). All health claims for probiotics have to be authorized 
Table 5 Approved Canadian Probiotics Claims for Sports Performance

\begin{tabular}{lll}
\hline NPN & $\begin{array}{l}\text { Probiotic Species Used (Strains } \\
\text { if available) and Potency }\end{array}$ & Sport Specific Claims Supported by Research outside of monograph \\
\hline 80,080, & $\begin{array}{l}\text { B. breve BR03 } 5 \text { Billion CFU } \\
\text { S. salivarius ssp. thermophilus }\end{array}$ & $\begin{array}{l}\text { Helps maintain gastrointestinal health which may assist in normal recovery of performance } \\
\text { following exercise. }\end{array}$ \\
80,077, & $\begin{array}{l}\text { B. coagulans GBI-30, } 6086 \\
863\end{array}$ & $\begin{array}{l}\text { 1 Billion CFU } \\
\text { B. coagulans GBI-30, } 6086 \text { could be used to improve symptoms of delayed onset muscle } \\
\text { soreness (DOMS) after exercise. } \\
\text { B. coagulans GBI-30, } 6086 \text { helps maintain gastrointestinal health which may assist in a normal } \\
\text { recovery of performance following exercise. }\end{array}$ \\
$80,040, \quad$ Lelveticus 400 million CFU & Helps maintain the health of the immune system following periods of physical stress.
\end{tabular}

\section{B. longum subsp. longum 600} million CFU

80,064, L. helveticus 10 Billion CFU

384

80,064, L. helveticus 10 Billion CFU $\times 2$

Helps maintain the health of the immune system following periods of physical stress.

Promotes gastrointestinal health in physically active adults

Helps reduce the incidence of cold-like symptoms in adults with exercise-induced stress

Promotes Gl health in physically active adults

Helps support immune defenses against winter infections in healthy adults and in those having weakened immunity due to intensive sports activities

Promotes Gl health, immune health and general well-being in physically active adults (including sporty individuals like athletes)

Reduces symptoms with upper respiratory tract infections

Helps reduce incidence of cold-like symptoms in adults with exercise-induced stress With 20 Billion CFU per day, this product helps support the first line of body's immune defenses (IgA production), which may be associated with lowering URTI risk in physically active adults (such as competitive athletes)

$80,050, \quad$ B. animalis subsp. lactis 23

736 Billion CFU

B. animalis subsp. lactis 50

million CFU

B. animalis subsp. lactis 1 Billion CFU

B. bifidum 50 million CFU

B. longum subsp. infantis 100 million CFU

L. acidophilus 24.8 Billion CFU

L. acidophilus 1 Billion CFU

80,064, B. animalis subsp. lactis BI-04

$494 \quad 10$ Billion CFU

B. animalis subsp. lactis $\mathrm{Bi}-07$

10 Billion CFU

L. acidophilus NCFM 10 Billion CFU

L. paracasei LPC-37 10 Billion CFU

80,068 , B. animalis subsp. lactis Bi-04 2

830 Billion CFU

80,080 , B. longum subsp. longum 320

161 million CFU

L. helveticus 2.68 billion CFU

L. helveticus 5 Biillion CFU

80,089, B. bifidum 3 Billion CFU

$514 \quad$ L. helveticus 5 Billion CFU

Reduces the risk of developing upper respiratory tract illness in physically active adults Reduces the duration of URTI in physically active adults

Helps reduce the risk of developing URTI in physically active adults

Reduces the risk of developing URTI in physically active adults Reduces the duration of URTI in physically active adults

Promotes GI health, immune health and general well-being in physically active adults (including sporty individuals like athletes)

Reduces symptoms associated with upper-respiratory tract illness (URTI). Helps shorten the duration of URTI episodes

Helps reduce the incidence of cold-like symptoms in adults with exercise-induced stress Helps support the first line of the body's immune defenses (IgA production), which may be associated with lowering URTI risk in physically active adults (such as competitive athletes) Helps support immune defenses against winter infections in healthy adults and in those having weakened immunity due to intensive sports activities

Helps to reduce gastrointestinal discomfort (e.g., abdominal pain, nausea, vomiting) in those experiencing mild to moderate stress resulting from life events (e.g., academic exams) Helps to moderate general feelings of anxiety

Promotes a healthy mood balance

Helps to reduce stress-related gastrointestinal complications such as abdominal pain

Helps support immune defenses against winter infections in healthy adults and in those having weakened immunity due to intensive sports activities

Helps to alleviate gastro-intestinal (GI) disturbances like flatulence, constipation, bloating and abdominal cramps in healthy adults

Promotes Gl health, immune health and general well-being in physically active adults (including sporty individuals like athletes)

Reduces symptoms associated with upper-respiratory tract illness (URTI)

Helps shorten the duration of URTI episodes

Helps reduce the incidence of cold-like symptoms in adults with exercise-induced 
Table 5 Approved Canadian Probiotics Claims for Sports Performance (Continued)

\begin{tabular}{|c|c|c|}
\hline NPN & $\begin{array}{l}\text { Probiotic Species Used (Strains } \\
\text { if available) and Potency }\end{array}$ & Sport Specific Claims Supported by Research outside of monograph \\
\hline & & $\begin{array}{l}\text { stress } \\
\text { Helps support the first line of the body's immune defenses (IgA production), which } \\
\text { may be associated with lowering URTI risk in physically active adults (such as } \\
\text { competitive athletes) } \\
\text { Helps reduce the incidence of cold-like symptoms in stressed adults }\end{array}$ \\
\hline $\begin{array}{l}80,091 \\
068\end{array}$ & $\begin{array}{l}\text { B. animalis subsp. lactis } 2 \text { Billion CFU } \\
\text { L. acidophilus } 1 \text { Billion CFU } \\
\text { L. acidophilus } 3 \text { Billion CFU } \\
\text { L. plantarum } 14 \text { Billion CFU }\end{array}$ & $\begin{array}{l}\text { Reduces the risk of developing upper respiratory track illness in physically active adults } \\
\text { Reduces the duration of upper respiratory tract illness in physically active adults }\end{array}$ \\
\hline $\begin{array}{l}80,091 \\
070\end{array}$ & $\begin{array}{l}\text { B. animalis subsp. lactis } 2 \text { Billion } \\
\text { L. acidophilus } 1 \text { Billion } \\
\text { L. acidophilus } 3 \text { Billion } \\
\text { L. plantarum } 14 \text { Billion }\end{array}$ & $\begin{array}{l}\text { Reduces the risk of developing upper respiratory track illness in physically active adults } \\
\text { Reduces the duration of upper respiratory tract illness in physically active adults }\end{array}$ \\
\hline $\begin{array}{l}80,087, \\
974\end{array}$ & $\begin{array}{l}\text { B. animalis subsp. lactis } 2.81 \text { Billion CFU } \\
\text { B. animalis subsp. lactis } 1.47 \text { Billion CFU } \\
\text { B. animalis subsp. lactis } 810 \text { million CFU } \\
\text { B. animalis subsp. lactis } 530 \text { million CFU } \\
\text { B. bifidum } 28 \text { million CFU } \\
\text { D-Glucose } 13 \mathrm{mg} \\
\text { D-Xylose } 13 \mathrm{mg} \\
\text { L-Arabinose } 7 \mathrm{mg} \\
\text { L. acidophilus } 630 \text { million CFU } \\
\text { L. casei } 610 \text { million CFU } \\
\text { L. paracasei } 690 \text { million CFU } \\
\text { L. plantarum } 890 \text { million CFU } \\
\text { L. salivarius } 560 \text { million CFU } \\
\text { Xylooligosaccharides } 631 \mathrm{mg}\end{array}$ & $\begin{array}{l}\text { Reduces the risk of developing upper respiratory track illness in physically active adults } \\
\text { Reduces the duration of upper respiratory tract illness in physically active adults }\end{array}$ \\
\hline
\end{tabular}

by EFSA which has issued a list of microbial cultures that have a Qualified Presumption of Safety [232], meaning that they do not require safety assessments. The EFSA is also responsible for assessing health claims made for probiotic products. So far, EFSA has rejected all submitted health claims for probiotics. While rigorous scrutiny of product claims is apparent, there appears to be little regulation of the manufacturing process and almost no post-marketing regulatory follow-up [233].

In the United States, government regulation of probiotics is complex. Depending on a probiotic product's intended use, the FDA might regulate it as a dietary supplement, a food ingredient, or a drug. Many probiotics are sold as dietary supplements, which do not require FDA approval before they are marketed. Dietary supplement labels are permitted to make claims about how the product affects the structure or function of the body without FDA approval, but they cannot make health claims (claims that the product reduces the risk of a disease) without the FDA's approval [234]. Further, dietary supplements are required to comply with Good Manufacturing Practice guidelines, but these do not extend to testing quality or efficacy [233]. From the examples provided, it is apparent that the current approach to regulation is inadequate and can lead to problems of quality, safety, and claim validity in commercial probiotic products used in a medical context, including those used in vulnerable populations [233].
In January 2017, the Council for Responsible Nutrition (CRN) and the International Probiotics Association (IPA) announced the development of scientifically-based best practices manufacturing guidelines for the labeling, storing, and stability testing of dietary supplements and functional foods containing probiotics [235]. These guidelines were designed to facilitate transparency and consistency in the probiotic sector. A key element of the guidelines is labelling probiotic products in CFU, the scientifically accepted unit of measure for probiotics and used to report probiotic quantity in many studies conducted to assess the safety or benefits of probiotics. Consistent with scientific literature, CFU are commonly used on probiotic product labels in many jurisdictions around the world to help consumers and healthcare professionals identify products providing probiotics in amounts shown to have benefit. However, United States regulations require dietary ingredients (with the exception of some vitamins) be labeled by weight. Labeling probiotic quantity by weight is not meaningful because this measure does not indicate the viability of the microorganisms in the product throughout shelf life. To the contrary, CFU are more representative of the quantity of viable microorganisms and gives consumers and healthcare professionals accurate information. The FDA has recently agreed that in addition to weight, probiotic amounts can also be labelled in CFU.

Upon examining the relevant literature investigating the effects of probiotic supplementation on athletes and 
those physically active, the genera commonly used included Lactobacillus $(n=35)$, Bifidobacterium $(n=18)$, Streptococcus $(n=8)$ and Bacillus $(n=5)$ (Table 3). In addition, several studies used a combination of species and strains $(n=17)$, ranging from two up to 14 different species/strains. The dose of probiotic administered is an important factor to be considered. In two reviews related to dietary supplementation in athletes, dosing regimens were reported in the range between $1 \times 10^{9}$ to $4 \times 10^{10} \mathrm{CFU}[10,40]$. In a 2018 consensus statement, the International Olympic Committee noted moderate support for probiotic use in athletes with a daily dose of $1 \times 10^{10}$ live bacteria [5]. In our review, we report a wide range of doses (Table 4), and in several studies the dosage was not reported.

Similar to the type of probiotic used, the duration of supplementation has also been variable in the studies reviewed (Table 3). The shortest duration lasted 7 days [75, 76] and the longest lasted 150 days [68]. The duration and consistency of probiotic supplementation are important factors. Coqueiro et al. [188] noted that in clinical practice probiotic supplementation should be implemented for at least 14 days prior to competition or important events for the athlete. Therefore, studies that supplement for a similar or shorter period should be evaluated with caution. With the interruption of probiotic intake, there is a reduction in the microorganism administered in the colon, and with 8 days of supplementation discontinuation, the probiotic is no longer detectable in the gut [236]. Finally, there is some limited evidence that discrepancies exist between males and females, even after supplementation of probiotics with the same dose [61]. Future studies are needed in this area, with the intention of establishing a recommendation for each sex.

\footnotetext{
Key Points 7 Regulation

- No universally agreed upon framework exists for regulating commercial products containing probiotics across countries globally.

- Probiotic products should be labelled in CFU, the scientifically accepted unit of measure for probiotics and used to report probiotic quantity in many studies conducted to assess the safety or benefits of probiotics.

- Dosing regimens typically fall in range between $1 \times 10^{9}$ to $1 \times 10^{11}$ CFU.

- The IOC noted moderate support for probiotic use when administered for several weeks in athletes with a daily dose of $1 \times$ $10^{10} \mathrm{CFU}$

- Genera of commonly used probiotics include Lactobacillus $(n=35)$, Bifidobacterium ( $n=18)$, Streptococcus $(n=8)$ and Bacillus $(n=5)$.

- Single-strain and multi- species/strain products are commonly used, but combinations and individual dosing recommendations are not currently understood

- Males and females may respond to probiotic supplementation differently. Future research is needed in this area.
}

\section{Future directions}

Overall, the effects of probiotics in athletes have received less attention compared to animal studies and human clinical conditions in the general population. A PubMed search conducted in October 2019 yielded the following listings for various combinations of key terms: probiotic and athlete, $n=145$; probiotic and rodent, $n=$ 3407; probiotic and diabetes, $n=844$; probiotic and child, $n=2930$; probiotic and elderly, $n=2257$. Clearly, the focus of the research community has been investigating the beneficial effects of probiotics on gut and immune health in various subgroups of the general population. In animals, probiotics have been associated with benefits including normalizing age-related drops in testosterone levels [237], increasing neurotransmitter synthesis [238], reducing stress-induced cortisol levels [239], reducing inflammation [100] and improving mood [240]. However, all these potential benefits lack current substantiation in human intervention trials in an athletic population. Here we discuss future research opportunities to explore in relation to the microbiome and athletes.

\section{Body composition and muscle mass}

It is well known that to increase levels of muscle mass, resistance training must be included in exercise regimens. Probiotic supplementation, both with and without resistance training, can decrease levels of body weight and fat mass in overweight and obese individuals, as well as female athletes [103, 241, 242]. Increases in fat free mass, however, have only been shown in animal models. Chen and colleagues [92] supplemented male Institute of Cancer Research (ICR) strain mice with $L$. plantarum TWK10 for 6 weeks. Mice were divided into three groups and daily doses of $0,2.05 \times 10^{8}$, or $1.03 \times$ $10^{9} \mathrm{CFU}$ were given to each group, respectively. The dosages chosen were modified from a comparable human dose equivalent to mouse body size. Relative muscle weight (\%), as measured by combining the gastrocnemius and soleus muscles, were significantly increased in mice consuming the probiotic compared to placebo. Additionally, the number of type I fibers were increased significantly.

Mechanistically, it is plausible that Lactobacillus strains decrease levels of inflammation, thereby decreasing activation of intracellular proteins linked to muscle atrophy, which may eventually link to an observed increase in muscle mass. Chen et al. [92] also determined that probiotic supplementation increased forelimb grip strength and swim-to-exhaustion performance in mice, which may or may not have been related to improvement in muscle mass. Though improvements in body composition have been shown in humans, more studies examining decreased 
inflammation as a mechanism to increase muscle mass, in conjunction with reduction in fat mass, is warranted.

\section{Buffering capacity in exercising muscles}

Physiological fatigue, such as extreme fatigue after exercise, is accompanied by poor athletic performance and loss of favorable working conditions for tissues [243]. In response to higher intensity exercise, the concentration of lactate and hydrogen ions increased markedly resulting in an acidification in muscle and subsequent fatigue [244, 245]. Approximately $75 \%$ of the total amount of lactate produced is used for oxidative production of energy in the exercising body and can be utilized for the de novo synthesis of glucose in the liver [246].

Probiotic supplementation may have potential to remove and utilize blood lactate after exercise. For instance, most Lactobacillus species produce lactic acid, which could facilitate the production of butyrate by lactate-utilizing bacteria that first produce acetyl-CoA from lactate [247]. In the classical pathway, the enzymes phosphotransbutyrylase and butyrate kinase convert butyryl-CoA to butyrate and coenzyme A with concomitant formation of ATP. Thus, probiotics and the gut microbiota could play important roles in maintaining normal physiology and energy production during exercise. Several animal studies have been conducted with promising results. In mice who consumed a probiotic kefir daily over 4 weeks, swimming time-to-exhaustion was significantly longer, forelimb grip strength was higher and serum lactate, ammonia, blood urea nitrogen (BUN), and creatine kinase levels were lower after the swimming test [248]. In mice supplemented with $L$. plantarum TWK10 over 6 weeks, supplementation dosedependently increased grip strength and endurance swimming time and decreased levels of serum lactate, ammonia, creatine kinase, and glucose after an acute exercise challenge [92]. Furthermore, the number of type I fibers in gastrocnemius muscle significantly increased with LP10 treatment. In a six-week human double-blind placebo-controlled clinical study, young healthy amateur runners supplemented with $L$. plantarum TWK10 and underwent an exhaustive treadmill exercise measurements and related biochemical indexes [85]. The TWK10 group had significantly higher endurance performance and glucose content in a maximal treadmill running test compared to the placebo group $(P<0.05)$, indicating that TWK10 supplementation may be beneficial to energy harvest. Together, these studies suggest a role in which certain probiotics may enhance energy harvesting, and have health-promotion, performanceimprovement, and anti-fatigue effects. These are areas that may warrant further research consideration.

\section{Considerations for future study designs}

Several important methodological shortcomings in research design should be addressed to improve scientific evidence for the biological and clinical benefits of probiotics. For example, discrepancies between men and women, even after supplementation of probiotics with the same dose, are evident [61]. In this sense, in studies with both sexes, conflicting results may occur. In many instances and products, the recommendation for probiotic supplementation is no different for men and women, necessitating studies investigating this topic, with the intention of establishing a recommendation for each sex.

Other design concerns include the relatively small number of subjects, which may compromise the accuracy and interpretation of results. The period of supplementation is another important factor as the time of adaptation of the organism to the probiotic is approximately 14 days. Thus, studies that supplement for a similar or shorter period should be evaluated with caution. Further, with the interruption of probiotic intake, there is a reduction in the microorganism administered in the colon, and with 8 days of supplementation discontinuation, the probiotic is no longer detectable in the gut [236]. In clinical practice, it is common sense that probiotic supplementation should be implemented for at least 14 days prior to competition or important events for the athlete, given that during this period the GI tract adapts to the administered microorganism [188], and there may be mild, transient GI symptoms, such as flatulence [10]. The long-term effects of probiotic administration in athletes over several months or years on gut health, immune function and rates of illness are unclear, as in most studies the supplementation period was between 4 to 16 weeks.

Since many effects are dose-dependent, the amount of probiotic administered is an important factor to be considered. The range of oral probiotic supplementation is, approximately, $10^{8}-10^{9} \mathrm{CFU}$ per day, however, this value varies in each country $[249,250]$ and notably, no specific probiotic recommendation has been established for athletes or physical activity practitioners. Most of the studies do not control for previous levels of physical activity, so individuals within the same study may have very different levels of physical activity, making comparisons unrealistic. Finally, very few studies have evaluated the performance in strength exercises after supplementation with probiotics and this is an important area of sports and physical training to be studied.

\section{Hormonal balance}

Oral supplementation with selective bacteria holds promise in positively affecting the endocrine system. In mice, the microbiota can regulate testicular development and 
function [251], while androgen deficiency has substantially altered the microbiome [252]. Supplementation with a selenium-enriched probiotic in conjunction with a high-fat diet in male mice significantly alleviated the adverse effects of hyperlipidemia by reducing testicular tissue injury, increasing serum testosterone levels, and improving sperm indexes [253]. Further, aging mice supplemented with the probiotic bacterium $L$. reuteri had larger testicles and increased serum testosterone levels compared to their agematched controls [237, 254].

In a human pilot study, supplementation with $L$. acidophilus and B. longum $\left(1 \times 10^{9} \mathrm{CFU}\right)$ did not alter plasma hormones, including testosterone, dihydrotesto sterone, androstenedione, dehydroepiandrosterone sulfate, and sex hormone-binding globulin, in 31 healthy males (18 to 37 years old) over a two-month period [255]. However, another pilot study supplementing a probiotic and prebiotic (L. paracasei B21060 $5 \times 10^{9}$ cells + arabinogalactan 1243 $\mathrm{mg}+$ fructooligosaccharides $700 \mathrm{mg}+\mathrm{L}$-glutamine $500 \mathrm{mg}$ ) over 6 months in infertile male patients improved gonadal pathway function including increased follicle stimulating hormone, luteinizing hormone, and testosterone levels compared to a control group [256].

Interestingly, Tremellen et al. [257] proposed that gutderived endotoxin can reduce gonadal function in obese males. Obesity and a high fat/high calorie diet can alter gut bacteria and intestinal wall permeability, leading to the passage of LPS from within the gut lumen into the circulation (metabolic endotoxemia), where it initiates systemic inflammation [258]. Endotoxin can reduce testosterone production by the testes, both by direct inhibition of Leydig cell steroidogenic pathways and indirectly by reducing pituitary luteinizing hormone drive and sperm production [259]. Tremellen and colleagues [257] theorized the male reproductive axis has evolved the capacity to lower testosterone production during times of infection and resulting endotoxin exposure, decreasing the immunosuppressive influence of testosterone, in turn enhancing the ability to fight infection. Weight loss and physical activity seem to improve these symptoms [260]. These novel findings suggest a potential impact for microbe therapy in obese and/or aging athletes by imparting hormonal and gonadal features of reproductive fitness typical of much younger healthy individuals. However, studies are severely lacking. In the future, larger sample sizes and more robust study designs will be needed.

\section{Inactivated "probiotics"}

There is an increasing interest in supplementation with non-viable microorganisms or microbial cell extracts. By definition, probiotics are required to be alive, therefore inactivated microorganisms cannot be classified as such. However, preparations from certain probiotic species and strains (such as those from lactobacilli and bifidobacteria) have shown to maintain health benefits even after no longer being viable [261-263]. Inactivation can be achieved by different methods, including heat, chemicals (e.g., formalin), gamma or ultraviolet rays, and sonication, with heat treatment being the method of choice in most cases [228, 264, 265]. Importantly, these methods of inactivation may affect structural components of the cell differently, and therefore their biological activities [264, 265]. Piqué et al. (2019) suggested the presence of key structures in the cell or supernatant fractions may confer probiotic properties, mainly through immune-modulation, protection against pathogens, and fortifying the mucosal barrier integrity [261]. These different bacterial components include lipoteichoic acids, peptidoglycans, and/or exopolysaccharides [261].

Favorable properties of heat-killed bacteria have been observed in vitro [266], in animal models [264], and human trials $[267,268]$. For example, in healthy subjects with high levels of self-reported psychological stress, supplementation with heat-killed L. plantarum L-137 significantly lowered incidence of URTI after 12 weeks compared to the control group [269]. This finding may have resulted from innate immunity stimulation as heatkilled $L$. plantarum L-137 has been reported to enhance type I IFN production in humans [270]. In athletes, there have only been two studies published examining the effect of these inactivated "probiotics". In a randomized, double blind, placebo-controlled trial, 51 male athletes engaged in high intensity exercise ( $>11 \mathrm{~h}$ per week) and consumed a placebo or heat-killed L. lactis JCM 5805 daily for 13 days [262]. Compared to placebo, supplementation increased the maturation marker of plasmacytoid DC pDC (CD86), responsible for the antiviral response, and decreased the cumulative days of URTI symptoms. Furthermore, ingestion decreased cumulative days of self-reported fatigue. In a longer duration randomized, double blind, placebo-controlled study, 49 long-distance runners consumed heat-inactivated $L$. gasseri CP2305 or placebo daily for 12 weeks [271]. No significant difference in physical performance between the CP2305 and placebo group were detected. However, CP2305 supplementation improved recovery from fatigue and relieved anxiety and depressive mood compared with placebo intake. Further, CP2305 intake prevented training-induced reduction of hemoglobin and facilitated exercise-induced increase in serum growth hormone levels. Moreover, gene expression profiling of peripheral blood leukocytes indicated that CP2305 prevented the stress-induced changes in the expression of genes related to mitochondrial functions. In relation to the gut microbiota, CP2305 intake increased the alpha- and beta-diversity, and the compositions of 
Bifidobacterium and Faecalibacterium. These compositional changes in the gut microbiota may have contributed to the recovery of fatigue and moderation of stress and anxiety through the gut-brain axis. Indeed, inactivated CP2305 can relieve stress in healthy young adults facing stressful conditions [272]. While encouraging, it is unclear how the daily intake of the heat-inactivated probiotics could affect the gut-brain axis and alter stress responses. Further research investigating potential mechanisms as well as more extensive studies with a wider range of athletes and exercise loads should be conducted. In addition, primary aims related to GI tract health and exercise performance should be more thoroughly assessed.

\section{Mood and cognition}

Physical health and mental health are strongly linked with depression, which is recognized as a leading cause of disability throughout the world [273]. Recently, it has been reported that $35 \%$ of individuals with depression also have symptoms of a leaky gut [274], which strengthens the notion of a link between the brain and the GI tract. As reported by Clarke et al. [275], gut bacteria contribute to various mood states in an individual. The gut-brain axis is a bidirectional pathway via the neural, endocrine, and immune systems. The mechanisms by which probiotics improve symptoms of depression and other mood disorders are via anti-inflammatory actions that reduce activity of the hypothalamic-pituitary-adrenal (HPA) axis [276].

Probiotics may be an effective treatment strategy for depression and mood disorders such as anxiety given the link between GI tract bacteria and the brain (i.e. the gutbrain axis), as decreased intestinal dysbiosis may have beneficial effects on mood. Only a few studies have been completed in human subjects that have examined the impact of probiotic supplementation on mood and anxiety. Benton and colleagues [210] reported that 3 weeks of supplementation with $1 \times 10^{8} \mathrm{CFU}$ of $L$. casei had positive effects on mood, with subjects feeling increased clear-headedness, confidence, and elation compared to baseline. A study by Rao et al. [277], reported that 8 weeks of $8 \times 10^{7} \mathrm{CFU}$ of $L$. casei given to individuals with chronic fatigue syndrome reduced anxiety symptoms. Similarly, Messaoudi and others [278] found decreased anxiety related behaviors after 2 weeks of a combination of $L$. helveticus and B. longum in 25 healthy adults. Moreover, 6 weeks supplementation of $4 \times 10^{9} \mathrm{CFU} /$ live cells of $L$. fermementum LF16, L. rhamnosus LR06, L. plantarum LP01, and B. longum BL04 improved mood and sleep quality with a reduction in depressive mood state, anger and fatigue [279].

Overall, research on probiotics and mood in athletic populations is lacking. One review, completed by Clark and Mach [280] likened the psychological demands of exercise to physical stress. These authors concluded that the gut microbiota acts as an endocrine organ, secreting neurotransmitters such as serotonin and dopamine, thereby controlling the hypothalamic-pituitary axis in athletes. It is unclear whether these conclusions are attributable to the physiological or psychological stress, and more research is needed to expand on the current findings.

\section{Muscle damage and recovery}

Inflammation has been implicated in probiotic supplementation impacting body fat levels in overweight and obese individuals, as well as athletic populations. Research in this area, however, has been completed entirely in animal models. Zhao et al. [281] reported that supplementation of Akkermancia muciniphila in lean mice fed a chow diet for 5 weeks significantly improved markers of low-grade, chronic inflammation via measurement of LPS, and alleviated gains in both body weight and fat mass. Probiotic supplementation also increased antiinflammatory factors $\alpha$-tocopherol and $\beta$-sitosterol. Interaction between $A$. muciniphila and inflammatory processes may subsequently impact metabolic health and consequently body composition regulation. In humans, low-grade, chronic inflammation is a marker of many disease states and aspects of the metabolic syndrome. To date, no such research has been completed in athletic populations to clarify the impact of probiotic supplementation on body composition in athletes.

\section{Neurotransmitter synthesis and release}

Choline and its derivatives serve as components of structural lipoproteins, blood and membrane lipids, and as a precursor of the neurotransmitter, acetylcholine [282]. Choline is converted into acetylcholine via the enzyme choline acetyltransferase. Increasing plasma levels of choline could improve the production of acetylcholine, increase muscular contraction, and possibly delay fatigue in endurance exercise [282]. Elevated choline levels were observed in plasma of mice supplemented with $L$. rhamnosus compared to those fed with $L$. paracasei and controls [283]. In humans, probiotics and choline have been studied in the context of Trimethylamine $\mathrm{N}$-oxide (TMAO). TMAO is an atherogenic metabolite that requires gut microbes for its generation through a metaorganismal pathway that begins with dietary consumption of trimethylamine (TMA) containing precursors such as choline, carnitine and phosphatidylcholine [284]. In a two-week clinical study on 19 healthy, non-obese males, supplementing with a multi-strain probiotic following a hypercaloric, high-fat diet failed to elevate plasma choline levels [285]. In a threemonth pilot study investigating the effects of probiotic supplementation on TMAO plasma levels in hemodialysis patients, choline did not change compared to control group [286]. There is currently no research in athletes or active individuals, yet increases in plasma choline could (in theory) 
support increases in acetylcholine and consequently power, and endurance.

\section{Nutrient timing}

As indicated previously, various supplementation protocols have been implemented regarding probiotic consumption supplementation, including taking on an empty stomach, with food, and even after exercise. In relation, little is known pertaining to the optimal timing of probiotic intake for improved microbial survival and nutrient absorption. Tompkins et al. utilized an in vitro digestive model of the upper GI tract to investigate the timing effects of probiotic intake utilizing a multi-species encapsulated product containing L. helveticus R0052, L. rhamnosus R0011, B. longum R0175, and S. cerevisiae boulardii [287]. Results of this investigation showed that when a probiotic was consumed $30 \mathrm{~min}$ before a meal or with a meal, the bacteria survived in high numbers. Conversely, when the probiotic was taken $30 \mathrm{~min}$ after a meal, the bacteria did not survive in high numbers. Additionally, this study reported that consumption of the probiotic with $1 \%$ milk and oatmeal-milk gruel allowed for higher bacteria survival than when consumed with apple juice or spring water. Thus, future work should focus on the most favorable time to consume probiotics to promote survival in humans along with optimal nutrient/foodstuffs co-ingestion.

\section{Response to a physical or mental stressor}

Cortisol is a steroid hormone released by the adrenal glands in response to stress and increased levels have been related to suppression of the immune system in athletes [288-290]. Moreover, a connection has been established between the digestive tract and stress [291, 292]. Several studies that supplemented healthy young college students during exam preparation with probiotics (L. plantarum $299 \mathrm{v}$ and $L$. casei Shirota) reported attenuation of cortisol compared to a control group [293-295]. However, in an eight-week crossover design, 29 healthy male volunteers who supplemented with $L$. rhamnosus exhibited little difference in stress-related measures, HPA axis response, inflammation, or cognitive performance in comparison to placebo [296]. More recently, a systematic review and meta-analysis of clinical and pre-clinical literature on the effects of probiotics on anxiety asserted that probiotics may help reduce anxiety [297]. However, these findings have not yet been fully translated in clinical research in humans. More relevant to performance, eight endurancetrained males in a blinded randomized crossover design who supplemented with a probiotic beverage (L. casei, $1 \times$ $10^{11} \mathrm{CFU}$ ) for seven consecutive days before a two-hour running exercise at $60 \% \mathrm{VO}_{2} \mathrm{max}$ in hot ambient conditions $\left(34.0^{\circ} \mathrm{C}\right.$ and $\left.32 \% \mathrm{RH}\right)$ failed to exhibit a decrease in cortisol response compared to a placebo [75].

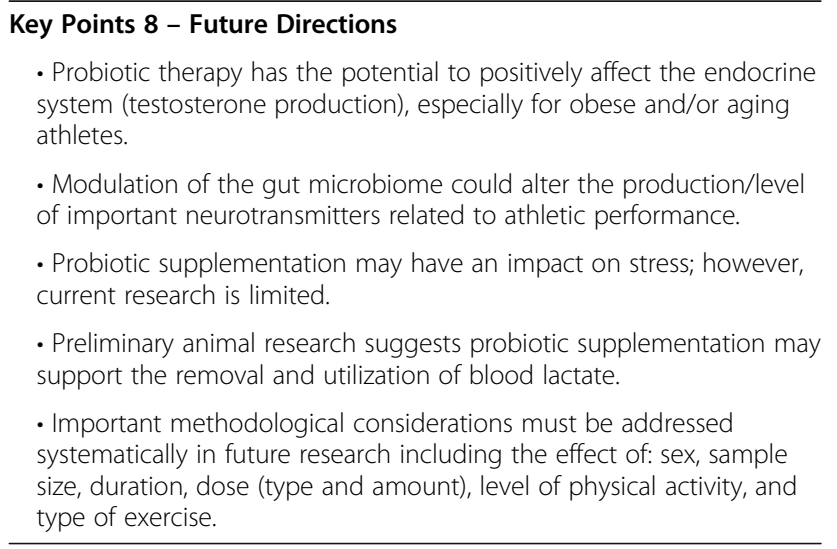

\section{Summary}

Understanding whether probiotic supplementation plays a role in athletic performance is of interest to athletes who work to improve their training and competition performance. Moreover, this knowledge may be of general benefit to human health. Further studies are required to understand how the microbiome influences anti-inflammatory effects, optimal breakdown and utilization of consumed food, and other beneficial effects for overall health in athletes. Overall, the studies reviewed in this position statement provide modest evidence that probiotics can provide some clinical benefits in athletes and other highly active individuals (Table 3 ). The difficulty in interpreting the studies is illustrated by variations in clinical outcome measures and most importantly, as probiotic benefits are strain-specific, by different strains used in these studies.

As outlined in Table 3, the following probiotic strains/ species have been linked to an increase in athletic performance and/or recovery:

1) B. coagulans GBI-30, $6086(\mathrm{BC} 30)$ at $1 \times 10^{9} \mathrm{CFU}$ has beneficial effects in combination with protein on exercise recovery;

2) Encapsulated B. breve BR03 in combination with $S$. thermophilus FP4 at $5 \times 10^{9} \mathrm{CFU}$ each has beneficial effects on exercise recovery and performance following muscle-damaging exercise;

3) L. delbrueckii ssp. bulgaricus at $1 \times 10^{5} \mathrm{CFU}$ can increase $\mathrm{VO}_{2}$ max and aerobic power;

4) L. acidophilus SPP, $L$. delbrueckii bulgaricus, $B$. bifidum, and S. salivarus thermophilus at $4 \times 10^{10}$ CFU administered in form of a yogurt drink can increase $\mathrm{VO}_{2}$ max;

5) L. plantarum TWK10 at $1 \times 10^{10} \mathrm{CFU}$ has been shown to increase endurance performance; 
6) L. acidophilus, L. rhamnosus, L. casei, L. plantarum, L. fermentum, B. lactis, B. breve, B. bifidum and $S$. thermophilus at $4.5 \times 10^{10} \mathrm{CFU}$ can increase run time to fatigue in the heat.

The following probiotic strains/species have been linked to improved gut health in athletes (see Table 3):

1) L. rhamnosus GG at $4 \times 10^{10} \mathrm{CFU}$ in form of a milk-based drink,

2) B. bifidum W23, B. lactis W51, E. faecium W54, L. acidophilus W22, L. brevis W63, and L. lactis W58, at $1 \times 10^{10} \mathrm{CFU}$;

3) L. salivarius (UCC118) (unknown dose).

The following strains/species have been shown to improve immune health in athletes, reducing the episodes, severity or duration of exercise-induced infections:

1) $1.2 \times 10^{10} \mathrm{CFU}$ L. fermentum VRI-003 (PCC) at $1.2 \times 10^{10} \mathrm{CFU}$ and at $1 \times 10^{9} \mathrm{CFU}$ in males;

2) L. casei Shirota (LcS) at $6.5 \times 10^{9}$ CFU twice daily;

3) L. delbrueckii bulgaricus, B. bifidum, and $S$. salivarus thermophilus at $4 \times 10^{10} \mathrm{CFU}$ administered in the form of a yogurt drink;

4) B. animalis subsp. lactis $\mathrm{BI}-042 \times 10^{10} \mathrm{CFU}$;

5) L. gasseri $2.6 \times 10^{9} \mathrm{CFU}$, B. bifidum $0.2 \times 10^{9}$, and $B$. longum $0.2 \times 10^{9} \mathrm{CFU}$;

6) B. bifidum W23, B. lactis W51, E. faecium W54, $L$. acidophilus W22, L. brevis W63, L. lactis W58 at $1 \times 10^{10} \mathrm{CFU}$;

7) L. helveticus Lafti L10 at $2 \times 10^{10} \mathrm{CFU}$.

Given the small number of studies, and substantial variation in experimental approaches, dependent measures, and outcomes, more well-designed studies of probiotic supplementation in various athlete groups are warranted. While a majority of probiotics currently on the market, and tested in humans, feature the Lactobacillus, Bifidobacterium, and Bacillus genera, new microbiome research and technological advances are identifying potential next-generation probiotic candidates. Further research is needed not only to identify these discoveries, and validate their performance and recovery benefits in clinical settings.

\section{Recommendations}

Athletes and physically active individuals should thoroughly review health care and consumer information on specific applications, dosage, and possible contraindications of probiotic supplementation. As with any dietary suppleme ntation, probiotics should be considered in the overall context of balanced dietary intake, i.e. nutrient needs should be met by a "food first" approach via consumption of whole foods rather than supplements. For example, recommending dietary supplements to developing athletes might overemphasize their importance in comparison to other training and dietary strategies [298]. In this context, it is also important to remember that some food-based probiotic products (e.g. yogurt) contain energy, carbohydrate, protein, and other nutrients that can form part of an athlete's overall nutrition plan. Only reputable sources of commercially available supplements should be used to reduce the risk of contaminants that might contravene doping in sport regulations [5]. Athletes should be educated on the likely risks of contamination given that the World Anti-Doping Agency enforces a principle of strict liability for positive test results involving banned substances. Different formulations of probiotics from tablets or capsules to powder (added to drinks) or probiotic-enriched chewable tablets are available to meet individual preferences.

Probiotic supplements should be packaged, stored, handled, and transported in an appropriate manner. Athletes should take particular care in warm to hot environments and avoid, where possible, leaving supplements outdoors for long periods in direct sunlight, in a motor vehicle, or near an oven or other heatgenerating appliances. New technology has led to probiotic supplements that do not require refrigeration, which may be ideal for athletes during travel. Supplements should also be kept dry at all times. During travel it might be useful for individuals to keep probiotics with other nutritional supplies, supplements, ergogenic acids or medications, or held by team personnel as required.

In terms of implementation, probiotic supplementation should commence at least 14 days before a major training period or competition to allow adequate time for transient colonization or adaptation period of bacterial species in the gut. Another important issue is the increased risk of GI problems during travel [299]. Supplementation with probiotics for individuals and athletes traveling could be included in an overall illness prevention plan. Tolerance and side effects should be monitored by the athlete, coach, and support staff and a medical opinion sought if there is ongoing concern. It is not unusual to experience transient increased activity in the gut during the colonization period (e.g., intestinal rumbling, increased flatulence, etc.) and athletes should be informed that mild side effects for a few days are not uncommon [61]. Athletes should be encouraged to review and monitor probiotic consumption on a daily basis to promote compliance and best practice usage. Compliance might be improved by having athletes take the probiotic supplement at the same time each day (e.g., at breakfast). Probiotic supplementation should be tested during the offseason or preseason phases, so the athlete is familiar with taking the probiotic supplements or foods before travel or major competition, and can see how he/she responds. This practice is also useful in the 
context of assessing individual tolerance and potential adverse effects.

\section{Position of the International Society of Sports Nutrition (ISSN)}

After reviewing the scientific and medical literature in this area, the International Society of Sports Nutrition concludes the following in terms of probiotic supplementation as the official Position of the Society:

1) Probiotics are live microorganisms that, when administered in adequate amounts, confer a health benefit on the host (FAO/WHO).

2) Probiotic administration has been linked to a multitude of health benefits, with gut and immune health being the most researched applications.

3) Despite the existence of shared, core mechanisms for probiotic function, health benefits of probiotics are strain- and dose-dependent.

4) Athletes have varying gut microbiota compositions that appear to reflect the activity level of the host in comparison to sedentary people, with the differences linked primarily to the volume of exercise and amount of protein consumption. Whether differences in gut microbiota composition affect probiotic efficacy is unknown.

5) The main function of the gut is to digest food and absorb nutrients. In athletic populations, certain probiotics strains can increase absorption of key nutrients such as amino acids from protein, and affect the pharmacology and physiological properties of multiple food components.

6) Immune depression in athletes worsens with excessive training load, psychological stress, disturbed sleep, and environmental extremes, all of which can contribute to an increased risk of respiratory tract infections. In certain situations, including exposure to crowds, foreign travel and poor hygiene at home, and training or competition venues, athletes' exposure to pathogens may be elevated leading to increased rates of infections. Approximately $70 \%$ of the immune system is located in the gut and probiotic supplementation has been shown to promote a healthy immune response. In an athletic population, specific probiotic strains can reduce the number of episodes, severity and duration of upper respiratory tract infections.

7) Intense, prolonged exercise, especially in the heat, has been shown to increase gut permeability which potentially can result in systemic toxemia. Specific probiotic strains can improve the integrity of the gut-barrier function in athletes.
8) Administration of selected anti-inflammatory probiotic strains have been linked to improved recovery from muscle-damaging exercise.

9) The minimal effective dose and method of administration (potency per serving, single vs. split dose, delivery form) of a specific probiotic strain depends on validation studies for this particular strain. Products that contain probiotics must include the genus, species, and strain of each live microorganism on its label as well as the total estimated quantity of each probiotic strain at the end of the product's shelf life, as measured by colony forming units (CFU) or live cells.

10) Preclinical and early human research has shown potential probiotic benefits relevant to an athletic population that include improved body composition and lean body mass, normalizing age-related declines in testosterone levels, reductions in cortisol levels indicating improved responses to a physical or mental stressor, reduction of exercise-induced lactate, and increased neurotransmitter synthesis, cognition and mood. However, these potential benefits require validation in more rigorous human studies and in an athletic population.

\section{Conclusion}

Given all the known benefits and favorable safety profile of probiotic supplementation reported in the scientific and medical literature, probiotics are commonly used to optimize the health of athletes. Regular consumption of specific probiotic strains may assist with immune function and may reduce the number of sick days an athlete experiences when training or during competition. Certain probiotic strains may reduce the severity of respiratory infection and GI disturbance when they occur. Probiotic benefits are strain specific and dose dependent, and include improved gut-barrier function, nutrient absorption, recovery and performance in athletes. When choosing a probiotic product, athletes are encouraged to use clinically researched strains with validated benefits, matching the athletes desired health benefit. Studies investigating the effects of probiotics in athletic populations and on sports performance are limited and warrant further investigation.

\footnotetext{
Abbreviations

AE: Adverse events; ANVISA: National Health Surveillance Agency Brazil; ATP: Adenosine triphosphate; BCAAs: Branched-chain amino acids; BMI: Body mass index; BUN: Blood urea nitrogen; CD14: Cluster of differentiation factor14; CFU: Colony forming units; CLA: Conjugated linoleic acid; CLR: C-type lectin receptor; CRN: Council for Responsible Nutrition; CRP: C-Reactive protein; EFSA: European Food Safety Authority; FAO: Food and Agricultural Organization; FDA: Food and Drug Administration; FOSHU: Foods for Specific Health Uses; GI: Gastrointestinal; GPR: G-Protein couple receptor; HIV: Human immunodeficiency virus; HPA: Hypothalamic-pituitary-adrenal axis; IBD: Inflammatory bowel disease; ICR: Institute of Cancer Research; IgA: Immunoglobulin A; IL-1 $\beta$ : Interleukin-1 beta; IL-6: Interleukin-6; IOC: International Olympic Committee; IPA: International Probiotic
} 
Association; ISSN: International Society of Sports Nutrition;

LPS: Lipopolysaccharide; MHLW: Ministry of Health and Welfare; NKK $\beta$ : Nuclear factor kappa beta; NOD: Nucleotide-binding oligomerization domain; PAG: Phenylacetylglutamine; PAMP: Pathogen associated molecular pattern; PCR: Polymerase chain reaction; PPR: Pattern recognition receptors; RNA Seq: RNA sequencing; SFCA: Short chain fatty acid; TLR: Toll-like receptor; TMAO: Trimethylamine N-oxide; TNF-a: Tumor necrosis factor-alpha; Treg: Regulatory T cells; URTI: Upper respiratory tract infection; $\mathrm{VO}_{2}$ : Volume of oxygen utilization; WGO: World Gastroenterology Organization; WHO: World Health Organization

\section{Acknowledgments}

The authors would like to thank the participants and researchers who contributed works cited in this paper.

\section{Author contributions}

RJ, AEM, KCC, CMK prepared and compiled the draft for review and editing by coauthors. All other co-authors reviewed, edited, and approved the draft, and the final manuscript.

\section{Funding}

This position stand was commissioned by the Editors of the Journal of the International Society of Sports Nutrition. The authors received no remuneration for writing and/or reviewing this position stand.

\section{Availability of data and materials}

Not applicable.

\section{Ethics approval and consent to participate}

This paper was reviewed by the International Society of Sports Nutrition Research Committee and represents the official position of the Society.

\section{Consent for publication}

Not applicable.

\section{Competing interests}

$A M, A S R, K B, L B$, and SDW declare no competing interests. RJ has received grants to evaluate the efficacy and safety of probiotics, serves on scientific advisory boards, and has served as an expert witness, legal and scientific consultant. AEM and KCC are employed by Isagenix, a company selling branded probiotics products. CMK has previously received external funding to conduct research studies involving nutritional supplements and is currently conducting studies involving prebiotics and probiotics. MP has received grants to evaluate the efficacy and safety of probiotics, and has served as a scientific consultant. JRT reports no conflicts of interest regarding the material or paper presented. JRT has previously received grants to evaluate the efficacy of various nutritional supplements including probiotics. $\mathrm{ML}$ conducts industry sponsored studies and serves as a scientific consultant to the Juice Plus+ Company. MG reports no conflicts of interest regarding the material or paper presented. MG has previously received external funding to conduct research studies involving nutritional supplements including probiotics. DBP reports no conflicts of interest regarding the material or paper presented, and has received grants to evaluate the effectiveness of probiotic supplementation in athletes. BIC serves on the scientific advisory board of Dymatize (Post Holdings). SMA reports no conflicts of interest related to the material presented in this paper. He has conducted industry sponsored studies at the universities he has been affiliated with and has occasionally served as an expert witness and scientific consultant. RBK reports no conflicts of interest related to the material presented in this paper. He has conducted industry sponsored studies at the universities he has been affiliated with and occasionally serves as a scientific and legal consultant related to exercise and nutrition intervention studies. CJW is employed by Jamieson Labs, a company selling branded probiotics products. MPa is employed by Biolab research Srl, performing research \& development activities for Probiotical SpA, a leading probiotic supplier. DSK works for a Contract Research Organization (Nutrasource) that has received funding from the probiotic industry for clinical trials and serves on the Scientific Advisory Board for Dymatize (Post Holdings). JS is a co-founder of FitBiomics, a company identifying, researching and commercializing new probiotic strains. JAT is employed by the International Probiotic Association and further consults within the probiotic and microbiome industries. JA is the CEO of the International Society of Sports Nutrition.

\section{Author details}

${ }^{1}$ Increnovo LLC, Milwaukee, WI, USA. ${ }^{2}$ College of Health Solutions, Arizona State University, Phoenix, AZ, USA. ${ }^{3}$ Isagenix International LLC, Gilbert, AZ, USA. ${ }^{4}$ Exercise and Performance Nutrition Laboratory, School of Health Sciences, Lindenwood University, St. Charles, MO, USA. ${ }^{5}$ University of Münster, Department of Physics Education, Münster, Germany. ${ }^{6}$ Exercise and Nutrition Science Graduate Program, Lipscomb University, Nashville, TN, USA. ${ }^{7}$ Otto Loewi Research Center, Medical University of Graz, Graz, Austria. ${ }^{8}$ School of Medical Science and Menzies Health Institute of QLD, Griffith Health, Griffith University, Southport, Australia. ${ }^{9}$ Department of Human Nutrition, University of Otago, Dunedin, New Zealand. ${ }^{10}$ School of Sport, Exercise and Health Sciences, Loughborough University, Loughborough, UK. ${ }^{11}$ Research Institute for Sport and Exercise, University of Canberra, Canberra, ACT 2617, Australia. ${ }^{12}$ WGI, Lewisville, TX, USA. ${ }^{13}$ UofSC Sport Science Lab, Department of Exercise Science, University of South Carolina, Columbia, SC, USA. ${ }^{14}$ Applied Physiology Laboratory, Department of Exercise and Sport Science, University of North Carolina, Chapel Hill, NC, USA. ${ }^{15}$ Exercise \& Sport Nutrition Lab, Human Clinical Research Facility, Department of Health \& Kinesiology, Texas A\&M University, College Station, TX, USA. ${ }^{16}$ Performance \& Physique Enhancement Laboratory, University of South Florida, Tampa, FL, USA. ${ }^{17}$ Institute of Performance Nutrition, London, UK. ${ }^{18}$ Fitbiomics, Inc, New York, NY, USA. ${ }^{19}$ Jamieson Wellness Inc, Windsor, Ontario, Canada. ${ }^{20}$ Bioloab Research, Novara, Italy. ${ }^{21}$ Scientific Affairs. Nutrasource Diagnostics, Inc. Guelph, Guelph, Ontario, Canada. ${ }^{22}$ Research Institute for Sport and Exercise Sciences, Liverpool John Moores University, Tom Reilly Building, Byrom St Campus, Liverpool, UK. ${ }^{23}$ International Probiotic Association, Los Angeles, CA, USA. ${ }^{24}$ Exercise and Sport Science, Nova Southeastern University, Davie, FL, USA.

Received: 18 November 2019 Accepted: 4 December 2019 Published online: 21 December 2019

\section{References}

1. Hill C, Guarner F, Reid G, Gibson GR, Merenstein DJ, Pot B, Morelli L, Canani RB, Flint HJ, Salminen S, et al. Expert consensus document. The international scientific Association for Probiotics and Prebiotics consensus statement on the scope and appropriate use of the term probiotic. Nat Rev Gastroenterol Hepatol. 2014;11:506-14. https://doi.org/10.1038/nrgastro.2014.66.

2. Gibson GR, Hutkins R, Sanders ME, Prescott SL, Reimer RA, Salminen SJ, Scott K, Stanton C, Swanson KS, Cani PD, et al. Expert consensus document: the international scientific Association for Probiotics and Prebiotics (ISAPP) consensus statement on the definition and scope of prebiotics. Nat Rev Gastroenterol Hepatol. 2017;14:491-502. https://doi.org/10.1038/nrgastro. 2017.75.

3. de Vrese, M.; Schrezenmeir, J. Probiotics, prebiotics, and synbiotics. Adv Biochem Eng Biotechnol 2008, 111, 1-66, doi:https://doi.org/10.1007/10_ 2008_097.

4. Aguilar-toala J, Garcia-Perez R, Garcia H, Mata-Haro V, Gonzalez-Cordova A Vallego-Cordoba B, Hernandez-Mendoza A. Postbiotics: An evolving term within the functional foods field. Trends Food Sci Technol. 2018;75:105-14.

5. Maughan RJ, Burke LM, Dvorak J, Larson-Meyer DE, Peeling P, Phillips SM, Rawson ES, Walsh NP, Garthe I, Geyer H, et al. IOC consensus statement: dietary supplements and the high-performance athlete. Br J Sports Med. 2018;52:439-55. https://doi.org/10.1136/bjsports-2018-099027.

6. Rowland I, Capurso L, Collins K, Cummings J, Delzenne N, Goulet O, Guarner F, Marteau P, Meier R. Current level of consensus on probiotic science-report of an expert meeting--London, 23 November 2009. Gut Microbes. 2010;1:436-9. https://doi.org/10.4161/gmic.1.6.13610.

7. Metchnikoff E. The prolongated of life; optimistic studies. New York: G.P. Putnam's Son; 1908.

8. Duranti S, Ferrario C, van Sinderen D, Ventura M, Turroni F. Obesity and microbiota: an example of an intricate relationship. Genes Nutr. 2017;12:18. https://doi.org/10.1186/s12263-017-0566-2.

9. Staley JT. Biodiversity: are microbial species threatened? Curr Opin Biotechnol. 1997;8:340-5.

10. Pyne DB, West NP, Cox AJ, Cripps AW. Probiotics supplementation for athletes - clinical and physiological effects. Eur J Sport Sci. 2015;15:63-72. https://doi.org/10.1080/17461391.2014.971879. 
11. Costello EK, Lauber CL, Hamady M, Fierer N, Gordon Jl, Knight R. Bacterial community variation in human body habitats across space and time. Science. 1694-1697;2009:326. https://doi.org/10.1126/science.1177486.

12. Duffy LC, Raiten DJ, Hubbard VS, Starke-Reed P. Progress and challenges in developing metabolic footprints from diet in human gut microbial cometabolism. J Nutr. 2015;145:1123S-30S. https://doi.org/10.3945/jn.114. 194936

13. Yatsunenko T, Rey FE, Manary MJ, Trehan I, Dominguez-Bello MG, Contreras M, Magris M, Hidalgo G, Baldassano RN, Anokhin AP, et al. Human gut microbiome viewed across age and geography. Nature. 2012;486:222-7. https://doi.org/10.1038/nature11053.

14. Zhou Y, Mihindukulasuriya KA, Gao H, La Rosa PS, Wylie KM, Martin JC, Kota K, Shannon WD, Mitreva M, Sodergren E, et al. Exploration of bacterial community classes in major human habitats. Genome Biol. 2014;15:R66. https://doi.org/10.1186/gb-2014-15-5-r66.

15. Bressa C, Bailen-Andrino M, Perez-Santiago J, Gonzalez-Soltero R, Perez M, Montalvo-Lominchar MG, Mate-Munoz JL, Dominguez R, Moreno D, Larrosa M. Differences in gut microbiota profile between women with active lifestyle and sedentary women. PLoS One. 2017;12:e0171352. https://doi.org/ 10.1371/journal.pone.0171352.

16. Clarke SF, Murphy EF, O'Sullivan O, Lucey AJ, Humphreys M, Hogan A, Hayes P, O'Reilly M, Jeffery IB, Wood-Martin R, et al. Exercise and associated dietary extremes impact on gut microbial diversity. Gut. 1913-1920;2014:63. https:// doi.org/10.1136/gutjnl-2013-306541.

17. Petersen LM, Bautista EJ, Nguyen H, Hanson BM, Chen L, Lek SH, Sodergren E, Weinstock GM. Community characteristics of the gut microbiomes of competitive cyclists. Microbiome. 2017;5:98. https://doi.org/10.1186/s40168017-0320-4.

18. MorkI S, Lackner S, Muller W, Gorkiewicz G, Kashofer K, Oberascher A, Painold A, Holl A, Holzer P, Meinitzer A, et al. Gut microbiota and body composition in anorexia nervosa inpatients in comparison to athletes, overweight, obese, and normal weight controls. Int J Eat Disord. 2017;50: 1421-31. https://doi.org/10.1002/eat.22801.

19. Barton W, Penney NC, Cronin O, Garcia-Perez I, Molloy MG, Holmes E, Shanahan F, Cotter PD, O'Sullivan O. The microbiome of professional athletes differs from that of more sedentary subjects in composition and particularly at the functional metabolic level. Gut. 2018;67:625-33. https:// doi.org/10.1136/gutjnl-2016-313627.

20. Estaki M, Pither J, Baumeister P, Little JP, Gill SK, Ghosh S, Ahmadi-Vand Z, Marsden KR, Gibson DL. Cardiorespiratory fitness as a predictor of intestinal microbial diversity and distinct metagenomic functions. Microbiome. 2016;4: 42. https://doi.org/10.1186/s40168-016-0189-7

21. Cerda B, Perez M, Perez-Santiago JD, Tornero-Aguilera JF, Gonzalez-Soltero R, Larrosa M. Gut microbiota modification: another piece in the puzzle of the benefits of physical exercise in health? Front Physiol. 2016;7:51. https:// doi.org/10.3389/fphys.2016.00051.

22. Choi JJ, Eum SY, Rampersaud E, Daunert S, Abreu MT, Toborek M. Exercise attenuates PCB-induced changes in the mouse gut microbiome. Environ Health Perspect. 2013;121:725-30. https://doi.org/10.1289/ehp.1306534.

23. Evans CC, LePard KJ, Kwak JW, Stancukas MC, Laskowski S, Dougherty J, Moulton L, Glawe A, Wang Y, Leone $V$, et al. Exercise prevents weight gain and alters the gut microbiota in a mouse model of high fat diet-induced obesity. PLoS One. 2014;9:e92193. https:/doi.org/10.1371/journal.pone.0092193.

24. Petriz BA, Castro AP, Almeida JA, Gomes CP, Fernandes GR, Kruger RH, Pereira RW, Franco OL. Exercise induction of gut microbiota modifications in obese, non-obese and hypertensive rats. BMC Genomics. 2014;15:511. https://doi.org/10.1186/1471-2164-15-511.

25. Queipo-Ortuno MI, Seoane LM, Murri M, Pardo M, Gomez-Zumaquero JM, Cardona F, Casanueva F, Tinahones FJ. Gut microbiota composition in male rat models under different nutritional status and physical activity and its association with serum leptin and ghrelin levels. PLoS One. 2013;8:e65465. https://doi.org/10.1371/journal.pone.0065465.

26. Campbell SC, Wisniewski PJ, Noji M, McGuinness LR, Haggblom MM, Lightfoot SA, Joseph LB, Kerkhof $\amalg$. The effect of diet and exercise on intestinal integrity and microbial diversity in mice. PLoS One. 2016;11: e0150502. https://doi.org/10.1371/journal.pone.0150502.

27. Cook MD, Martin SA, Williams C, Whitlock K, Wallig MA, Pence BD, Woods $J A$. Forced treadmill exercise training exacerbates inflammation and causes mortality while voluntary wheel training is protective in a mouse model of colitis. Brain Behav Immun. 2013;33:46-56. https://doi.org/10.1016/j.bbi.2013. 05.005 .
28. Allen JM, Mailing $\sqcup$, Niemiro GM, Moore R, Cook MD, White BA, Holscher HD, Woods JA. Exercise alters gut microbiota composition and function in lean and obese humans. Med Sci Sports Exerc. 2018;50:747-57. https://doi. org/10.1249/MSS.0000000000001495.

29. Matsumoto M, Inoue R, Tsukahara T, Ushida K, Chiji H, Matsubara N, Hara H. Voluntary running exercise alters microbiota composition and increases nbutyrate concentration in the rat cecum. Biosci Biotechnol Biochem. 2008; 72:572-6. https://doi.org/10.1271/bbb.70474.

30. Scheiman J, Luber JM, Chavkin TA, MacDonald T, Tung A, Pham LD, Wibowo MC Wurth RC, Punthambaker S, Tierney BT, et al. Meta-omics analysis of elite athletes identifies a performance-enhancing microbe that functions via lactate metabolism. Nat Med. 2019;25:1104-9. https://doi.org/10.1038/s41591-019-0485-4.

31. Cronin O, O'Sullivan O, Barton W, Cotter PD, Molloy MG, Shanahan F. Gut microbiota: implications for sports and exercise medicine. Br J Sports Med. 2017:51:700-1. https://doi.org/10.1136/bjsports-2016-097225.

32. David LA, Maurice CF, Carmody RN, Gootenberg DB, Button JE, Wolfe BE, Ling AV, Devlin AS, Varma Y, Fischbach MA, et al. Diet rapidly and reproducibly alters the human gut microbiome. Nature. 2014;505:559-63. https://doi.org/10.1038/nature12820.

33. Wu GD, Chen J, Hoffmann C, Bittinger K, Chen YY, Keilbaugh SA, Bewtra M, Knights $D$, Walters WA, Knight $R$, et al. Linking long-term dietary patterns with gut microbial enterotypes. Science. 2011;334:105-8. https://doi.org/10. 1126/science.1208344.

34. Sheflin AM, Melby CL, Carbonero F, Weir TL. Linking dietary patterns with gut microbial composition and function. Gut Microbes. 2017;8:113-29. https://doi.org/10.1080/19490976.2016.1270809.

35. Moreno-Perez D, Bressa C, Bailen M, Hamed-Bousdar S, Naclerio F, Carmona M, Perez M, Gonzalez-Soltero R, Montalvo-Lominchar MG, Carabana C, et al. Effect of a protein supplement on the gut microbiota of endurance athletes: a randomized, controlled, Double-Blind Pilot Study. Nutrients. 2018; 10. https://doi.org/10.3390/nu10030337.

36. Gleeson M. Immune function in sport and exercise. J App Physiol (1985). 2007;103:693-9. https://doi.org/10.1152/japplphysiol.00008.2007.

37. Tap J, Furet JP, Bensaada M, Philippe C, Roth H, Rabot S, Lakhdari O, Lombard V, Henrissat B, Corthier G, et al. Gut microbiota richness promotes its stability upon increased dietary fibre intake in healthy adults. Environ Microbiol. 2015;17:4954-64. https://doi.org/10.1111/1462-2920.13006.

38. Cramp T, Broad E, Martin D, Meyer BJ. Effects of preexercise carbohydrate ingestion on mountain bike performance. Med Sci Sports Exerc. 1602-1609;2004:36.

39. Caesar R, Tremaroli V, Kovatcheva-Datchary P, Cani PD, Backhed F. Crosstalk between gut microbiota and dietary lipids aggravates WAT inflammation through TLR signaling. Cell Metab. 2015;22:658-68. https://doi.org/10.1016/j. cmet.2015.07.026.

40. Rawson ES, Miles MP, Larson-Meyer DE. Dietary supplements for health, adaptation, and recovery in athletes. Int J Sport Nutr Exerc Metab. 2018;28: 188-99. https://doi.org/10.1123/ijsnem.2017-0340.

41. de Oliveira EP, Burini RC, Jeukendrup A. Gastrointestinal complaints during exercise: prevalence, etiology, and nutritional recommendations. Sports Med. 2014;44(Suppl 1):S79-85. https://doi.org/10.1007/s40279-014-0153-2.

42. Jäger R, Purpura M, Stone JD, Turner SM, Anzalone AJ, Eimerbrink MJ, Pane M, Amoruso A, Rowlands DS, Oliver JM. Probiotic Streptococcus thermophilus FP4 and Bifidobacterium breve BR03 supplementation attenuates performance and range-of-motion decrements following muscle damaging exercise. Nutrients. 2016;8. https://doi.org/10.3390/nu8100642.

43. Jäger R, Shields KA, Lowery RP, De Souza EO, Partl JM, Hollmer C, Purpura M, Wilson JM. Probiotic Bacillus coagulans GBI-30, 6086 reduces exerciseinduced muscle damage and increases recovery. PeerJ. 2016;4:e2276. https://doi.org/10.7717/peerj.2276.

44. Salarkia N, Ghadamli L, Zaeri F, Sabaghian Rad L. Effects of probiotic yogurt on performance, respiratory and digestive systems of young adult female endurance swimmers: a randomized controlled trial. Med J Islam Repub Iran. 2013;27:141-6.

45. Salehzadeh K. The effects of probiotic yogurt drink on lipid profile, CRP, and record changes in aerobic athletes. Life Sci. 2015;9:32-7.

46. Shing CM, Peake JM, Lim CL, Briskey D, Walsh NP, Fortes MB, Ahuja KD, Vitetta L. Effects of probiotics supplementation on gastrointestinal permeability, inflammation and exercise performance in the heat. Eur J Appl Physiol. 2014;114:93-103. https://doi.org/10.1007/s00421-013-2748-y.

47. Klaenhammer TR, Kleerebezem M, Kopp MV, Rescigno M. The impact of probiotics and prebiotics on the immune system. Nat Rev Immunol. 2012; 12:728-34. https://doi.org/10.1038/nri3312. 
48. Sang LX, Chang B, Zhang WL, Wu XM, Li XH, Jiang M. Remission induction and maintenance effect of probiotics on ulcerative colitis: a meta-analysis. World J Gastroenterol. 1908-1915;2010:16.

49. Ng SC, Hart AL, Kamm MA, Stagg AJ, Knight SC. Mechanisms of action of probiotics: recent advances. Inflamm Bowel Dis. 2009;15:300-10. https://doi. org/10.1002/ibd.20602.

50. Plaza-Diaz J, Gomez-Llorente C, Fontana L, Gil A. Modulation of immunity and inflammatory gene expression in the gut, in inflammatory diseases of the gut and in the liver by probiotics. World J Gastroenterol. 2014;20:1563249. https://doi.org/10.3748/wjg.v20.i42.15632

51. Miettinen M, Vuopio-Varkila J, Varkila K. Production of human tumor necrosis factor alpha, interleukin-6, and interleukin-10 is induced by lactic acid bacteria. Infect Immun. 1996;64:5403-5.

52. Nazemian V, Shadnoush M, Manaheji H, Zaringhalam J. Probiotics and inflammatory pain: a literature review study. Middle East J Rehab Health 2016:3:e36087

53. Clancy RL, Gleeson M, Cox A, Callister R, Dorrington M, D'Este C, Pang G, Pyne D, Fricker $P$, Henriksson A. Reversal in fatigued athletes of a defect in interferon gamma secretion after administration of Lactobacillus acidophilus. Br J Sports Med. 2006;40:351-4. https://doi.org/10.1136/bjsm. 2005.024364.

54. Moreira A, Kekkonen R, Korpela R, Delgado L, Haahtela T. Allergy in marathon runners and effect of Lactobacillus GG supplementation on allergic inflammatory markers. Respir Med. 2007;101:1123-31. https://doi. org/10.1016/j.rmed.2006.11.015.

55. Kekkonen RA, Vasankari TJ, Vuorimaa T, Haahtela T, Julkunen I, Korpela R. The effect of probiotics on respiratory infections and gastrointestinal symptoms during training in marathon runners. Int J Sport Nutr Exerc Metab. 2007;17:352-63.

56. Tiollier E, Chennaoui M, Gomez-Merino D, Drogou C, Filaire E, Guezennec $\mathrm{CY}$. Effect of a probiotics supplementation on respiratory infections and immune and hormonal parameters during intense military training. Mil Med. 2007;172:1006-11. https://doi.org/10.7205/milmed.172.9.1006.

57. Cox AJ, Pyne DB, Saunders PU, Fricker PA. Oral administration of the probiotic Lactobacillus fermentum VRI-003 and mucosal immunity in endurance athletes. Br J Sports Med. 2010;44:222-6. https://doi.org/10.1136/ bjsm.2007.044628.

58. Martarelli D, Verdenelli MC, Scuri S, Cocchioni M, Silvi S, Cecchini C, Pompei P. Effect of a probiotic intake on oxidant and antioxidant parameters in plasma of athletes during intense exercise training. Curr Microbiol. 16891696;2011:62. https://doi.org/10.1007/s00284-011-9915-3.

59. Gleeson M, Bishop NC, Stensel DJ, Lindley MR, Mastana SS, Nimmo MA. The anti-inflammatory effects of exercise: mechanisms and implications for the prevention and treatment of disease. Nat Rev Immunol. 2011;11:607-15. https://doi.org/10.1038/nri3041

60. Gleeson M, Bishop NC, Oliveira M, Tauler P. Daily probiotic's (Lactobacillus casei Shirota) reduction of infection incidence in athletes. Int J Sport Nutr Exerc Metab. 2011;21:55-64.

61. West NP, Pyne DB, Cripps AW, Hopkins WG, Eskesen DC, Jairath A, Christophersen CT, Conlon MA, Fricker PA. Lactobacillus fermentum (PCC(R)) supplementation and gastrointestinal and respiratory-tract illness symptoms: a randomised control trial in athletes. Nutr J. 2011;10:30. https://doi.org/10. 1186/1475-2891-10-30

62. Välimäki et al. Int J Sports Med. 2012;33(4):291-6. https://doi.org/10.1055/ s-0031-1291223.

63. Lamprecht M, Bogner S, Schippinger G, Steinbauer K, Fankhauser F, Hallstroem S, Schuetz B, Greilberger JF. Probiotic supplementation affects markers of intestinal barrier, oxidation, and inflammation in trained men; a randomized, double-blinded, placebo-controlled trial. J Int Soc Sports Nutr. 2012;9:45. https://doi.org/10.1186/1550-2783-9-45.

64. Gleeson M, Bishop N, Oliveira M, McCauley T, Tauler P, Muhamad AS. Respiratory infection risk in athletes: association with antigen-stimulated IL10 production and salivary IgA secretion. Scand J Med Sci Sports. 2012;22: 410-7. https://doi.org/10.1111/j.1600-0838.2010.01272.x.

65. Grobbelaar et al. The influence of probiotic supplementation on selected athletic performance-related blood markers in men. African Journal for Physical, Health Education, Recreation and Dance. 2012;18(1):1-11.

66. West NP, Pyne DB, Cripps AW, Christophersen CT, Conlon MA, Fricker PA. Gut balance, a synbiotic supplement, increases fecal Lactobacillus paracasei but has little effect on immunity in healthy physically active individuals. Gut Microbes. 2012;3:221-7. https://doi.org/10.4161/gmic.19579.
67. Sashihara T, Nagata M, Mori T, Ikegami S, Gotoh M, Okubo K, Uchida M, Itoh H. Effects of Lactobacillus gasseri OLL2809 and alpha-lactalbumin on university-student athletes: a randomized, double-blind, placebo-controlled clinical trial. Appl Physiol Nutr Metab. 2013;38:1228-35. https://doi.org/10. 1139/apnm-2012-0490.

68. West NP, Horn PL, Pyne DB, Gebski VJ, Lahtinen SJ, Fricker PA, Cripps AW. Probiotic supplementation for respiratory and gastrointestinal illness symptoms in healthy physically active individuals. Clin Nutr. 2014;33:581-7. https://doi.org/10.1016/j.clnu.2013.10.002.

69. Haywood BA, Black KE, Baker D, McGarvey J, Healey P, Brown RC. Probiotic supplementation reduces the duration and incidence of infections but not severity in elite rugby union players. J Sci Med Sport. 2014;17:356-60. https://doi.org/10.1016/j.jsams.2013.08.004

70. Aghaee M, Khosravi N, Hanachi P, Kordi MR, Aghaee R. Effect of probiotic supplement on immune response in male athletes. Qom Univ Med Sci. 2014;7:27-33

71. Georges J, Lowery R, Yaman G, Kerio C, Ormes J, McCleary S, Sharp M, Shields K, Rauch J, Silva J, et al. The effects of probiotic supplementation on lean body mass, strength, power, and health indicators in resistance trained males: a pilot study. J Int Soc Sports Nutr. 2014;11:P38.

72. Narimani-Rad et al. Indian Journal of Fundamental and Applied Life Sciences (Online) An Open Access, Online International Journal Available at www. cibtech.org/sp.ed/jls/2014/03/jls.htm. 2014;4(S3):231-5. ISSN: 2231-6345.

73. Muhamad A, Gleeson M. Effects of a 14-strain probiotics supplement on salivary antimicrobial proteins at rest and in reponse to an acute bout of prolonged exercise. Int J Sports Sci. 2014;4:60-6.

74. O'Brien KV, Stewart LK, Forney LA, Aryana KJ, Prinyawiwatkul W, Boeneke CA. The effects of postexercise consumption of a kefir beverage on performance and recovery during intensive endurance training. J Dairy Sci. 2015;98:7446-9. https://doi.org/10.3168/jds.2015-9392.

75. Gill SK, Teixeira AM, Rosado F, Cox M, Costa RJ. High-dose probiotic supplementation containing Lactobacillus casei for 7 days does not enhance salivary antimicrobial protein responses to exertional heat stress compared with placebo. Int J Sport Nutr Exerc Metab. 2016;26:150-60. https://doi.org/10.1123/ijsnem.2015-0171.

76. Gill SK, Allerton DM, Ansley-Robson P, Hemmings K, Cox M, Costa R. Does shortterm high dose probiotic supplementation containing Lactobacillus casei attenuate exertional-heat stress induced Endotoxaemia and Cytokinaemia? Int J Sport Nutr Exerc Metab. 2016;26:268-75. https:/doi.org/10.1123/ijsnem.2015-0186.

77. Roberts JD, Suckling CA, Peedle GY, Murphy JA, Dawkins TG, Roberts MG. An exploratory investigation of endotoxin levels in novice long distance triathletes, and the effects of a multi-strain probiotic/prebiotic. Antioxidant Intervention Nutrients. 2016;8. https://doi.org/10.3390/nu8110733.

78. Strasser B, Geiger D, Schauer M, Gostner JM, Gatterer H, Burtscher M, Fuchs D. Probiotic supplements beneficially affect tryptophan-kynurenine metabolism and reduce the incidence of upper respiratory tract infections in trained athletes: a randomized, double-blinded, Placebo-Controlled Trial. Nutrients. 2016;8. https://doi.org/10.3390/nu8110752.

79. Michalickova D, Minic R, Dikic N, Andjelkovic M, Kostic-Vucicevic M, Stojmenovic T, Nikolic I, Djordjevic B. Lactobacillus helveticus Lafti L10 supplementation reduces respiratory infection duration in a cohort of elite athletes: a randomized, double-blind, placebo-controlled trial. Appl Physiol Nutr Metab. 2016;41:782-9. https://doi.org/10.1139/apnm-2015-0541.

80. Gleeson M, Bishop NC, Struszczak L. Effects of Lactobacillus casei Shirota ingestion on common cold infection and herpes virus antibodies in endurance athletes: a placebo-controlled, randomized trial. Eur J Appl Physiol. 2016;116:1555-63. https://doi.org/10.1007/s00421-016-3415-X.

81. Marshall H, Chrismas BCR, Suckling CA, Roberts JD, Foster J, Taylor L. Chronic probiotic supplementation with or without glutamine does not influence the eHsp72 response to a multi-day ultra-endurance exercise event. Appl Physiol Nutr Metab. 2017;42:876-83. https://doi.org/10.1139/apnm-2017-0131.

82. Brennan et al. Med. Sci. Sports Exerc. 2018;50:840. https://doi.org/10.1249/01. mss.0000538764.55259.9c.

83. Townsend JR, Bender D, Vantrease WC, Sapp PA, Toy AM, Woods CA Johnson KD. Effects of Probiotic (Bacillus subtilis DE111) Supplementation on Immune Function, Hormonal Status, and Physical Performance in Division I Baseball Players. Sports (Basel). 2018:6. https://doi.org/10.3390/ sports6030070.

84. Antonio J, Leaf A, Carson C, Ellerbroek A, Axelrod C, Silver T, Burgess V, Peacock $C$. The effects of probiotic supplementation in active men and women. J Exerc Nutr. 2018;1. 
85. Huang WC, Hsu YJ, Li H, Kan NW, Chen YM, Lin JS, Hsu TK, Tsai TY, Chiu YS, Huang CC. Effect of Lactobacillus Plantarum TWK10 on improving endurance performance in humans. Chin J Phys. 2018;61:163-70. https://doi. org/10.4077/CJP.2018.BAH587.

86. Carbuhn AF, Reynolds SM, Campbell CW, Bradford LA, Deckert JA, Kreutzer A. Fry, A.C. Effects of Probiotic (Bifidobacterium longum 35624) Supplementation on Exercise Performance, Immune Modulation, and Cognitive Outlook in Division I Female Swimmers. Sports (Basel). 2018:6. https://doi.org/10.3390/sports6040116.

87. Huang et al. Nutrients. 2019;11(2). https://doi.org/10.3390/nu11020353.

88. Pugh et al. Eur J Appl Physiol. 2019;119(7):1491-501. https://doi.org/10.1007/ s00421-019-04136-3.

89. Pumpa et al. J Sci Med Sport. 2019;22(8):876-81. https://doi.org/10.1016/j. jsams.2019.03.013.

90. Vaisberg M, Paixao V, Almeida EB, Santos JMB, Foster R, Rossi M, Pithon-Curi TC, Gorjao R, Momesso CM, Andrade MS, et al. Daily intake of fermented Milk containing Lactobacillus casei Shirota (LCS) modulates systemic and upper airways immune/inflammatory responses in Marathon runners. Nutrients. 2019;11. https://doi.org/10.3390/nu1 1071678.

91. Meeusen R. Exercise, nutrition and the brain. Sports Med. 2014;44(Suppl 1): S47-56. https://doi.org/10.1007/s40279-014-0150-5.

92. Chen YM, Wei L, Chiu YS, Hsu YJ, Tsai TY, Wang MF, Huang CC. Lactobacillus plantarum TWK10 supplementation improves exercise performance and increases muscle mass in mice. Nutrients. 2016;8:205. https://doi.org/10. 3390/nu8040205.

93. Wang X, Shao C, Liu L, Guo X, Xu Y, Lu X. Optimization, partial characterization and antioxidant activity of an exopolysaccharide from Lactobacillus plantarum KX041. Int J Biol Macromol. 2017;103:1173-84. https://doi.org/10.1016/j.jijbiomac.2017.05.118.

94. Storelli G, Defaye A, Erkosar B, Hols P, Royet J, Leulier F. Lactobacillus plantarum promotes Drosophila systemic growth by modulating hormonal signals through TOR-dependent nutrient sensing. Cell Metab. 2011;14:40314. https://doi.org/10.1016/j.cmet.2011.07.012.

95. Schwarzer M, Makki K, Storelli G, Machuca-Gayet I, Srutkova D, Hermanova P, Martino ME, Balmand S, Hudcovic T, Heddi A, et al. Lactobacillus plantarum strain maintains growth of infant mice during chronic undernutrition. Science. 2016;351:854-7. https://doi.org/10.1126/science.aad8588.

96. Minevich J, Olson M, Mannion J, Boublik J, McPerson J, Lowery R, Shields K, Sharp M, De Souza E, Wilson J, et al. Digestive enzymes reduce quality difference between plant and animal proteins: a double-blind crossover study (abstract). J Int Soc Sports Nutr. 2015;12:P26.

97. Wang Y, Gu Q. Effect of probiotic on growth performance and digestive enzyme activity of arbor acres broilers. Res Vet Sci. 2010;89:163-7. https:// doi.org/10.1016/j.rvsc.2010.03.009.

98. Kimmel M, Keller D, Farmer S, Warrino DE. A controlled clinical trial to evaluate the effect of GanedenBC(30) on immunological markers. Methods Find Exp Clin Pharmacol. 2010;32:129-32. https:/doi.org/10.1358/mf.2010.32.2.1423881.

99. Maathuis AJ, Keller D, Farmer S. Survival and metabolic activity of the GanedenBC30 strain of Bacillus coagulans in a dynamic in vitro model of the stomach and small intestine. Benefic Microbes. 2010;1:31-6. https://doi. org/10.3920/BM2009.0009.

100. Klemenak M, Dolinsek J, Langerholc T, Di Gioia D, Micetic-Turk D. Administration of Bifidobacterium breve decreases the production of TNFalpha in children with celiac disease. Dig Dis Sci. 2015;60:3386-92. https:// doi.org/10.1007/s10620-015-3769-7.

101. Nicola S, Mogna L, Allesina S, Barba M, Deidda F, Lorenzini P, Raiteri E, Strozzi G, Mogna G. Interaction between probiotics and human immune cells. The prospective anti-inflammatory activity of Bifidobacterium breve BRO3. Agro Food Ind Hi-Tech. 2010;21:9-13.

102. Saggioro A. Probiotics in the treatment of irritable bowel syndrome. J Clin Gastroenterol. 2004;38:5104-6.

103. Toohey JC, Townsend JR, Johnson SB, Toy AM, Vantrease WC, Bender D, Crimi CC, Stowers KL, Ruiz MD, VanDusseldorp TA, et al. Effects of probiotic (Bacillus subtilis) supplementation during offseason resistance training in female division I athletes. J Strength Cond Res. 2018. https://doi.org/10. 1519/JSC.0000000000002675.

104. Mekkes MC, Weenen TC, Brummer RJ, Claassen E. The development of probiotic treatment in obesity: a review. Benefic Microbes. 2014;5:19-28. https://doi.org/10.3920/BM2012.0069.

105. Minami J, Kondo S, Yanagisawa N, Odamaki T, Xiao JZ, Abe F, Nakajima S, Hamamoto Y, Saitoh S, Shimoda T. Oral administration of Bifidobacterium breve B-3 modifies metabolic functions in adults with obese tendencies in a randomised controlled trial. J Nutr Sci. 2015;4:e17. https://doi.org/10.1017/ jns.2015.5.

106. Kondo S, Xiao JZ, Satoh T, Odamaki T, Takahashi S, Sugahara H, Yaeshima T, Iwatsuki K, Kamei A, Abe K. Antiobesity effects of Bifidobacterium breve strain B-3 supplementation in a mouse model with high-fat diet-induced obesity. Biosci Biotechnol Biochem. 1656-1661;2010:74. https://doi.org/10. 1271/bbb.100267.

107. Hardin BJ, Campbell KS, Smith JD, Arbogast S, Smith J, Moylan JS, Reid MB. TNF-alpha acts via TNFR1 and muscle-derived oxidants to depress myofibrillar force in murine skeletal muscle. J App Physiol (1985). 2008;104: 694-9. https://doi.org/10.1152/japplphysiol.00898.2007.

108. Lang CH, Frost RA, Nairn AC, MacLean DA, Vary TC. TNF-alpha impairs heart and skeletal muscle protein synthesis by altering translation initiation. Am J Physiol Endocrinol Metab. 2002;282:E336-47. https://doi.org/10.1152/ ajpendo.00366.2001.

109. Main LC, Dawson B, Heel K, Grove JR, Landers GJ, Goodman C. Relationship between inflammatory cytokines and self-report measures of training overload. Res Sports Med (Print). 2010;18:127-39. https://doi.org/10.1080/ 15438621003627133

110. Kristensen NB, Bryrup T, Allin KH, Nielsen T, Hansen TH, Pedersen O. Alterations in fecal microbiota composition by probiotic supplementation in healthy adults: a systematic review of randomized controlled trials. Genome Med. 2016;8:52. https://doi.org/10.1186/s13073-016-0300-5.

111. McFarland LV. Use of probiotics to correct dysbiosis of normal microbiota following disease or disruptive events: a systematic review. BMJ Open. 2014; 4:e005047. https://doi.org/10.1136/bmjopen-2014-005047.

112. Turnbaugh PJ, Hamady M, Yatsunenko T, Cantarel BL, Duncan A, Ley RE, Sogin ML, Jones WJ, Roe BA, Affourtit JP, et al. A core gut microbiome in obese and lean twins. Nature. 2009;457:480-4. https://doi.org/10.1038/ nature07540.

113. Donmez N, Kisadere I, Balaban C, Kadiralieva N. Effects of traditional homemade koumiss on some hematological and biochemical characteristics in sedentary men exposed to exercise. Biotech Histochem. 2014;89:558-63. https://doi.org/10.3109/10520295.2014.915428.

114. Lollo PC, Cruz AG, Morato PN, Moura CS, Carvalho-Silva LB, Oliveira CA, Faria $J A$, Amaya-Farfan J. Probiotic cheese attenuates exercise-induced immune suppression in Wistar rats. J Dairy Sci. 2012;95:3549-58. https://doi.org/10. 3168/jds.2011-5124.

115. Wells JM, Rossi O, Meijerink M, van Baarlen P. Epithelial crosstalk at the microbiota-mucosal interface. Proc Natl Acad Sci U S A. 2011;108(Suppl 1): 4607-14. https://doi.org/10.1073/pnas. 1000092107.

116. Schwellnus M, Soligard T, Alonso JM, Bahr R, Clarsen B, Dijkstra HP, Gabbett TJ, Gleeson M, Hagglund M, Hutchinson MR, et al. How much is too much? (part 2) International Olympic Committee consensus statement on load in sport and risk of illness. Br J Sports Med. 2016;50:1043-52. https://doi.org/10. 1136/bjsports-2016-096572.

117. Geuking MB, McCoy KD, Macpherson AJ. Metabolites from intestinal microbes shape Treg. Cell Res. 2013;23:1339-40. https://doi.org/10.1038/cr. 2013.125.

118. Hiramatsu Y, Hosono A, Konno T, Nakanishi Y, Muto M, Suyama A, Hachimura S, Sato R, Takahashi K, Kaminogawa S. Orally administered Bifidobacterium triggers immune responses following capture by $\mathrm{CD} 11 \mathrm{C}(+)$ cells in Peyer's patches and cecal patches. Cytotechnology. 2011;63:307-17. https://doi.org/10.1007/s10616-011-9349-6.

119. Shephard RJ. Special feature for the Olympics: effects of exercise on the immune system: overview of the epidemiology of exercise immunology. Immunol Cell Biol. 2000;78:485-95. https://doi.org/10.1111/j.1440-1711.2000.t01-1-X.

120. Chakravarti A. The CD4/CD8 ratio: message in a bottle? Nat Med. 1995;1: 1240-1. https://doi.org/10.1038/nm1295-1240.

121. Sanders M, Merenstein D, Merrifield C, Hutkins R. Probiotics for Human Use. Nutr Bull. 2019;43:212-25.

122. Azad MAK, Sarker M, Wan D. Immunomodulatory effects of probiotics on cytokine profiles. Biomed Res Int. 2018;2018:8063647. https://doi.org/10. $1155 / 2018 / 8063647$.

123. Šušković J, Kos B, Novak J, Pavunc A, Habjanič K, Matoć S. Antimicrobial activity - the most important property of probiotic and starter lactic acid bacteria. Food Technol Biotechnol. 2010;48:296-307.

124. Dobson A, Cotter PD, Ross RP, Hill C. Bacteriocin production: a probiotic trait? Appl Environ Microbiol. 2012;78:1-6. https://doi.org/10.1128/AEM. 05576-11. 
125. Cotter PD, Hill C, Ross RP. Bacteriocins: developing innate immunity for food. Nat Rev Microbiol. 2005;3:777-88. https://doi.org/10.1038/nrmicro1273.

126. Wosinska L, Cotter PD, O'Sullivan O, Guinane C. The potential impact of probiotics on the gut microbiome of athletes. Nutrients. 2019;11. https://doi. org/10.3390/nu11102270.

127. Rehrer NJ, van Kemenade M, Meester W, Brouns F, Saris WH. Gastrointestinal complaints in relation to dietary intake in triathletes. Int J Sport Nutr. 1992;2:48-59.

128. van Wijck K, Lenaerts K, Grootjans J, Wijnands KA, Poeze M, van Loon LJ, Dejong $\mathrm{CH}$, Buurman WA. Physiology and pathophysiology of splanchnic hypoperfusion and intestinal injury during exercise: strategies for evaluation and prevention. Am J Physiol Gastrointest Liver Physiol. 2012;303:G155-68. https://doi.org/10.1152/ajpgi.00066.2012.

129. van Wijck K, Lenaerts K, van Loon LJ, Peters WH, Buurman WA, Dejong $\mathrm{CH}$. Exercise-induced splanchnic hypoperfusion results in gut dysfunction in healthy men. PLoS One. 2011;6:e22366. https://doi.org/10.1371/journal.pone. 0022366.

130. Jeukendrup $A E$, Jentjens RL, Moseley L. Nutritional considerations in triathlon. Sports Med. 2005;35:163-81 doi:3525 [pii].

131. Jeukendrup AE. Training the gut for athletes. Sports Med. 2017:47:101-10. https://doi.org/10.1007/s40279-017-0690-6.

132. Brennan, C.J.; Axelrod, C.; Paul, D.; Hull, M.; Kirwan, J.P. Effects of a novel probiotic on exercise-induced gut permeability and microbiota in endurance athletes (abstract). In proceedings of American College of Sports Medicine, Minneapolis, MN.

133. Fasano A. Zonulin and its regulation of intestinal barrier function: the biological door to inflammation, autoimmunity, and cancer. Physiol Rev. 2011:91:151-75. https://doi.org/10.1152/physrev.00003.2008.

134. de Oliveira EP, Burini RC. Food-dependent, exercise-induced gastrointestinal distress. J Int Soc Sports Nutr. 2011;8:12. https://doi.org/10.1186/1550-27838-12.

135. Groschwitz KR, Hogan SP. Intestinal barrier function: molecular regulation and disease pathogenesis. J Allergy Clin Immunol. 2009;124:3-20; quiz 2122. https://doi.org/10.1016/j.jaci.2009.05.038.

136. Sonier B, Patrick C, Ajjikuttira P, Scott FW. Intestinal immune regulation as a potential diet-modifiable feature of gut inflammation and autoimmunity. Int Rev Immunol. 2009;28:414-45. https://doi.org/10.3109/08830180903208329.

137. Jeukendrup AE, Vet-Joop K, Sturk A, Stegen JH, Senden J, Saris WH, Wagenmakers AJ. Relationship between gastro-intestinal complaints and endotoxaemia, cytokine release and the acute-phase reaction during and after a long-distance triathlon in highly trained men. Clin Sci (Lond). 2000; 98:47-55.

138. Reid G. Probiotics: definition, scope and mechanisms of action. Best Pract Res Clin Gastroenterol. 2016;30:17-25. https://doi.org/10.1016/j.bpg.2015.12.001.

139. Langa S, Martin-Cabrejas I, Montiel R, Landete JM, Medina M, Arques JL. Short communication: combined antimicrobial activity of reuterin and diacetyl against foodborne pathogens. J Dairy Sci. 2014;97:6116-21. https:// doi.org/10.3168/jds.2014-8306.

140. Velraeds MM, van de Belt-Gritter B, van der Mei HC, Reid G, Busscher HJ. Interference in initial adhesion of uropathogenic bacteria and yeasts to silicone rubber by a Lactobacillus acidophilus biosurfactant. J Med Microbiol. 1998:47:1081-5. https://doi.org/10.1099/00222615-47-12-1081.

141. Bermudez-Brito M, Plaza-Diaz J, Munoz-Quezada S, Gomez-Llorente C, Gil A. Probiotic mechanisms of action. Ann Nutr Metab. 2012;61:160-74. https:// doi.org/10.1159/000342079.

142. Ohland CL, Macnaughton WK. Probiotic bacteria and intestinal epithelial barrier function. Am J Physiol Gastrointest Liver Physiol. 2010;298:G807-19. https://doi.org/10.1152/ajpgi.00243.2009.

143. Hooper LV, Stappenbeck TS, Hong CV, Gordon Jl. Angiogenins: a new class of microbicidal proteins involved in innate immunity. Nat Immunol. 2003;4: 269-73. https://doi.org/10.1038/ni888.

144. Hooper LV, Wong MH, Thelin A, Hansson L, Falk PG, Gordon Jl. Molecular analysis of commensal host-microbial relationships in the intestine. Science. 2001;291:881-4. https://doi.org/10.1126/science.291.5505.881.

145. Anderson RC, Cookson AL, McNabb WC, Park Z, McCann MJ, Kelly WJ, Roy NC. Lactobacillus plantarum MB452 enhances the function of the intestinal barrier by increasing the expression levels of genes involved in tight junction formation. BMC Microbiol. 2010;10:316. https://doi.org/10.1186/ 1471-2180-10-316.

146. Mack DR, Ahrne S, Hyde L, Wei S, Hollingsworth MA. Extracellular MUC3 mucin secretion follows adherence of Lactobacillus strains to intestinal epithelial cells in vitro. Gut. 2003;52:827-33.
147. Mattar AF, Teitelbaum DH, Drongowski RA, Yongyi F, Harmon CM, Coran AG. Probiotics up-regulate MUC-2 mucin gene expression in a Caco-2 cellculture model. Pediatr Surg Int. 2002;18:586-90. https://doi.org/10.1007/ s00383-002-0855-7.

148. Zuhl M, Schneider S, Lanphere K, Conn C, Dokladny K, Moseley P. Exercise regulation of intestinal tight junction proteins. Br J Sports Med. 2014;48: 980-6. https://doi.org/10.1136/bjsports-2012-091585.

149. Flynn MG, McFarlin BK. Toll-like receptor 4: link to the anti-inflammatory effects of exercise? Exerc Sport Sci Rev. 2006;34:176-81. https://doi.org/10. 1249/01.jes.0000240027.22749.14.

150. Stuempfle KJ, Valentino T, Hew-Butler T, Hecht FM, Hoffman MD. Nausea is associated with endotoxemia during a 161-km ultramarathon. J Sports Sci. 1662-1668;2016:34. https://doi.org/10.1080/02640414.2015.1130238.

151. Munford RS. Sensing gram-negative bacterial lipopolysaccharides: a human disease determinant? Infect Immun. 2008;76:454-65. https://doi.org/10.1128/ |Al.00939-07.

152. Mach N, Fuster-Botella D. Endurnace exercise and gut microbiota: a review. J Sport Health Sci. 2017;6:179-97.

153. Lescheid D. Probiotics as regulators of inflammation: a review. Functional Foods in Health and Disease. 2014;4:299-311.

154. Pagnini C, Saeed R, Bamias G, Arseneau KO, Pizarro TT, Cominelli F. Probiotics promote gut health through stimulation of epithelial innate immunity. Proc Natl Acad Sci U S A. 2010;107:454-9. https://doi.org/10.1073/ pnas.0910307107.

155. Karczewski J, Troost FJ, Konings I, Dekker J, Kleerebezem M, Brummer RJ, Wells JM. Regulation of human epithelial tight junction proteins by Lactobacillus plantarum in vivo and protective effects on the epithelial barrier. Am J Physiol Gastrointest Liver Physiol. 2010;298:G851-9. https://doi. org/10.1152/ajpgi.00327.2009.

156. Cario E, Gerken G, Podolsky DK. Toll-like receptor 2 controls mucosal inflammation by regulating epithelial barrier function. Gastroenterology. 2007:132:1359-74. https://doi.org/10.1053/j.gastro.2007.02.056.

157. Perdigon G, Maldonado Galdeano C, Valdez JC, Medici M. Interaction of lactic acid bacteria with the gut immune system. Eur J Clin Nutr. 2002; 56(Suppl 4):S21-6. https://doi.org/10.1038/sj.ejcn.1601658.

158. Schiffrin EJ, Brassart D, Servin AL, Rochat F, Donnet-Hughes A. Immune modulation of blood leukocytes in humans by lactic acid bacteria: criteria for strain selection. Am J Clin Nutr. 1997;66:515S-20S. https://doi.org/10. 1093/ajcn/66.2.515S

159. Hirano J, Yoshida T, Sugiyama T, Koide N, Mori I, Yokochi T. The effect of Lactobacillus rhamnosus on enterohemorrhagic Escherichia coli infection of human intestinal cells in vitro. Microbiol Immunol. 2003;47:405-9.

160. Kim YS, Ho SB. Intestinal goblet cells and mucins in health and disease: recent insights and progress. Curr Gastroenterol Rep. 2010;12:319-30. https://doi.org/10.1007/s11894-010-0131-2

161. Ayabe T, Satchell DP, Wilson CL, Parks WC, Selsted ME, Ouellette AJ. Secretion of microbicidal alpha-defensins by intestinal Paneth cells in response to bacteria. Nat Immunol. 2000;1:113-8. https://doi.org/10.1038/77783.

162. Ostaff MJ, Stange EF, Wehkamp J. Antimicrobial peptides and gut microbiota in homeostasis and pathology. EMBO Mol Med. 2013;5:1465-83. https://doi.org/10.1002/emmm.201201773.

163. Furrie E, Macfarlane S, Kennedy A, Cummings JH, Walsh SV, O'Neil DA, Macfarlane GT. Synbiotic therapy (Bifidobacterium longum/Synergy 1) initiates resolution of inflammation in patients with active ulcerative colitis: a randomised controlled pilot trial. Gut. 2005;54:242-9. https://doi.org/10. 1136/gut.2004.044834.

164. Servin AL. Antagonistic activities of lactobacilli and bifidobacteria against microbial pathogens. FEMS Microbiol Rev. 2004;28:405-40. https://doi.org/ 10.1016/j.femsre.2004.01.003

165. Chenoll E, Casinos B, Bataller E, Astals P, Echevarria J, Iglesias JR, Balbarie P Ramon D, Genoves S. Novel probiotic Bifidobacterium bifidum CECT 7366 strain active against the pathogenic bacterium helicobacter pylori. Appl Environ Microbiol. 2011;77:1335-43. https://doi.org/10.1128/AEM.01820-10.

166. Chu H, Kang S, Ha S, Cho K, Park SM, Han KH, Kang SK, Lee H, Han SH, Yun $\mathrm{CH}$, et al. Lactobacillus acidophilus expressing recombinant $\mathrm{K} 99$ adhesive fimbriae has an inhibitory effect on adhesion of enterotoxigenic Escherichia coli. Microbiol Immunol. 2005;49:941-8.

167. Munoz JA, Chenoll E, Casinos B, Bataller E, Ramon D, Genoves S, Montava R, Ribes JM, Buesa J, Fabrega J, et al. Novel probiotic Bifidobacterium longum subsp. infantis CECT 7210 strain active against rotavirus infections. Appl Environ Microbiol. 2011;77:8775-83. https://doi.org/10.1128/AEM.05548-11. 
168. Sgouras D, Maragkoudakis P, Petraki K, Martinez-Gonzalez B, Eriotou E, Michopoulos S, Kalantzopoulos G, Tsakalidou E, Mentis A. In vitro and in vivo inhibition of helicobacter pylori by Lactobacillus casei strain Shirota. Appl Environ Microbiol. 2004;70:518-26.

169. Todoriki K, Mukai T, Sato S, Toba T. Inhibition of adhesion of food-borne pathogens to Caco-2 cells by Lactobacillus strains. J Appl Microbiol. 2001;91: 154-9.

170. Tsai CC, Lin PP, Hsieh YM. Three Lactobacillus strains from healthy infant stool inhibit enterotoxigenic Escherichia coli grown in vitro. Anaerobe. 2008; 14:61-7. https://doi.org/10.1016/j.anaerobe.2007.11.003.

171. Nakamura S, Kuda T, An C, Kanno T, Takahashi H, Kimura B. Inhibitory effects of Leuconostoc mesenteroides 1RM3 isolated from narezushi, a fermented fish with rice, on listeria monocytogenes infection to Caco-2 cells and a/J mice. Anaerobe. 2012;18:19-24. https://doi.org/10.1016/j.anaerobe.2011.11. 006.

172. Schiffrin EJ, Blum S. Interactions between the microbiota and the intestinal mucosa. Eur J Clin Nutr. 2002;56(Suppl 3):S60-4. https://doi.org/10.1038/sj. ejcn.1601489.

173. Fujiwara S, Hashiba H, Hirota T, Forstner JF. Inhibition of the binding of enterotoxigenic Escherichia coli Pb176 to human intestinal epithelial cell line HCT-8 by an extracellular protein fraction containing BIF of Bifidobacterium longum SBT2928: suggestive evidence of blocking of the binding receptor gangliotetraosylceramide on the cell surface. Int J Food Microbiol. 2001;67:97-106.

174. Neeser JR, Granato D, Rouvet M, Servin A, Teneberg S, Karlsson KA. Lactobacillus johnsonii La1 shares carbohydrate-binding specificities with several enteropathogenic bacteria. Glycobiology. 2000;10:1193-9.

175. Mukai T, Asasaka T, Sato E, Mori K, Matsumoto M, Ohori H. Inhibition of binding of helicobacter pylori to the glycolipid receptors by probiotic Lactobacillus reuteri. FEMS Immunol Med Microbiol. 2002;32:105-10.

176. Coconnier MH, Bernet MF, Chauviere G, Servin AL. Adhering heat-killed human Lactobacillus acidophilus, strain LB, inhibits the process of pathogenicity of diarrhoeagenic bacteria in cultured human intestinal cells. J Diarrhoeal Dis Res. 1993;11:235-42.

177. Konstantinov SR, Kuipers EJ, Peppelenbosch MP. Functional genomic analyses of the gut microbiota for CRC screening. Nat Rev Gastroenterol Hepatol. 2013;10:741-5. https://doi.org/10.1038/nrgastro.2013.178.

178. Oberg TS, Steele JL, Ingham SC, Smeianov W, Briczinski EP, Abdalla A, Broadbent JR. Intrinsic and inducible resistance to hydrogen peroxide in Bifidobacterium species. J Ind Microbiol Biotechnol. 1947-1953;2011:38. https://doi.org/10.1007/s10295-011-0983-y.

179. Tsilingiri K, Rescigno M. Postbiotics: what else? Benefic Microbes. 2013;4: 101-7. https://doi.org/10.3920/BM2012.0046

180. Sharma M, Shukla G. Metabiotics: one step ahead of probiotics; an insight into mechanisms involved in Anticancerous effect in colorectal Cancer. Front Microbiol. 1940;2016:7. https://doi.org/10.3389/fmicb.2016.01940.

181. Shenderov BA. Metabiotics: novel idea or natural development of probiotic conception. Microb Ecol Health Dis. 2013;24. https://doi.org/10.3402/mehd. v24i0.20399

182. Canfora EE, Jocken JW, Blaak EE. Short-chain fatty acids in control of body weight and insulin sensitivity. Nat Rev Endocrinol. 2015;11:577-91. https:// doi.org/10.1038/nrendo.2015.128.

183. Kimura I, Ozawa K, Inoue D, Imamura T, Kimura K, Maeda T, Terasawa K, Kashihara D, Hirano K, Tani T, et al. The gut microbiota suppresses insulinmediated fat accumulation via the short-chain fatty acid receptor GPR43. Nat Commun. 1829;2013:4. https://doi.org/10.1038/ncomms2852.

184. den Besten G, van Eunen K, Groen AK, Venema K, Reijngoud DJ, Bakker BM. The role of short-chain fatty acids in the interplay between diet, gut microbiota, and host energy metabolism. J Lipid Res. 2013;54:2325-40. https://doi.org/10.1194/jlr. R036012.

185. Kullisaar T, Zilmer M, Mikelsaar M, Vihalemm T, Annuk H, Kairane C, Kilk A. Two antioxidative lactobacilli strains as promising probiotics. Int J Food Microbiol. 2002;72:215-24.

186. Lin MY, Chang FJ. Antioxidative effect of intestinal bacteria Bifidobacterium longum ATCC 15708 and Lactobacillus acidophilus ATCC 4356. Dig Dis Sci. 1617-1622;2000:45.

187. Saide JA, Gilliland SE. Antioxidative activity of lactobacilli measured by oxygen radical absorbance capacity. J Dairy Sci. 2005;88:1352-7. https://doi. org/10.3168/jds. S0022-0302(05)72801-0.

188. Coqueiro AY, de Oliveira Garcia AB, Rogero MM, Tirapegui J. Probiotic supplementation in sports and physical exercise: does it present any ergogenic effect? Nutr Health. 2017;23:239-49. https://doi.org/10.1177/ 0260106017721000

189. Akbari V, Hendijani F. Effects of probiotic supplementation in patients with type 2 diabetes: systematic review and meta-analysis. Nutr Rev. 2016;74: 774-84. https://doi.org/10.1093/nutrit/nuw039.

190. Ruan Y, Sun J, He J, Chen F, Chen R, Chen H. Effect of probiotics on glycemic control: a systematic review and meta-analysis of randomized, Controlled Trials. PLoS One. 2015;10:e0132121. https://doi.org/10.1371/ journal.pone.0132121.

191. Alakomi HL, Skytta E, Saarela M, Mattila-Sandholm T, Latva-Kala K, Helander IM. Lactic acid permeabilizes gram-negative bacteria by disrupting the outer membrane. Appl Environ Microbiol. 2001-2005;2000:66.

192. De Keersmaecker SC, Verhoeven TL, Desair J, Marchal K, Vanderleyden J, Nagy I. Strong antimicrobial activity of Lactobacillus rhamnosus GG against Salmonella typhimurium is due to accumulation of lactic acid. FEMS Microbiol Lett. 2006;259:89-96. https://doi.org/10.1111/j.1574-6968.2006. 00250.x.

193. Makras L, Triantafyllou V, Fayol-Messaoudi D, Adriany T, Zoumpopoulou G, Tsakalidou E, Servin A, De Vuyst L. Kinetic analysis of the antibacterial activity of probiotic lactobacilli towards Salmonella enterica serovar typhimurium reveals a role for lactic acid and other inhibitory compounds. Res Microbiol. 2006;157:241-7. https://doi.org/10.1016/j.resmic.2005.09.002.

194. Russell JB, Diez-Gonzalez F. The effects of fermentation acids on bacterial growth. Adv Microb Physiol. 1998;39:205-34.

195. Macouzet M, Lee BH, Robert N. Production of conjugated linoleic acid by probiotic Lactobacillus acidophilus La-5. J Appl Microbiol. 1886-1891;2009: 106. https://doi.org/10.1111/j.1365-2672.2009.04164.x.

196. O'Shea EF, Cotter PD, Stanton C, Ross RP, Hill C. Production of bioactive substances by intestinal bacteria as a basis for explaining probiotic mechanisms: bacteriocins and conjugated linoleic acid. Int J Food Microbiol. 2012;152:189-205. https://doi.org/10.1016/j.ijfoodmicro.2011.05.025.

197. Lee K, Paek K, Lee HY, Park JH, Lee Y. Antiobesity effect of trans-10,cis-12conjugated linoleic acid-producing Lactobacillus plantarum PL62 on dietinduced obese mice. J Appl Microbiol. 2007;103:1140-6. https://doi.org/10. 1111/j.1365-2672.2007.03336.x.

198. Nieman DC, Henson DA, Austin MD, Sha W. Upper respiratory tract infection is reduced in physically fit and active adults. Br J Sports Med. 2011:45:98792. https://doi.org/10.1136/bjsm.2010.077875.

199. Gleeson M, Bishop NC. URI in athletes: are mucosal immunity and cytokine responses key risk factors? Exerc Sport Sci Rev. 2013;41:148-53. https://doi. org/10.1097/JES.0b013e3182956ead.

200. Walsh NP. Recommendations to maintain immune health in athletes. Eur J Sport Sci. 2018;18:820-31. https://doi.org/10.1080/17461391.2018.1449895.

201. Walsh NP, Gleeson M, Shephard RJ, Gleeson M, Woods JA, Bishop NC, Fleshner M, Green C, Pedersen BK, Hoffman-Goetz L, et al. Position statement. Part one: Immune function and exercise. Exerc Immunol Rev. 2011;17:6-63.

202. Gomez-Llorente C, Munoz S, Gil A. Role of toll-like receptors in the development of immunotolerance mediated by probiotics. Proc Nutr Soc 2010;69:381-9. https://doi.org/10.1017/S0029665110001527.

203. Lebeer S, Vanderleyden J, De Keersmaecker SC. Host interactions of probiotic bacterial surface molecules: comparison with commensals and pathogens. Nat Rev Microbiol. 2010;8:171-84. https://doi.org/10.1038/ nrmicro2297.

204. Bermon S, Petriz B, Kajeniene A, Prestes J, Castell L, Franco OL. The microbiota: an exercise immunology perspective. Exerc Immunol Rev. 2015; 21:70-9.

205. Lancaster Gl, Halson SL, Khan Q, Drysdale P, Wallace F, Jeukendrup AE, Drayson MT, Gleeson M. Effects of acute exhaustive exercise and chronic exercise training on type 1 and type 2 T lymphocytes. Exerc Immunol Rev. 2004;10:91-106.

206. Martin SA, Pence BD, Woods JA. Exercise and respiratory tract viral infections. Exerc Sport Sci Rev. 2009:37:157-64. https://doi.org/10.1097/JES 0b013e3181b7b57b.

207. Jager R, Purpura M, Farmer S, Cash HA, Keller D. Probiotic Bacillus coagulans GBI-30, 6086 improves protein absorption and utilization. Probiotics Antimicrob Proteins. 2018;10:611-5. https://doi.org/10.1007/s12602-017-9354-y.

208. Keller D, Van Dinter R, Cash H, Farmer S, Venema K. Bacillus coagulans GBI30,6086 increases plant protein digestion in a dynamic, computercontrolled in vitro model of the small intestine (TIM-1). Benefic Microbes. 2017;8:491-6. https://doi.org/10.3920/BM2016.0196. 
209. Buckley JD, Thomson RL, Coates AM, Howe PR, DeNichilo MO, Rowney MK. Supplementation with a whey protein hydrolysate enhances recovery of muscle force-generating capacity following eccentric exercise. J Sci Med Sport. 2010;13:178-81. https://doi.org/10.1016/j.jsams.2008.06.007.

210. Benton D, Williams C, Brown A. Impact of consuming a milk drink containing a probiotic on mood and cognition. Eur J Clin Nutr. 2007;61: 355-61. https://doi.org/10.1038/sj.ejcn.1602546.

211. de Simone C. The unregulated probiotic market. Clin Gastroenterol Hepatol. 2018. https://doi.org/10.1016/j.cgh.2018.01.018.

212. World Gastroenterology Organisation. Global Guidelines: Probiotics and Prebiotics. World Gastroentereology Oganisation. Milwaukee; 2017.

213. Sanders ME, Akkermans LM, Haller D, Hammerman C, Heimbach J, Hormannsperger G, Huys G, Levy DD, Lutgendorff F, Mack D, et al. Safety assessment of probiotics for human use. Gut Microbes. 2010;1:164-85. https://doi.org/10.4161/gmic.1.3.12127.

214. Marteau P. Safety aspects of probiotic products. Naringsforskning. 2001;45: 22-4.

215. Cesaro C, Tiso A, Del Prete A, Cariello R, Tuccillo C, Cotticelli G, Del Vecchio Blanco C, Loguercio C. Gut microbiota and probiotics in chronic liver diseases. Dig Liver Dis. 2011;43:431-8. https://doi.org/10.1016/j.dld.2010.10. 015.

216. Besselink MG, van Santvoort HC, Buskens E, Boermeester MA, van Goor H, Timmerman HM, Nieuwenhuijs VB, Bollen TL, van Ramshorst B, Witteman BJ, et al. Probiotic prophylaxis in predicted severe acute pancreatitis: a randomised, double-blind, placebo-controlled trial. Lancet. 2008;371:651-9. https://doi.org/10.1016/S0140-6736(08)60207-X.

217. Sanders ME, Merenstein DJ, Ouwehand AC, Reid G, Salminen S, Cabana MD, Paraskevakos G, Leyer G. Probiotic use in at-risk populations. J Am Pharm Assoc (2003). 2016;56:680-6. https://doi.org/ 10.1016/j.japh.2016.07.001

218. Vallabhaneni S, Walker TA, Lockhart SR, Ng D, Chiller T, Melchreit R, Brandt ME, Smith RM. Centers for Disease Control and Prevention, see https://www. cdc.gov/mmwr/preview/mmwrhtml/mm6406a6.htm.

219. FDA. New Dietary Ingredients Notification Process. Washington; 2016.

220. Didari T, Solki S, Mozaffari S, Nikfar S, Abdollahi M. A systematic review of the safety of probiotics. Expert Opin Drug Saf. 2014;13:227-39. https://doi. org/10.1517/14740338.2014.872627.

221. Boyle RJ, Robins-Browne RM, Tang ML. Probiotic use in clinical practice: what are the risks? Am J Clin Nutr. 2006;83:1256-64; quiz 1446-1257. https:// doi.org/10.1093/ajen/83.6.1256.

222. Tapiovaara L, Lehtoranta L, Poussa T, Makivuokko H, Korpela R, Pitkaranta A. Absence of adverse events in healthy individuals using probiotics--analysis of six randomised studies by one study group. Benefic Microbes. 2016;7: 161-9. https://doi.org/10.3920/BM2015.0096

223. Larsen CN, Nielsen S, Kaestel P, Brockmann E, Bennedsen M, Christensen HR, Eskesen DC, Jacobsen BL, Michaelsen KF. Dose-response study of probiotic bacteria Bifidobacterium animalis subsp lactis BB-12 and Lactobacillus paracasei subsp paracasei CRL-341 in healthy young adults. Eur J Clin Nutr. 2006;60:1284-93. https://doi.org/10.1038/sj.ejcn.1602450.

224. Ford AC, Quigley EM, Lacy BE, Lembo AJ, Saito YA, Schiller LR, Soffer EE, Spiegel BM, Moayyedi P. Efficacy of prebiotics, probiotics, and synbiotics in irritable bowel syndrome and chronic idiopathic constipation: systematic review and meta-analysis. Am J Gastroenterol, 2014;109:1547-61; quiz 1546, 1562. https://doi.org/10.1038/ajg.2014.202.

225. Monteiro R, Azevedo I. Chronic inflammation in obesity and the metabolic syndrome. Mediat Inflamm. 2010;2010. https://doi.org/10 1155/2010/289645.

226. Food and Agriculture Organization of the United Nations and World Health Organization. Joint FAO/WHO working group report on drafting guidelines fro the evaluation of probiotics in food. 2002.

227. Health Canada. Natural Health Products Ingredients Database: Probiotics. Availabe online: http://webprod.hc-sc.gc.ca/nhpid-bdipsn/atReq.do?atid= probio\&lang=eng (accessed on Oct 23).

228. Zorzela L, Ardestani SK, McFarland LV, Vohra S. Is there a role for modified probiotics as beneficial microbes: a systematic review of the literature. Benefic Microbes. 2017;8:739-54. https://doi.org/10.3920/BM2017.0032

229. Health Canada. Licensed Natural Health Products Database. 2019. . Availabe online: https://health-products.canada.ca/Inhpd-bdpsnh/index-eng.jsp (accessed on Oct 23).

230. Arora M, Baldi A. Regulatory categories of probiotics across the globe: a review representing existing and recommended categorization. Indian J
Med Microbiol. 2015;33(Suppl):2-10. https://doi.org/10.4103/0255-0857. 150868.

231. Amagase H. Current marketplace for probiotics: a Japanese perspective. Clin Infect Dis. 2008:46(Suppl 2):S73-5; discussion S144-151. https://doi.org/10. $1086 / 523338$

232. European Food Standards Agency. Qualified Presumption of Safety. Available from: http://www.efsa.europa.eu/en/topics/topic/qualifiedpresumption-safety-qps. Access date: 10 Aug 2018.

233. Kolacek S, Hojsak I, Berni Canani R, Guarino A, Indrio F, Orel R, Pot B, Shamir $\mathrm{R}$, Szajewska $\mathrm{H}$, Vandenplas $Y$, et al. Commercial probiotic products: a call for improved quality control. A position paper by the ESPGHAN working Group for Probiotics and Prebiotics. J Pediatr Gastroenterol Nutr. 2017;65: 117-24. https://doi.org/10.1097/MPG.0000000000001603.

234. NIH. Probiotics: In Depth. https://nccih.nih.gov/health/probiotics/ introduction.htm. 2016.

235. Giordano-Schaefer, J.; Ruthsatz, M.; Schneider, H. Overcoming distinctive regulatory barriers for the development of medical foods. Availabe online: https://www.raps.org/regulatory-focus\%E2\%84\%A2/news-articles/2017/10/ overcoming-distinctive-regulatory-barriers-for-the-development-of-medicalfoods (Accessed on Oct 2017).

236. Kullen MJ, Amann MM, O'Shaughnessy MJ, O'Sullivan DJ, Busta FF, Brady LJ. Differentiation of ingested and endogenous bifidobacteria by DNA fingerprinting demonstrates the survival of an unmodified strain in the gastrointestinal tract of humans. J Nutr. 1997;127:89-94. https://doi.org/10. 1093/jn/127.1.89.

237. Poutahidis T, Springer A, Levkovich T, Qi P, Varian BJ, Lakritz JR, Ibrahim YM, Chatzigiagkos A, Alm EJ, Erdman SE. Probiotic microbes sustain youthful serum testosterone levels and testicular size in aging mice. PLoS One. 2014; 9:e84877. https://doi.org/10.1371/journal.pone.0084877.

238. Lyte M. Probiotics function mechanistically as delivery vehicles for neuroactive compounds: microbial endocrinology in the design and use of probiotics. Bioessays. 2011;33:574-81. https://doi.org/10.1002/bies. 201100024.

239. Bravo JA, Forsythe $P$, Chew MV, Escaravage E, Savignac HM, Dinan TG, Bienenstock J, Cryan JF. Ingestion of Lactobacillus strain regulates emotional behavior and central GABA receptor expression in a mouse via the vagus nerve. Proc Natl Acad Sci U S A. 2011;108:16050-5. https://doi.org/10.1073/ pnas.1102999108.

240. Steenbergen L, Sellaro R, van Hemert S, Bosch JA, Colzato LS. A randomized controlled trial to test the effect of multispecies probiotics on cognitive reactivity to sad mood. Brain Behav Immun. 2015;48:258-64. https://doi.org/ 10.1016/j.bbi.2015.04.003.

241. Kim J, Yun JM, Kim MK, Kwon O, Cho B. Lactobacillus gasseri BNR17 supplementation reduces the visceral fat accumulation and waist circumference in obese adults: a randomized, double-blind, Placebo-Controlled Trial. J Med Food. 2018;21:454-61. https://doi.org/10.1089/jmf.2017.3937.

242. Sanchez M, Darimont C, Drapeau V, Emady-Azar S, Lepage M, Rezzonico E, Ngom-Bru C, Berger B, Philippe L, Ammon-Zuffrey C, et al. Effect of Lactobacillus rhamnosus CGMCC1.3724 supplementation on weight loss and maintenance in obese men and women. Br J Nutr. 2014;111:1507-19. https://doi.org/10.1017/S0007114513003875.

243. Gauchard GC, Gangloff P, Vouriot A, Mallie JP, Perrin PP. Effects of exerciseinduced fatigue with and without hydration on static postural control in adult human subjects. Int J Neurosci. 2002;112:1191-206.

244. Green H, Halestrap A, Mockett C, O'Toole D, Grant S, Ouyang J. Increases in muscle MCT are associated with reductions in muscle lactate after a single exercise session in humans. Am J Physiol Endocrinol Metab. 2002;282:E15460. https://doi.org/10.1152/ajpendo.2002.282.1.E154.

245. Hobson RM, Saunders B, Ball G, Harris RC, Sale C. Effects of beta-alanine supplementation on exercise performance: a meta-analysis. Amino Acids. 2012;43:25-37. https://doi.org/10.1007/s00726-011-1200-z.

246. Brooks SP, Storey KB. A quantitative evaluation of the effect of enzyme complexes on the glycolytic rate in vivo: mathematical modeling of the glycolytic complex. J Theor Biol. 1991;149:361-75.

247. Duncan SH, Louis P, Flint HJ. Lactate-utilizing bacteria, isolated from human feces, that produce butyrate as a major fermentation product. Appl Environ Microbiol. 2004;70:5810-7. https://doi.org/10.1128/AEM.70.10.5810-5817.2004.

248. Hsu YJ, Huang WC, Lin JS, Chen YM, Ho ST, Huang CC, Tung YT. Kefir supplementation modifies gut microbiota composition, reduces physical fatigue, and improves exercise performance in mice. Nutrients. 2018;10. https://doi.org/10.3390/nu10070862. 
249. ANVISA-Ministry of Health. Technical Regulation of Bioeactive and Probiotic Substances Isolated with Allegations of Functional or Health Properties. 2008.

250. Ministerio della Salute. Linee guida su probiotici e prebioticic. Available oneline at: http://www.salute.gov; 2013.

251. Al-Asmakh M, Stukenborg JB, Reda A, Anuar F, Strand ML, Hedin L, Pettersson S, Soder O. The gut microbiota and developmental programming of the testis in mice. PLoS One. 2014;9:e103809. https://doi. org/10.1371/journal.pone.0103809.

252. Harada N, Hanaoka R, Horiuchi H, Kitakaze T, Mitani T, Inui H, Yamaji R. Castration influences intestinal microflora and induces abdominal obesity in high-fat diet-fed mice. Sci Rep. 2016;6:23001. https://doi.org/10.1038/ srep23001.

253. Ibrahim HA, Zhu Y, Wu C, Lu C, Ezekwe MO, Liao SF, Huang K. Seleniumenriched probiotics improves murine male fertility compromised by high fat diet. Biol Trace Elem Res. 2012;147:251-60. https://doi.org/10.1007/s12011011-9308-2.

254. Lee J, Yang W, Hostetler A, Schultz N, Suckow MA, Stewart KL, Kim DD, Kim HS. Characterization of the anti-inflammatory Lactobacillus reuteri BM36301 and its probiotic benefits on aged mice. BMC Microbiol. 2016;16:69. https:// doi.org/10.1186/s12866-016-0686-7.

255. McMullen MH, Hamilton-Reeves JM, Bonorden MJ, Wangen KE, Phipps WR, Feirtag JM, Kurzer MS. Consumption of Lactobacillus acidophilus and Bifidobacterium longum does not alter phytoestrogen metabolism and plasma hormones in men: a pilot study. J Altern Complement Med. 2006;12: 887-94. https://doi.org/10.1089/acm.2006.12.887.

256. Maretti C, Cavallini G. The association of a probiotic with a prebiotic (Flortec, Bracco) to improve the quality/quantity of spermatozoa in infertile patients with idiopathic oligoasthenoteratospermia: a pilot study. Andrology. 2017:5:439-44. https://doi.org/10.1111/andr.12336.

257. Tremellen K. Gut endotoxin leading to a decline IN gonadal function (GELDING) - a novel theory for the development of late onset hypogonadism in obese men. Basic Clin Androl. 2016;26:7. https://doi.org/ 10.1186/s12610-016-0034-7.

258. Tremellen K, McPhee N, Pearce K. Metabolic endotoxaemia related inflammation is associated with hypogonadism in overweight men. Basic Clin Androl. 2017;27:5. https://doi.org/10.1186/s12610-017-0049-8.

259. Tremellen K, McPhee N, Pearce K, Benson S, Schedlowski M, Engler H. Endotoxin-initiated inflammation reduces testosterone production in men of reproductive age. Am J Physiol Endocrinol Metab. 2018;314:E206-13. https://doi.org/10.1152/ajpendo.00279.2017.

260. De Lorenzo A, Noce A, Moriconi E, Rampello T, Marrone G, Di Daniele N, Rovella V. MOSH syndrome (male obesity secondary hypogonadism): clinical assessment and possible therapeutic approaches. Nutrients. 2018;10. https:// doi.org/10.3390/nu10040474.

261. Pique N, Berlanga M, Minana-Galbis D. Health benefits of heat-killed (Tyndallized) probiotics: An overview. Int J Mol Sci. 2019;20(10):2534. https:// doi.org/10.3390/ijms20102534.

262. Komano Y, Shimada K, Naito H, Fukao K, Ishihara Y, Fujii T, Kokubo T, Daida H. Efficacy of heat-killed Lactococcus lactis JCM 5805 on immunity and fatigue during consecutive high intensity exercise in male athletes: a randomized, placebo-controlled, double-blinded trial. J Int Soc Sports Nutr. 2018;15:39. https://doi.org/10.1186/s12970-018-0244-9.

263. Kalman D, Hewlings S. Inactivated probiotic Bacillus coagulans GBI-30 demonstrates Immunosupportive properties in healthy adults following stressful exercise. J Probiotics and Health. 2018;6.

264. Taverniti V, Guglielmetti S. The immunomodulatory properties of probiotic microorganisms beyond their viability (ghost probiotics: proposal of paraprobiotic concept). Genes Nutr. 2011;6:261-74. https://doi.org/10.1007/ s12263-011-0218-X

265. Deshpande G, Athalye-Jape G, Patole S. Para-probiotics for preterm neonates-the next frontier. Nutrients. 2018;10. https://doi.org/10.3390/ nu10070871.

266. Sugahara $H$, Yao R, Odamaki T, Xiao JZ. Differences between live and heatkilled bifidobacteria in the regulation of immune function and the intestinal environment. Benefic Microbes. 2017;8:463-72. https://doi.org/10.3920/ BM2016.0158.

267. Burta O, lacobescu C, Mateescu RB, Nicolaie T, Tiuca N, Pop CS. Efficacy and safety of APT036 versus simethicone in the treatment of functional bloating: a multicentre, randomised, double-blind, parallel group, clinical study. Transl Gastroenterol Hepatol. 2018;3, 72. https://doi.org/10.21037/tgh.2018.09.11.
268. Vandenplas Y, Bacarea A, Marusteri M, Bacarea V, Constantin M, Manolache M. Efficacy and safety of APT198K for the treatment of infantile colic: a pilot study. J Comp Eff Res. 2017;6:137-44. https://doi.org/10.2217/cer-2016-0059.

269. Hirose $Y$, Yamamoto $Y$, Yoshikai $Y$, Murosaki S. Oral intake of heat-killed Lactobacillus plantarum L-137 decreases the incidence of upper respiratory tract infection in healthy subjects with high levels of psychological stress. J Nutr Sci. 2013;2:e39. https://doi.org/10.1017/jns.2013.35.

270. Arimori Y, Nakamura R, Hirose Y, Murosaki S, Yamamoto Y, Shidara O, Ichikawa H, Yoshikai Y. Daily intake of heat-killed Lactobacillus plantarum L137 enhances type I interferon production in healthy humans and pigs. Immunopharmacol Immunotoxicol. 2012;34(6):937-43. https://doi.org/10. 3109/08923973.2012.672425.

271. Sawada D, Kuwano Y, Tanaka T, Hara S, Uchiyama Y, Sugawara T, Fujiwara S, Rokutan K, Nishida K. Daily intake of Lactobacillus gasseri CP2305 relieves fatigue and stress-related symptoms in male university Ekiden runners: A double-blind, randomized, and placebo-controlled clinical trial. J Funct Foods. 2019;57:465-76.

272. Nishida K, Sawadab D, Kuwanoa Y, Tanakaa H, Sugawarab T, Aokib Y, Fujiwarab S, Rokutana K. Daily administration of paraprobiotic Lactobacillus gasseri CP2305 ameliorates chronic stress-associated symptoms in Japanese medical students. J Funct Foods. 2017;36:112-21.

273. Friedrich MJ. Depression is the leading cause of disability around the world. JAMA. 2017;317:1517. https://doi.org/10.1001/jama.2017.3826.

274. Maes M, Kubera M, Leunis JC, Berk M, Geffard M, Bosmans E. In depression, bacterial translocation may drive inflammatory responses, oxidative and nitrosative stress (O\&NS), and autoimmune responses directed against O\&NS-damaged neoepitopes. Acta Psychiatr Scand. 2013;127:344-54. https://doi.org/10.1111/j.1600-0447.2012.01908.x.

275. Clarke G, Grenham S, Scully P, Fitzgerald P, Moloney RD, Shanahan F, Dinan TG, Cryan JF. The microbiome-gut-brain axis during early life regulates the hippocampal serotonergic system in a sex-dependent manner. Mol Psychiatry. 2013;18:666-73. https://doi.org/10.1038/mp.2012.77.

276. Vitetta L, Bambling M, Alford $H$. The gastrointestinal tract microbiome probiotics, and mood. Inflammopharmacology. 2014;22:333-9. https://doi. org/10.1007/s10787-014-0216-x.

277. Rao AV, Bested AC, Beaulne TM, Katzman MA, lorio C, Berardi JM, Logan AC. A randomized, double-blind, placebo-controlled pilot study of a probiotic in emotional symptoms of chronic fatigue syndrome. Gut Pathog. 2009;1:6. https://doi.org/10.1186/1757-4749-1-6.

278. Messaoudi M, Lalonde R, Violle N, Javelot H, Desor D, Nejdi A, Bisson JF, Rougeot C, Pichelin M, Cazaubiel M, et al. Assessment of psychotropic-like properties of a probiotic formulation (Lactobacillus helveticus R0052 and Bifidobacterium longum R0175) in rats and human subjects. Br J Nutr. 2011; 105:755-64. https://doi.org/10.1017/S0007114510004319.

279. Marotta A, Sarno E, Del Casale A, Pane M, Mogna L, Amoruso A, Felis GE, Fiorio M. Effects of probiotics on cognitive reactivity, mood, and sleep quality. Front Psychiatry. 2019;10:164. https://doi.org/10.3389/fpsyt.2019.00164.

280. Clark A, Mach N. Exercise-induced stress behavior, gut-microbiota-brain axis and diet: a systematic review for athletes. J Int Soc Sports Nutr. 2016;13:43. https://doi.org/10.1186/s12970-016-0155-6.

281. Zhao S, Liu W, Wang J, Shi J, Sun Y, Wang W, Ning G, Liu R, Hong J. Akkermansia muciniphila improves metabolic profiles by reducing inflammation in chow dietfed mice. J Mol Endocrinol. 2017;58:1-14. https://doi.org/10.1530/JME-16-0054.

282. Warber JP, Patton JF, Tharion WJ, Zeisel SH, Mello RP, Kemnitz CP Lieberman HR. The effects of choline supplementation on physical performance. Int J Sport Nutr Exerc Metab. 2000;10:170-81.

283. Martin FP, Wang Y, Sprenger N, Holmes E, Lindon JC, Kochhar S, Nicholson JK. Effects of probiotic Lactobacillus paracasei treatment on the host gut tissue metabolic profiles probed via magic-angle-spinning NMR spectroscopy. J Proteome Res. 2007;6:1471-81. https://doi.org/10.1021/pr060596a.

284. Wang Z, Klipfell E, Bennett BJ, Koeth R, Levison BS, Dugar B, Feldstein AE, Britt EB, Fu $X$, Chung YM, et al. Gut flora metabolism of phosphatidylcholine promotes cardiovascular disease. Nature. 2011;472:57-63. https:/doi.org/10.1038/nature09922.

285. Boutagy NE, Neilson AP, Osterberg KL, Smithson AT, Englund TR, Davy BM, Hulver MW, Davy KP. Probiotic supplementation and trimethylamine-Noxide production following a high-fat diet. Obesity (Silver Spring). 2015;23: 2357-63. https://doi.org/10.1002/oby.21212.

286. Borges NA, Stenvinkel P, Bergman P, Qureshi AR, Lindholm B, Moraes C, StocklerPinto MB, Mafra D. Effects of probiotic supplementation on trimethylamine-Noxide plasma levels in hemodialysis patients: a pilot study. Probiotics Antimicrob Proteins. 2018. https://doi.org/10.1007/s12602-018-9411-1, https://doi.org/10.1007/ s12602-018-9411-1. 
287. Tompkins TA, Mainville I, Arcand Y. The impact of meals on a probiotic during transit through a model of the human upper gastrointestinal tract. Benefic Microbes. 2011;2:295-303. https://doi.org/10.3920/BM2011.0022.

288. He CS, Tsai ML, Ko MH, Chang CK, Fang SH. Relationships among salivary immunoglobulin a, lactoferrin and cortisol in basketball players during a basketball season. Eur J Appl Physiol. 2010;110:989-95. https://doi.org/10. 1007/s00421-010-1574-8

289. Li TL, Lin HC, Ko MH, Chang CK, Fang SH. Effects of prolonged intensive training on the resting levels of salivary immunoglobulin a and cortisol in adolescent volleyball players. J Sports Med Phys Fitness. 2012;52:569-73.

290. Tsai ML, Li TL, Chou LW, Chang CK, Huang SY, Fang SH. Resting salivary levels of IgA and cortisol are significantly affected during intensive resistance training periods in elite male weightlifters. J Strength Cond Res. 2012;26:2202-8. https://doi.org/10.1519/JSC.0b013e31823a4246.

291. Ait-Belgnaoui A, Durand H, Cartier C, Chaumaz G, Eutamene H, Ferrier L, Houdeau E, Fioramonti J, Bueno L, Theodorou V. Prevention of gut leakiness by a probiotic treatment leads to attenuated HPA response to an acute psychological stress in rats. Psychoneuroendocrinology. 2012;37:1885-95. https://doi.org/10.1016/j.psyneuen.2012.03.024.

292. Knowles SR, Nelson EA, Palombo EA. Investigating the role of perceived stress on bacterial flora activity and salivary cortisol secretion: a possible mechanism underlying susceptibility to illness. Biol Psychol. 2008;77:132-7. https://doi.org/10.1016/j.biopsycho.2007.09.010.

293. Andersson H, Tullberg C, Ahrne S, Hamberg K, Lazou Ahren I, Molin G, Sonesson M, Hakansson A. Oral Administration of Lactobacillus plantarum $299 \mathrm{v}$ reduces cortisol levels in human saliva during examination induced stress: a randomized, Double-Blind Controlled Trial. Int J Microbiol. 2016; 2016:8469018. https://doi.org/10.1155/2016/8469018.

294. Kato-Kataoka A, Nishida K, Takada M, Kawai M, Kikuchi-Hayakawa H, Suda K, Ishikawa H, Gondo Y, Shimizu K, Matsuki T, et al. Fermented Milk containing Lactobacillus casei strain Shirota preserves the diversity of the gut microbiota and relieves abdominal dysfunction in healthy medical students exposed to academic stress. Appl Environ Microbiol. 2016;82:3649-58. https://doi.org/10.1128/AEM.04134-15.

295. Takada M, Nishida K, Kataoka-Kato A, Gondo Y, Ishikawa H, Suda K, Kawai M, Hoshi R, Watanabe O, Igarashi T, et al. Probiotic Lactobacillus casei strain Shirota relieves stress-associated symptoms by modulating the gut-brain interaction in human and animal models. Neurogastroenterol Motil. 2016;28: 1027-36. https://doi.org/10.1111/nmo.12804.

296. Kelly JR, Allen AP, Temko A, Hutch W, Kennedy PJ, Farid N, Murphy E, Boylan G, Bienenstock J, Cryan JF, et al. Lost in translation? The potential psychobiotic Lactobacillus rhamnosus (JB-1) fails to modulate stress or cognitive performance in healthy male subjects. Brain Behav Immun. 2017; 61:50-9. https://doi.org/10.1016/j.bbi.2016.11.018.

297. Reis DJ, llardi SS, Punt SEW. The anxiolytic effect of probiotics: a systematic review and meta-analysis of the clinical and preclinical literature. PLoS One. 2018;13:e0199041. https://doi.org/10.1371/journal.pone.0199041.

298. Desbrow B, McCormack J, Burke LM, Cox GR, Fallon K, Hislop M, Logan R, Marino N, Sawyer SM, Shaw G, et al. Sports dietitians Australia position statement: sports nutrition for the adolescent athlete. Int J Sport Nutr Exerc Metab. 2014;24:570-84. https://doi.org/10.1123/ijsnem.2014-0031.

299. Shaw MT, Leggat PA, Chatterjee S. Travelling to India for the Delhi XIX commonwealth games 2010. Travel Med Infect Dis. 2010;8:129-38. https:// doi.org/10.1016/j.tmaid.2010.04.007.

\section{Publisher's Note}

Springer Nature remains neutral with regard to jurisdictional claims in published maps and institutional affiliations.

Ready to submit your research? Choose BMC and benefit from:
- fast, convenient online submission
- thorough peer review by experienced researchers in your field
- rapid publication on acceptance
- support for research data, including large and complex data types
- gold Open Access which fosters wider collaboration and increased citations
- maximum visibility for your research: over 100M website views per year
At BMC, research is always in progress.
Learn more biomedcentral.com/submissions

